NBER WORKING PAPER SERIES

\title{
LACK OF SELECTION AND LIMITS TO DELEGATION: FIRM DYNAMICS IN DEVELOPING COUNTRIES
}

\author{
Ufuk Akcigit \\ Harun Alp \\ Michael Peters \\ Working Paper 21905 \\ http://www.nber.org/papers/w21905 \\ NATIONAL BUREAU OF ECONOMIC RESEARCH \\ 1050 Massachusetts Avenue \\ Cambridge, MA 02138 \\ January 2016, Revised April 2018
}

This is a heavily revised version of Akcigit, Alp, and Peters (2016). We thank the seminar and conference participants at Harvard, MIT, University of Chicago, Stanford, Princeton, Yale, USC, LSE, the Productivity, Development \& Entrepreneurship, and Macroeconomics Within and Across Borders Meetings at the NBER Summer Institute, the NBER Development Program and EFG Meeting, Stanford CID/IGC Conference, AEA Meetings, OECD/NBER Conference on Productivity and Innovation, Minnesota Macro, NYU, Penn State, Einaudi, University of Houston, Barcelona GSE Summer Forum, Kauffman Entrepreneurship Conference, London Macroeconomics Conference, CAED 2015 Conference, Cologne Workshop on Macroeconomics, SKEMA Growth Conference, UPenn Growth Reading Group, and UPenn Macro Lunch for helpful comments. In particular we would like to thank our discussants Francesco Caselli, John Haltiwanger, Chang-Tai Hsieh, Rasmus Lentz, and Yongs Shin. We furthermore received very valuable feedback from Abhijit Banerjee, Nick Bloom, Matthew Cook, Jeremy Greenwood, Bill Kerr, Pete Klenow, Chad Jones, Sam Kortum, Robert E. Lucas, Giuseppe Moscarini, Luis Serven, Andrei Shleifer, and Nancy Stokey. Chang-Tai Hsieh and Pete Klenow have kindly shared some of their data with us. Jeremy Pearce provided excellent research assistance. Akcigit gratefully acknowledges financial support from the World Bank, the Alfred P. Sloan Foundation, the Ewing Marion Kauffman Foundation, and the National Science Foundation. The views expressed herein are those of the authors and do not necessarily reflect the views of the National Bureau of Economic Research.

NBER working papers are circulated for discussion and comment purposes. They have not been peer-reviewed or been subject to the review by the NBER Board of Directors that accompanies official NBER publications.

(C) 2016 by Ufuk Akcigit, Harun Alp, and Michael Peters. All rights reserved. Short sections of text, not to exceed two paragraphs, may be quoted without explicit permission provided that full credit, including $\odot$ notice, is given to the source. 
Lack of Selection and Limits to Delegation: Firm Dynamics in Developing Countries

Ufuk Akcigit, Harun Alp, and Michael Peters

NBER Working Paper No. 21905

January 2016, Revised April 2018

JEL No. O31,O38,O40

\begin{abstract}
$\underline{\text { ABSTRACT }}$ between the ease of delegation and other factors affecting firm growth.

Ufuk Akcigit

Department of Economics

University of Chicago

1126 East 59th Street

Saieh Hall, Office 403

Chicago, IL 60637

and NBER

uakcigit@uchicago.edu

Harun Alp

University of Pennsylvania

3718 Locust Walk

McNeil 160

Philadelphia, PA, 19104

aharun@sas.upenn.edu

Michael Peters

Department of Economics

Yale University

28 Hillhouse Avenue

New Haven, CT 06511

and NBER

m.peters@yale.edu
\end{abstract}

Managerial delegation is essential for firm growth. While firms in poor countries often shun outside managers and instead recruit among family members, the pattern is quite the opposite for firms in rich countries. In this paper, we ask whether these differences in managerial delegation have important aggregate effects. We construct a model of firm growth where entrepreneurs have fixed-time endowments to run their daily operations. As firms grow larger, the need to delegate decision-making authority increases. Firms in poor countries might therefore decide to remain small if delegating managerial tasks is difficult. We calibrate the model to firm-level data from the U.S. and India. We show that the model is quantitatively consistent with the experimental micro evidence on managerial efficiency and firm growth reported in Bloom et al. (2013). Our quantitative analysis shows that the low efficiency of delegation in India can account for 5\% of productivity and $15 \%$ of income differences between the U.S. and India in steady state. We also show that such inefficient delegation possibilities reduce the size of Indian firms, but would cause substantially more harm for U.S. firms. This is because there are important complementarities 


\section{Introduction}

Managerial delegation is essential for firm growth. In the developed world, many family-owned industrial giants, such as Walmart, The Lego Group, or Ford Motor Co., have managed to expand to hundreds of thousands of employees by relying on non-family managers to run their key operations. In contrast, in developing economies there seem to be serious obstacles to managerial delegation, which make firm owners often shun outside managers and recruit managers exclusively among family members. This is arguably one of the reasons why the number of sons in the family is a strong predictor of firm size in India (Bloom et al., 2013). These observations lead to the following important questions: How do cross-country differences in the ease of managerial delegation affect the process of firm growth and selection? What are the implications for the aggregate economy? In this paper, we answer these questions both theoretically and quantitatively.

In this paper, our aim is to understand the link between the microeconomics of managerial delegation and firm growth and their macroeconomic implications. While we try to go from micro to macro, we inform our theoretical setup using micro data on millions of establishments in India and the U.S. More specifically, we introduce the need for managerial delegation into a Schumpeterian growth model, which we then calibrate to the Indian and U.S. micro data. We show that our framework is quantitatively consistent with various out-of-sample moments in the data and we compare the implications of our model to the well-known experimental evidence on managerial efficiency and firm growth by Bloom et al. (2013). Finally, once we establish enough confidence in the validity of our model, we conduct various counterfactual exercises to quantify the importance of managerial delegation and firm selection for the aggregate economy and its transitional dynamics. In particular, our framework stresses the role of catch-up growth, whereby improvements in the process of firm dynamics help a developing country converge to the frontier faster. This is arguably the most relevant growth margin for a non-frontier country, such as India.

The central piece of our theory is that firms' expansion incentives respond to the underlying delegation environment (and other factors as described below). As the entrepreneur's own managerial time is a fixed factor, production features decreasing returns and marginal profits decrease in firm size. This reduces the incentive to expand to a large firm. Entrepreneurs can overcome such declining marginal returns by delegating decision power to outside managers as their firms expand. If the economy's delegation efficiency is low (for instance due to imperfect contractual enforcement or a lack of trust), entrepreneurs have little incentive to adopt new technologies as they anticipate to not be able to efficiently delegate decision-making power as they grow. Improvements in delegation efficiency therefore raise the returns to growing large, induce more creative destruction, increase the extent of catch-up growth, and reduce long-run productivity differences.

To analyze the quantitative importance of this delegation mechanism, we explicitly allow the key structural parameters of our model to be country specific and calibrate them to micro data from India and the U.S. independently. This calibration strategy is important because it prevents us from loading all the differences between the U.S. and India onto our mechanism of interest differences in the efficiency of delegation. The key empirical moment to infer such differences in the delegation environment between the U.S. and India is the aggregate employment share of outside, i.e. non-family, managers. In our model, this share is of course an equilibrium outcome and depends 
explicitly on three components:

1. Delegation Efficiency: Firms' demand for outside managers depends on the delegation efficiency. If delegation is easier (e.g., due to a stronger rule of law or higher trust in non-family managers), entrepreneurs are more likely to delegate managerial tasks. Quantifying the extent to which differences in delegation efficiency can explain the observed differences in firmdynamics and aggregate economic performance, is the main focus of this paper.

2. Firm Growth due to Non-managerial Factors: Because firm size and managerial hiring are complements, countries with larger firms will have more managerial employment in equilibrium. Our model, for example, explicitly recognizes the fact that firms differ in their growth potential, i.e. that some entrepreneurs are transformative and have the necessary skills to expand, while others are subsistence entrepreneurs, who may simply lack the ability to grow their firms beyond a certain size (Schoar, 2010; Decker et al., 2014). If the share of subsistence entrepreneurs or the costs of expansion are lower in the U.S. (e.g. due to more efficient capital markets or less distortionary regulation, lower payroll taxes or better infrastructure), firms would grow more and demand more managers.

3. Managerial Human Capital: Naturally, the extent of managerial hiring depends directly on the supply of managerial human capital. If managerial skills are relatively abundant in the U.S., everything else equal, the equilibrium share of managers in the workforce would be higher.

Empirically, outside managers account for only 1.7\% of the labor force in India. In the U.S., this number amounts to $12.4 \%$. To distinguish the relative importance of the above three channels to explain such differences and to identify the direct effect of differences in delegation efficiency, we rely on different sources of information. First, we use establishment-level information from the manufacturing sector in India and the U.S. to measure establishments' life-cycle growth, and entry and exit patterns. These moments are informative about the initial importance of subsistence entrepreneurs and other non-managerial determinants of firm growth (i.e., item \#2 in the above list). Second, we rely on data about managerial employment patterns and managerial wages from the Indian and the U.S. Census, to distinguish the effects of delegation efficiency and managerial human capital. In particular, we exploit information on pre- and post-migration outcomes of Indian immigrants to the U.S., also taking into account the selection among immigrants from India.

In addition to the targeted moments, we show that our model is consistent with various nontargeted moments. Among others, one such moment comes from the well-known field experiment by Bloom et al. (2013). In that study, the authors provided a randomly selected group of Indian textile companies with management consulting to introduce them to American-style frontier management practices and measured impact on subsequent output growth. Motivated by that study, we replicate this experiment in our estimated model. In particular, we treat a subset of firms in our estimated Indian economy with the U.S.-level delegation efficiency and follow that subset of firms over a 100-week period. We show that this exercise can be mapped to our framework and that our model implies output responses which are in the same ballpark as the experimental results. Hence, our model generates the right microeconomic responses to the experimental "management" intervention. Since our model is consistent with this "identified moment" (Nakamura and Steinsson, 2018), 
it is arguably an attractive laboratory to quantify the aggregate effects of cross-country differences in delegation efficiency.

Our cross-country analysis yields three main conclusions. First, we find that the Indian economy suffers from a significant lack of selection, whereby subsistence producers with little growth potential survive for a long time. While this is partly due to a high initial share of subsistence firms at the time of entry, the main culprit of this lack of selection is the low rate of creative destruction, which allows even small firms to survive. This result is important because it provides a somewhat different way to think about firms in developing countries: The glut of small firms in India is not a reflection of frictions that those small firms face, but rather an indication of a lack of competition coming from larger firms, which helps subsistence producers survive. Policies aimed at supporting small firms, e.g., micro-finance programs, while potentially desirable for their redistributive properties, could be harmful to the economy by reducing the reallocation of resources from small stagnant firms to firms with growth potential. This is consistent with the dual economic view of development by La Porta and Shleifer $(2008,2014)$, who argue that the decline in informality associated with economic growth "is the result of a replacement of inefficient informal firms by efficient formal ones" (La Porta and Shleifer, 2014, p. 121).

Second, we show that India's delegation efficiency, which we estimate to be substantially smaller than in the U.S., is partly responsible for this lack of creative destruction and therefore has important implications for aggregate economic performance. In our model, both economies grow at the same rate in the long run. Differences in creative destruction therefore affect the speed of catch-up growth and long-run levels of economic development. Our estimates imply that the Indian economy achieves today's U.S.-level of output per capita in about 45 years. If firms in India had access to the U.S.-level of delegation efficiency, this duration would decline by $10 \%$ to 41 years. In the long-run, the lower delegation efficiency in India can plausibly account for 5\% of the steady-state productivity and $15 \%$ of the steady-state income differences between the U.S. and India.

Finally, there are important complementarities between the returns to delegation and other differences between India and the U.S. While the process of firm-dynamics in India does depend on the delegation environment, the implications are modest. We find that an increase of delegation quality to U.S. standards would increase average firm size by $1.5 \%$ and reduce the employment share of small firms by a similar amount. If, in contrast, U.S. firms had to operate within the underdeveloped delegation environment of India, the implications would be much more pronounced. The reason is that delegation frictions and other non-managerial factors that determine firm expansion naturally interact. Hence other frictions, such as credit market imperfections or distortions to market entry, not only hamper firm growth directly, but also reduce the effect of improvements in the delegation environment on firms' expansion incentives.

Related Literature: That managerial delegation might be a key aspect to firm dynamics goes back to the early work of Penrose (1959), who argues not only that managerial resources are essential for firms to expand, but that this scarcity of managerial inputs prevents the weeding out of small firms as "bigger firms have not got around to mopping them up" (Penrose, 1959, p. 221). Recently, empirical evidence for this managerial margin has accumulated. Using data across countries, there is also evidence that managerial practices differ across countries (Bloom and Van Reenen, 2007, 2010), 
that firms in developed countries are both larger and delegate more managerial tasks to outside (non-family) managers (Fukuyama, 1996; La Porta et al., 1997; Bloom et al., 2012), and that both human capital and contractual imperfections are important in explaining the lack of managerial delegation in poor countries (Laeven and Woodruff, 2007; Bloom et al., 2009). The importance of managerial and entrepreneurial human capital for economic development is also stressed in the empirical work by Gennaioli et al. (2013).

We formalize and quantify the macroeconomic importance of such managerial considerations by providing a new theory of firm dynamics, and the resulting firm size distribution in developing countries. ${ }^{1}$ While many recent papers have attempted to measure and explain the static differences in allocative efficiency across firms (e.g., Restuccia and Rogerson, 2008; Hsieh and Klenow, 2009, and more recently Gopinath et al. 2017, among many others ${ }^{2}$ ), there has been less theoretical work explaining why firm dynamics differ across countries. A notable exception is the work by Cole et al. (2016), which argues that cross-country differences in the financial system affect the type of technologies that can be implemented. Like them, we let the productivity process take center stage. However, we turn to the recent generation of micro-founded models of Schumpeterian growth, following Klette and Kortum (2004), who have been shown to provide a tractable and empirically successful theory of firm dynamics (see for instance, Acemoglu et al., 2017; Akcigit and Kerr, 2017; Garcia-Macia et al., 2015; Lentz and Mortensen, 2005, 2008). ${ }^{3}$

Importantly, we explicitly allow for heterogeneity in firms' growth potential. This heterogeneity is not only important for our mechanism, but also empirically required to match the micro-data. There is ample empirical evidence for the importance of such heterogeneity. Besides the contributions of Schoar (2010) and Decker et al. (2014) cited above, Hurst and Pugsley (2012), for example, show that there are heterogeneous types of entrepreneurs in the U.S. economy, a majority of whom intentionally choose to remain small. In the context of developing countries, Banerjee et al. (2015) present experimental evidence on persistent differences in growth potential. Similar findings are also reported in De Mel et al. (2008). Additionally, a recent theoretical literature argues that models without such heterogeneity in growth potential are unable to explain the very rapid growth of a subset of the U.S. firms (see e.g. Luttmer (2011) or Lentz and Mortensen (2016)). Recently, Gabaix et al. (2016) generalized this logic to the debate on inequality.

We focus on inefficiencies in the interaction between outside managers and owners of firms to explain the differences in firms' demand for expansion. Caselli and Gennaioli (2013) also stress the negative consequences of inefficient management, but focus on static misallocation. Powell (2012), Bertrand and Schoar (2006), and Grobvosek (2015) study within-firm considerations where firms ("owners") need to hire managers subject to contractual frictions. In contrast to our theory, all these papers assume that firm productivity is constant, i.e., there is no interaction between the delegation

\footnotetext{
${ }^{1}$ An overview of some regularities of the firm size distributions in India, Indonesia, and Mexico is contained in Hsieh and Olken (2014).

${ }^{2}$ As far as theories are concerned, there is now a sizable literature on credit market frictions (Buera et al., 2011; Moll, 2014; Midrigan and Xu, 2014), size-dependent policies (Guner et al., 2008), monopolistic market power (Peters, 2016) and adjustment costs (Collard-Wexler et al., 2011). A synthesis of the literature is also contained in Hopenhayn (2012) and Jones (2013).

${ }^{3}$ As in Aghion and Howitt (1992), firm dynamics are determined through creative destruction, whereby successful firms expand through replacing other producers. See Aghion et al. (2014) for a survey of the Schumpeterian growth literature and Akcigit (2017) for the importance of firm dynamics in economic growth.
} 
environment and firms' endogenous growth incentives. Guner et al. (2015) and Roys and Seshadri (2014) present recent dynamic models of (managerial) human capital accumulation and economic development, but do not focus on the implications of creative destruction for the resulting process of selection and firm dynamics. Finally, there is a large literature on management and the hierarchical structure of the internal organization of the firm; see Garicano and Rossi-Hansberg (2015) for a survey. This literature has a much richer micro structure of firms' delegation environment, but does not focus on the resulting properties of firm dynamics.

The remainder of the paper is organized as follows: In Section 2, we describe the theoretical model, where we explicitly derive the interaction between firms' delegation decisions and their incentives to grow. Section 3 summarizes the data that we use in our quantitative analysis and discusses the identification of the model. In Section 4, we present the calibration results for India and the U.S., and assess the model fit based on various out-of-sample moments. In Section 5 and 6 , we provide our main analysis to quantify the importance of the delegation environment on firm dynamics and the aggregate economy. Section 7 provides various robustness checks of the main quantitative results. Section 8 concludes. All proofs and additional details are contained in the Appendix. The Online Appendix contains further results.

\section{Theory}

We consider a continuous time economy, where a representative household maximizes the sum of per period utilities $U\left(C_{t}\right)=\ln \left(C_{t}\right)$ and discounts the future at rate $\rho$. The members of the household can work as either managers or production workers. Household optimization delivers the usual Euler equation where the interest rate $r_{t}$ is equal to the sum of the discount rate $\rho$ and the growth rate of consumption of the final good $g_{t, C}$, which we take as the numeraire:

$$
r_{t}=\rho+g_{t, C}
$$

The final good $Y_{t}$ is used for consumption $C_{t}$ and investment in productivity growth by incumbents $R_{t}$ and entrants $R_{E, t}$. Therefore the resource constraint is simply:

$$
Y_{t}=C_{t}+R_{t}+R_{E, t}
$$

To save on notation we will drop the time subscript $t$ whenever it does not cause any confusion.

\subsection{Technology}

The final good $Y$ is a Cobb-Douglas composite of intermediate varieties: $\ln Y=\int_{0}^{1} \ln y_{j} d j$, where $y_{j}$ denotes the amount of variety $j$. A firm is a collection of varieties as we explain below. The production of such varieties requires both production workers and managers. In particular, we assume that managers increase the efficiency of production workers so that firm $f$ can produce good $j$ according to

$$
y_{j f}=q_{j f} \mu\left(e_{j f}\right) l_{j f}
$$


where $q_{j f}$ is the firm-product specific efficiency, $l_{j f}$ is the number of production workers employed for producing intermediate good $j, e_{j f}$ denotes the amount of managerial services firm $f$ allocates toward the production of good $j$, and $\mu\left(e_{j f}\right) \geq 1$ is an increasing function translating managerial services into productivity units. As in Klette and Kortum (2004), firm productivity in each variety $q_{j f}$ is endogenous and the result of past innovation decisions. Also, note that the technology in (3) implies that the labor cost of producing one unit $y_{j f}$ is given by $M C_{j}=\frac{w_{P}}{q_{j f} \mu\left(e_{j f}\right)}$, where $w_{P}$ is the equilibrium wage for production workers.

Because firms' outputs within product variety $j$ are perfect substitutes, in equilibrium each variety $j$ is produced by a single firm $f$, which has the highest productivity $q_{j f}$. We will therefore refer to this firm as the producer of product $j$ and denote the producer's productivity for variety $j$ by $q_{j}$. Note that a given firm can produce multiple varieties if it was successful in innovating in the past and hence has the highest efficiency in multiple markets.

In order to focus on the interaction between managerial delegation and the resulting equilibrium process of firm dynamics, we keep the static market structure as tractable as possible. To do so, we assume that in each market $j$ there is a competitive fringe of potential producers that can produce variety $j$ at marginal costs $w_{P} / q_{j}{ }^{4}$ Because the market leader faces a demand function with unitary elasticity it will engage in limit pricing, i.e., set its price equal to the marginal costs of the competitive fringe. The gross profits after paying for production workers $l_{j}$ (but before paying for the managers) are therefore given by:

$$
\pi_{j}(e)=\left[p_{j}-M C_{j}\right] y_{j}=\left[\frac{\mu(e)-1}{\mu(e)}\right] Y .
$$

Expression (4) stresses that firm $f^{\prime}$ 's profits on variety $j$ depend only on the amount of managerial services that it allocates toward the production of the $j$ th variety. Because managerial inputs increase physical productivity, more managerial inputs allow firms to increase their profitability.

For analytical convenience, we assume that $\mu(e)=\frac{1}{1-e^{\sigma}}$, where $e \in[0,1)$ and $\sigma<1$. This implies that firm $f^{\prime}$ s profit in variety $j$ is given by:

$$
\pi\left(e_{j}\right)=e_{j}^{\sigma} Y,
$$

i.e., profits are a simple power function of managerial effort parameterized by the elasticity $\sigma$. Note that if the producing firm has no managerial services at its disposal, it is unable to outcompete the competitive fringe and hence earns no profits.

Finally, we can also characterize the aggregate variables of the economy. In particular (see Section OA-1.1 in the Online Appendix), aggregate output $Y$ is given by:

$$
Y=Q \mathcal{M} L^{P}
$$

where $L^{P}=\int_{0}^{1} l_{j} d j$ denotes the mass of production workers, $\ln Q=\int_{0}^{1} \ln q_{j} d j$ is an index of aggregate physical productivity and $\mathcal{M}=\left(1-\int_{0}^{1} e_{j}^{\sigma} d j\right)^{-1}$ summarizes the static effect of the available

\footnotetext{
${ }^{4}$ This assumption allows us to abstract from strategic pricing decisions of firms who compete with firms of different productivity. A related model with strategic pricing behavior is analyzed in Peters (2016). In terms of primitives, the fringe firms have access to the same technology as the leading firm and to a level of managerial services $\mu^{\text {fringe }}$, which we normalize to unity.
} 
managerial resources on aggregate productivity. In particular, $\mathcal{M}$ is increasing in $e_{j}$, reflecting the positive effect of managerial inputs on labor productivity at the firm-level.

\subsection{Delegation and Managerial Services}

Managerial services $e$ can be provided both internally by the entrepreneur herself who owns the firm, and by outside managers. Each individual can work either as a production worker or as an outside manager, and is endowed with a single efficiency unit of production labor and $h_{M}$ units of managerial human capital. For simplicity, we assume that $h_{M}$ is drawn from a Pareto distribution, i.e., $P\left(h_{M}>h\right)=\left(\frac{\vartheta-1}{\vartheta} \mu_{M}\right)^{\vartheta} \times h^{-\vartheta}$. Here $\mathbb{E}\left(h_{M}\right)=\mu_{M}$ parametrizes the average level of managerial skills relative to workers and $\vartheta$ governs the heterogeneity in managerial talent.

Given the production worker wage $w_{P}$ and the managerial wage $w_{M}$, the individual decides to be a manager if and only if $h_{M} w_{M} \geq w_{P}$. Hence, the total supply of managerial efficiency units is given by:

$$
H^{M}=\left(\frac{\vartheta-1}{\vartheta} \mu_{M}\right)^{\vartheta}\left(\frac{w_{M}}{w_{P}}\right)^{\vartheta-1} \frac{\vartheta}{\vartheta-1},
$$

i.e. is increasing in the relative wage, with an elasticity of $\vartheta-1 .^{5}$ Moreover, holding relative wages fixed, managerial skill supplies are increasing in the average level of managerial human capital $\mu_{M}$.

\section{Delegation and the Demand for Outside Managers}

Each entrepreneur has a fixed endowment of $T$ managerial efficiency units, which she provides inelastically to her firm. If an entrepreneur is the current producer in $n$ markets and decides to run her firm alone, then she will have $e_{j}=T / n$ units of managerial services per variety. ${ }^{6}$ Equation (5) then implies that the total profits of the firm producing $n$ varieties are simply:

$$
\Pi(n)=\sum_{j=1}^{n} \pi\left(e_{j}\right)=n \times \pi\left(\frac{T}{n}\right)=T^{\sigma} n^{1-\sigma} Y .
$$

This expression has a simple but important implication: While the profits of the firm are increasing in the number of varieties $n$, they do so at a decreasing rate. The reason is that the owner has a fixed endowment $T$ and hence runs into span of control problem as in Lucas (1978). In particular, firm size $n$ and entrepreneur's managerial endowment $T$ are complements in that the marginal return to a unit of additional managerial resources is larger for larger firms

$$
\frac{\partial^{2} \Pi(n)}{\partial n \partial T}>0
$$

Hence, entrepreneurs with larger firms consider their fixed time endowment more of a bottleneck.

To counteract these decreasing returns, the entrepreneur can hire outside managers to augment her own endowment of managerial resources. In particular, suppose that the entrepreneur's and the manager's time are perfect substitutes, but that the relative productivity the manager's human capital is given by $\alpha$. Hence, if an owner of a firm with $n$ varieties hires $m_{j}$ units of managerial

\footnotetext{
${ }^{5}$ Note that $\vartheta$ must be greater than 1 for average managerial human capital to be finite.

${ }^{6}$ That she will want to spread her $T$ units of managerial time equally across all product lines follows directly from the concavity of $\pi$ in (5).
} 
human capital for the production of variety $j$, the total amount of managerial services $e_{j}$ is given by:

$$
e_{j}=T / n+\alpha \times m_{j}
$$

The parameter $\alpha$, which we refer to as the delegation efficiency, is the key parameter for our analysis. We think of $\alpha$ as being country-specific and dependent on various fundamentals. First, $\alpha$ could depend on the contractual environment. If contractual imperfections are severe, entrepreneurs might need to spend substantial amounts of their own time monitoring their managerial personnel. This reduces the net time gain each outside manager adds to the firm. Second, $\alpha$ could depend on the level of technology available to the firm. If managerial efficiency is complementary with IT equipment, for example, technological differences across countries will be a source of variation in $\alpha$. Third, $\alpha$ could capture cultural factors like trust or social norms, which facilitate the delegation of decision power. Finally, $\alpha$ might depend on the level of financial development, since more developed financial markets might give the entrepreneur the opportunity to incentivize her managers better. In this paper we are agnostic about the exact determinants of $\alpha$ and rather take it as a countryspecific parameter, which we calibrate directly within our model. However, in Section (OA-1.2) in the Online Appendix, we provide a simple micro-founded example, where a contractual game between the owner and outside managers leads to equation (8) and $\alpha$ is a combination of explicit structural parameters.

Because managers are hired on a spot market, the delegation problem is static and the owner simply maximizes the total profits of the firm by choosing the optimal amount of managerial inputs. Using (5) and (8), total profits of a firm who is producing $n$ varieties are therefore given by:

$$
\Pi(n) \equiv \sum_{j=1}^{n} \max _{m_{j} \geq 0}\left\{\left(\frac{T}{n}+\alpha m_{j}\right)^{\sigma} Y-w_{M} m_{j}\right\},
$$

where $w_{M}$ is the managerial wage.

The maximization problem in (9) defines both firms' demand for managerial inputs and their final profit function. Two properties are noteworthy. First of all, the entrepreneur's inelastically supplied managerial input $T$ generates a well-defined extensive margin for managerial hiring. In particular, the firm only hires outside managers if the size of the firm, in the number of varieties, exceeds the endogenous delegation cutoff $n^{*}(\alpha)$, which is given by

$$
n^{*}(\alpha)=T \times\left(\frac{\omega_{M}}{\sigma \alpha}\right)^{\frac{1}{1-\sigma}}
$$

where $\omega_{M}=w_{M} / Y$ is the normalized managerial wage. Hence, small firms rely purely on the time of the owner and only start delegating once they reach a size $n>n^{*}(\alpha)$. Note that the cutoff $n^{*}(\alpha)$ is decreasing in $\alpha$ and increasing in $\omega_{M}$. Hence, the more efficient the outside managers, the more likely is it that even small firms utilize outside managers. Conversely, if managers are expensive (relative to the size of the market $Y$ ), the critical size at which firms start to delegate increases. Second, it is easy to verify that the optimal managerial demand per variety $m(n)$, conditional on hiring, is given by $m(n)=\left(\frac{\sigma}{\omega_{M}}\right)^{\frac{1}{1-\sigma}} \alpha^{\frac{\sigma}{1-\sigma}}-\frac{1}{\alpha} \frac{T}{n}$, i.e. is increasing in $n$. This reflects the complemen- 
tarity between managerial hiring and firm size. As for the extensive margin, managerial demand is increasing in $\alpha$ and decreasing in $\omega_{M}$.

Substituting firms' optimal delegation policies into (9) implies the following endogenous profit function:

$$
\Pi(n ; \alpha)=\tilde{\pi}(n ; \alpha) \times Y \quad \text { where } \quad \tilde{\pi}(n ; \alpha)=\left\{\begin{array}{clc}
T^{\sigma} n^{1-\sigma} & \text { if } & n<n^{*}(\alpha) \\
T \frac{\omega_{M}}{\alpha}+(1-\sigma)\left(\frac{\sigma \alpha}{\omega_{M}}\right)^{\frac{\sigma}{1-\sigma}} n & \text { if } & n \geq n^{*}(\alpha)
\end{array} .\right.
$$

This profit function in (11) is a crucial object in our analysis, because it determines firms' marginal return to increase the number of markets in which they are active. Most importantly, firms' profits directly depend on the delegation efficiency $\alpha$.

To see this, consider Figure 1 where we depict the profit function $\tilde{\pi}(n ; \alpha)$ for two different levels of delegation efficiency $\alpha^{L}<\alpha^{H}$ holding the managerial wage $\omega_{M}$ fixed. Small firms are run only by their owner and are subject to diminishing returns: As long as they do not delegate, the marginal profit from an additional market is declining, i.e., $\tilde{\pi}(n ; \alpha)$ is concave in $n$. Once firms reach the critical size $n^{*}$ and start hiring outside managers, however, the profit function becomes linear in the number of markets $n$. Hence, entrepreneurs can overcome the decreasing returns to scale by delegating managerial tasks to outside managers. ${ }^{7}$ Moreover, conditional on delegating, an increase in delegation efficiency $\alpha$ increases the slope of the profit function. If there are frictions to delegation, i.e. $\alpha$ is low, the delegation cutoff is large, few firms delegate and the marginal profits for large firms are low. If delegation becomes more efficient, both the delegation cutoff declines and the slope of the profit function increases. These comparative statics already suggest the relationship between the delegation environment and the process of firm-dynamics: A higher delegation efficiency $\alpha$ raises the returns to being large and therefore affects firms' expansion decisions. This is where we turn now.

\subsection{Firm Dynamics: Expansion, Entry and Exit}

Following Klette and Kortum (2004), we consider a model of creative destruction where firms grow by stealing products from their competitors and decline in size if other firms replace them as the most productive producer in a particular market. There are two main differences with the baseline Klette and Kortum (2004) model. First of all, because firms' profits $\tilde{\pi}(n ; \alpha)$ directly depend on the delegation environment $\alpha$, delegation efficiency determines firms' growth and entry incentives and thereby directly affects the aggregate rate of creative destruction and the equilibrium growth rate. Second, we explicitly allow firms to be heterogeneous in their growth potential and exposure to creative destruction shocks. It is this heterogeneity across producers, which gives rise to the possibility of selection.

Delegation and the Incentives to Expand: Firms spend resources to increase the productivity of existing products in the economy. Formally, we assume that if a firm with $n$ varieties invests $R$ units

\footnotetext{
${ }^{7}$ Note that two special cases of our model resemble two workhorse models in the literature. When $\alpha=0$ there is no scope of outside delegation. In that case, we have that $n^{*}=\infty$ and all firms are subject to diminishing returns as in Lucas (1978). On the other hand when $\alpha$ is sufficiently large so that $n^{*}<1$, every firms delegates and firms' profits functions are linear as in the baseline version of Klette and Kortum (2004).
} 


\section{Figure 1: Delegation and Decreasing Returns To Scale}

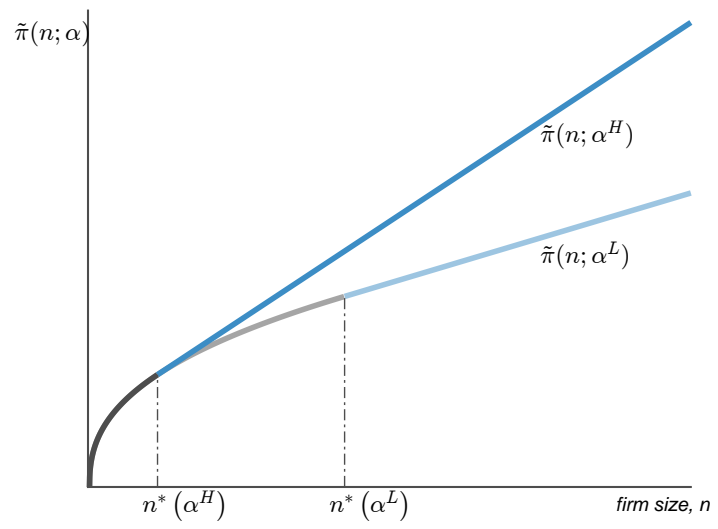

Notes: The figure depicts the profit function $\tilde{\pi}(n ; \alpha)$ characterized in (11) for $\alpha^{L}$ and $\alpha^{H}, \alpha^{L}<\alpha^{H}$ and a given the managerial wage $\omega_{M}$. That $n^{*}(\alpha)$ is decreasing in $\alpha$ follows from (10).

of the final good, it generates a flow rate of innovation equal to

$$
X(R ; \theta, n)=\theta[R / Q]^{\zeta} n^{1-\zeta}
$$

where $\theta$, which we refer to as firms' growth potential, determines the efficiency of innovation, $\zeta<1$ parametrizes the concavity of the innovation production function and $Q_{t}$ is the productivity index defined in (6). ${ }^{8}$ Conditional on innovating, the firm improves the productivity of a randomly selected product by a multiple $\gamma_{t}>1$ and replaces the existing firm as the producer of the product.

We assume that firms are heterogeneous in their growth potential $\theta$ and can be either transformative (high, $\theta_{H}$ ) or subsistence (low, $\theta_{L}$ ) types. A firm's type is persistent and determined upon entry. Formally, each new entrant draws a firm type $\theta \in\left\{\theta_{H}, \theta_{L}\right\}$ from a Bernoulli distribution, where

$$
\theta=\left\{\begin{array}{ll}
\theta_{H} & \text { with probability } \delta \\
\theta_{L} & \text { with probability } 1-\delta
\end{array} .\right.
$$

To capture the existence of subsistence entrepreneurs, we assume that $\theta_{L}=0$, so that low-type firms are entirely stagnant. This polar case is conceptually useful because it stresses that low types are never able to grow. Hence, the sole difference in firm dynamics across countries stems from the innovation incentives for high types - it is the high types' appetite for expansion that determines the degree of selection, i.e., the time it takes for low-type firms to be replaced.

In addition, we allow for firms to potentially differ in the rate at which they lose markets due to differences in their reputation, customer loyalty, or organizational capital. Formally, letting $\tau_{H}$ and $\tau_{L}$ be the rates at which high and low-type firms lose a given product to other firms (both of which,

\footnotetext{
${ }^{8}$ Because we denote innovation costs in terms of the final good, the growing scaling variable $Q$ is required to keep the model stationary. We also assume that firms' innovation costs depend on the number of varieties $n$ to generate deviations from Gibrat's law solely through incomplete delegation. In particular, if the profit function in (11) was linear, e.g. as in Klette and Kortum (2004), the specification in (12) would imply that firm growth was independent of size.
} 
will be determined in equilibrium), we assume that

$$
\tau_{L}=\beta \tau_{H}
$$

If $\beta>1$, low-type firms are easier to replace (or are targeted by expanding firms more intensely), if $\beta<1$, the opposite is the case. The parameter $\beta$ will be one of our structural parameters, which we will calibrate from the data.

To characterize the optimal expansion policies of high-type firms, which are forward-looking, we need to solve for their value functions. The value of a high-type firm with $n$ products, $V_{t}^{H}(n)$, solves the continuous time Hamilton-Jacobi-Bellman equation:

$$
\begin{aligned}
r_{t} V_{t}^{H}(n)-\dot{V}_{t}^{H}(n)= & \Pi_{t}(n ; \alpha)-n \tau_{H, t}\left[V_{t}^{H}(n)-V_{t}^{H}(n-1)\right]+ \\
& \max _{X}\left\{X\left[V_{t}^{H}(n+1)-V_{t}^{H}(n)\right]-Q_{t} n^{\frac{\zeta-1}{\zeta}}\left[\frac{X}{\theta_{H}}\right]^{\frac{1}{\zeta}},\right\} .
\end{aligned}
$$

where $\dot{V}_{t}^{H} \equiv \partial V_{t}^{H} / \partial t$. Note that the value function $V_{t}^{H}$ directly depends on the delegation environment $\alpha$ via the profit function. The right-hand-side of (14) consists of three parts. First of all, the firm earns the flow profits $\Pi_{t}(n ; \alpha)$ given in (11). Secondly, the firm might lose one of its products to other firms. This occurs with the endogenous rate of creative destruction $n \tau_{H, t}$. Finally, the value function incorporates the option value of expansion: The firm experiences a capital gain $V_{t}^{H}(n+1)-V_{t}^{H}(n)$ with flow rate $X$ but has to pay the associated innovation costs stemming from (12). Similarly, we can also derive the value function of low-type firms. Because subsistence entrepreneurs never grow beyond a single product and they exit at rate $\tau_{L, t}$, this value function is given by:

$$
r_{t} V_{t}^{L}-\dot{V}_{t}^{L}=\Pi_{t}(1 ; \alpha)-\tau_{L, t} V_{t}^{L} .
$$

Given the definition of the value function $V_{t}^{H}$, we can characterize high types' expansion policies. Let us denote the innovation intensity (i.e. the innovation per product line) by $x \equiv X / n$. Equation (14) then implies that the optimal innovation intensity is given by:

$$
x_{t}(n ; \alpha)=\theta_{H}^{\frac{1}{1-\zeta}} \zeta^{\frac{\zeta}{1-\zeta}} \times\left(\frac{V_{t}^{H}(n+1)-V_{t}^{H}(n)}{Q_{t}}\right)^{\frac{\zeta}{1-\zeta}} .
$$

Naturally, the incentives to grow depend on the marginal returns of doing so, $V_{t}^{H}(n+1)-V_{t}^{H}(n)$. It is this marginal return that links firms' innovation incentives to the delegation environment. In equation (11) and Figure 1 we showed that the delegation efficiency $\alpha$ determines the concavity of the profit function, and hence the marginal flow profit of expansion. Because the value function inherits the properties of the profit function, the delegation efficiency also determines the slope of the value function, and hence the optimal innovation rate for firms of different size. The lower the delegation efficiency $\alpha$, the more concave the resulting value function, and the more innovation incentives will decline in firm size. Intuitively, if firms anticipate they will not be able to efficiently delegate decision power once they reach a size where delegation becomes essential, their incentives to expand diminish. A higher delegation efficiency $\alpha$ will therefore increase firms' expansion incentives by 
increasing the slope of the value function.

Figure 2: Overview of the Life-Cycle Dynamics in the Model

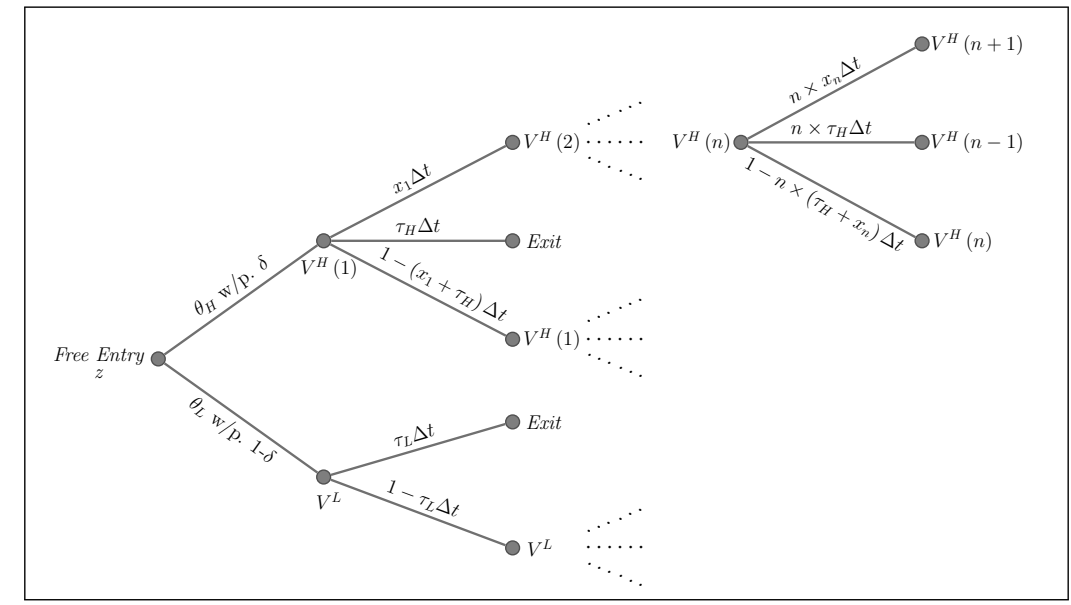

Figure 2 provides an overview of the life cycle dynamics in our model. Firms enter the economy with a single product and are either transformative, high-type entrepreneurs (with probability $\delta$ ) or subsistence, low-type entrepreneurs (with probability $1-\delta$ ). The corresponding value functions are $V_{H}(1)$ and $V_{L}$. Within the next time interval $\Delta t$, high-type firms either expand (at rate $x_{1}$ ), lose their only product and exit (at rate $\tau_{H}$ ) or remain a one-product firm. In contrast, low-type firms never expand but instead either exit the economy (at rate $\tau_{L}$ ) or remain in the economy by serving their initial market.

Entry: A unit mass of potential entrants attempts to enter the economy at any point in time using a similar innovation technology as incumbent firms, $z=\theta_{E}\left[R_{E} / Q\right]^{\zeta}$, where $z$ is the entry flow rate and $R_{E}$ is amount of final goods spent on entry efforts. Entrants enter the economy with a single, randomly selected product and the realization of $\theta$ is revealed only after entering the market. Recall from (13) that an entrant becomes a high-type with probability $\delta$. Hence, the equilibrium entry flow is given by:

$$
\begin{aligned}
z_{t}(\alpha) & =\underset{z}{\operatorname{argmax}}\left\{z\left[\delta V_{t}^{H}(1 ; \alpha)+(1-\delta) V_{t}^{L}(\alpha)\right]-Q_{t} \theta_{E}^{-\frac{1}{\zeta}} z^{\frac{1}{\zeta}}\right\} \\
& =\theta_{E}^{\frac{1}{1-\zeta}} \zeta^{\frac{\zeta}{1-\zeta}}\left[\frac{\delta V_{t}^{H}(1 ; \alpha)+(1-\delta) V_{t}^{L}(\alpha)}{Q_{t}}\right]^{\frac{\zeta}{1-\zeta}} .
\end{aligned}
$$

The equilibrium entry flow $z_{t}(\alpha)$ depends on the delegation environment through firms' value function. Importantly, the effect of $\alpha$ on the entry rate is ambiguous. A better delegation environment tends to increase the value of being a small high-type firm, $V_{t}^{H}(1 ; \alpha)$, as seamless delegation carries an option value of becoming large in the future. At the same time, the value of being a low-type firm might decline. The reason is that a more efficient delegation environment increases competition by increasing the expansion rate of high-type firms. This shortens the horizon of low-type producers by reducing their probability of survival. 
Delegation and the Process of Firm Dynamics: Firms expansion and entry incentives in (16) and (17) fully summarize the relationship between delegation efficiency and the process of firmdynamics. To get some intuition, consider an increase in delegation efficiency $\alpha$ holding all wages and the flow rate of entry $z$ fixed. This will increase managerial hiring (both on the intensive and extensive margin) and raise firms' marginal profits conditional on delegating. Such higher marginal profits will also increase the slope of value function and hence high-type firms' expansion rates $x(n ; \alpha)$. We depict this expansion response in Figure 3. First of all, an increase in the efficiency of the delegation from $\alpha^{L}$ to $\alpha^{H}$ will shift the whole expansion schedule upwards. Intuitively, if firms anticipate to be able to hire outside managers once they reach the delegation cutoff $n^{*}$ in the future, their incentives to expand today are already higher. Secondly, innovation incentives increase more for larger firms and the schedule $x(n ; \alpha)$ becomes flatter, i.e. innovation incentives decline less in the size of the firm. Hence, improvements in the delegation environment are particularly important for large firms, who heavily rely on outside managers.

\section{Figure 3: Delegation and Expansion Incentives}

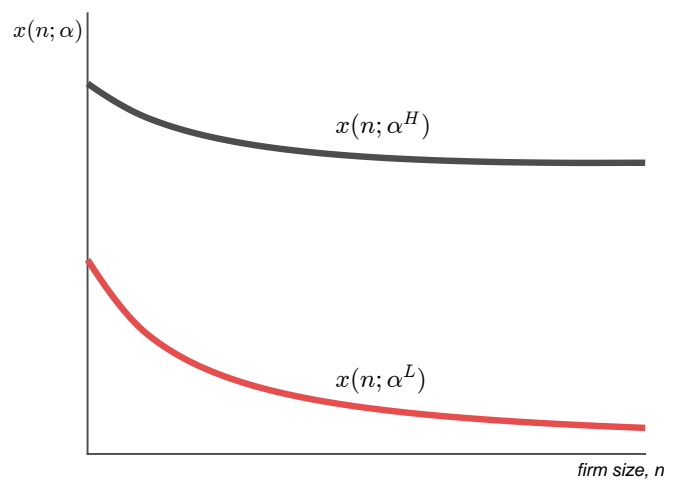

Notes: The figure depicts the innovation intensity $x(n ; \alpha)$ characterized in (16) for $\alpha^{L}$ and $\alpha^{H}, \alpha^{L}<\alpha^{H}$ and a given the managerial wage $\omega_{M}$ and creative destruction $\tau_{H}$.

Because high-type firms expand partly at the expense of low-type firms, increasing the delegation efficiency $\alpha$ has the direct implication that low-type firms will exit faster. The fact that stagnant firms in poor countries survive for a long time, is therefore consistent with the view that efficient firms expand too little to drive them out of the market quickly. Moreover, because an increase in delegation efficiency will have a disproportionate effect on expansion incentives of large firms, the firm size distribution shifts to the right so that a larger share of economic activity will be generated in big firms. From the point of view of a firm's life cycle, this implies that the growth rate of large firms will respond more to an increase in delegation efficiency, so that firm age becomes a stronger predictor of firm size. This pattern is qualitatively consistent with the cross-country evidence (Hsieh and Olken (2014); Hsieh and Klenow (2014); Bento and Restuccia (2017)).

The above intuition neglects two countervailing general equilibrium forces. First of all, managerial wages will adjust to ensure labor market clearing. Secondly, there will be a change in entry. To fully characterize the effects of changes in the delegation environment on the process of firm dynamics, we turn to a quantitative analysis in Section 5. 


\subsection{Aggregate Dynamics}

The equilibrium rate of creative destruction in the economy is endogenous and driven by firms' expansion and entry incentives $x_{t}(n ; \alpha)$ and $z_{t}(\alpha)$. Because firms' expansion rates are size-dependent, the rate of creative destruction (and all the remaining general equilibrium variables) depends on the cross-sectional distribution of firm size. In particular, let $F_{t}^{H}$ and $F_{t}^{L}$ be the mass of active high- and low-type producers at time $t$. Also, let $v_{n, t}^{H}$ denote the share of high-type firms with $n$ products. ${ }^{9}$ In Section A.1 in the Appendix we formally derive the flow equations of these objects and show that the stationary firm-size distribution has a closed form expression.

Because firms' rates of expansion and the equilibrium rate of entry depend on the delegation environment $\alpha$, both the aggregate rate of creative destruction $\tau_{t}$ and the firm-size distribution explicitly depends on the delegation efficiency. In particular, $\tau_{t}$ is given by:

$$
\tau_{t}(\alpha)=F_{t}^{H}(\alpha) \sum_{n=1}^{\infty} n x_{t}(n ; \alpha) v_{n, t}^{H}(\alpha)+z_{t}(\alpha) .
$$

Differences in the efficiency of delegation affect creative destruction directly through differences in expansion and entry rates $x_{t}(n ; \alpha)$ and $z_{t}(\alpha)$, and indirectly through changes in the firm-size distribution $v_{n, t}^{H}(\alpha)$ and the number of high-type firms $F_{t}^{H}(\alpha)$. Quantifying the extent to which the firm size distribution and the rate of creative destruction depends on the delegation efficiency will be at the heart of our quantitative analysis below. Finally, recall that we allowed the extent of productreplacement to be type-specific. Consistency therefore requires that $\tau_{t}=\tau_{H, t}\left(1-F_{t}^{L}\right)+\tau_{L, t} F_{t}^{L}$, as $F_{t}^{L}$ is the share of products which is produced by low-type firms (all of which have only a single product).

The rate of creative destruction is also the main driver of aggregate growth in our economy. Recall that each successful innovation increases productivity by the step size $\gamma_{t}$. The aggregate growth rate of the productivity index $Q_{t}$ is then given by (see Appendix A.2)

$$
g_{t}(\alpha) \equiv \frac{\dot{Q}_{t}}{Q_{t}}=\ln \left(\gamma_{t}\right) \times \tau_{t}(\alpha),
$$

i.e. is proportional to the aggregate rate of creative destruction. Equation (19) highlights the relationship between delegation and aggregate growth: In our model, more efficient delegation increases aggregate growth through its effect on expansion and entry and hence creative destruction.

To account for the fact that the Indian economy is technologically backward (relative to the U.S.), and might therefore be able to benefit from "catch-up" growth, we assume that its step-size $\gamma_{t}^{I N D}$ is given by

$$
\gamma_{t}^{I N D}=\gamma^{U S} \times\left(\frac{Q_{U S, t}}{Q_{I N D, t}}\right)^{\lambda},
$$

where $\lambda \geq 0$ and $\gamma^{U S}$ is the step size for the U.S., which we assume to be constant. ${ }^{10}$ Equation (20)

\footnotetext{
${ }^{9}$ Recall that all low-type firms only have a single product.

${ }^{10}$ Taking the U.S. as the frontier economy is purely for simplicity. Suppose there is an exogenous technological frontier $Q_{t}^{F}$, which grows at rate $g$. Suppose that the step size in country $c$ is given by (20) relative to this frontier, i.e. $\gamma_{t}^{c}=$ $\gamma \times\left(Q_{t}^{F} / Q_{c, t}\right)^{\lambda}$. If the U.S. economy already reached its BGP, (20) holds with $\gamma^{U S}=g / \tau_{U S}$.
} 
captures - in a reduce form way - the existence of knowledge spillovers. In particular, to the extent that productivity in India is relatively low and $\lambda>0$, the Indian step-size might exceed the one for the U.S. If $\lambda=0$, there are no "benefits from backwardness".

While our empirical analysis focuses on a time period where the Indian economy has not reached a balanced growth path, note that the formulation in (20) implies that, in the long run, the Indian and the U.S. economy grow at the same rate and the distribution of income is stationary. Hence, differences in the delegation efficiency manifest themselves in level differences, not in growth differences. To see this, note that along a balanced growth path, both the rate of creative destruction and the equilibrium step size have to be constant. This implies that - as long as $\lambda>0-$ aggregate productivity differences, $Q_{U S, t} / Q_{I N D, t}$ also have to be constant. In particular, (19) and (20) imply that

$$
\ln \left(\frac{Q_{I N D, t}}{Q_{U S, t}}\right)=-\frac{\ln \gamma^{U S}}{\lambda} \times\left(\frac{\tau_{U S}-\tau_{I N D}}{\tau_{I N D}}\right) .
$$

Equation (21) highlights that differences in creative destruction determine the long-run distribution of income across countries. In particular, the lower the rate of creative destruction in India relative to the U.S., the higher the differences in productivity. For the limiting case of $\lambda=0$, there are no linkages across countries, and the long-run income distribution is non-stationary as countries generically grow at different rates.

Equation (21) also provides the link between differences in delegation efficiency and aggregate productivity. Suppose that the U.S. and India only differed in their delegation efficiency. ${ }^{11}$ Because more efficient delegation in the U.S. increases the equilibrium rate of creative destruction relative to India, (21) shows that long-run productivity in the U.S. will be higher. We will quantify the importance of the delegation environment on long-run income and productivity differences between India and the U.S. in Section 6 below.

\subsection{Dynamic Equilibrium}

For completeness we can now formally define the full dynamic equilibrium for our economy.

Definition 1 Consider the environment described above. A dynamic equilibrium path is characterized by a time path of

$$
\left[p_{j t}, y_{j t},\left\{V_{t}^{H}(n)\right\}_{n=1}^{\infty}, V_{t}^{L},\left\{x_{t}(n)\right\}_{n=1}^{\infty}, z_{t}, w_{t, M}, w_{t, P},\left\{v_{t, n}^{H}\right\}_{n=1}^{\infty}, F_{t}^{H}, F_{t}^{L}, r_{t}, g_{t}\right]_{t=0}^{\infty},
$$

such that (i) $p_{j t}$ and $y_{j t}$ maximize monopoly profits in (4), (ii) the value functions $V_{t}^{H}(n)$ and $V_{t}^{L}$ are given by (14) and (15) (iii) the innovation rates $x_{t}(n)$ are optimal and given in (16), (iv) the entry rate $z_{t}$ satisfies (17), (v) $w_{t, P}$ and $w_{t, M}$ clear the labor market for production and managerial labor, (vi) the number of firms $\left[F_{t}^{H}, F_{t}^{L}\right]$ and the firm size distributions $v_{t, n}^{H}$ are consistent with the flow equations in Section A.1 in the Appendix, (vii) the interest rate $r_{t}$ satisfies the household's Euler equation in (1), and (viii) the aggregate productivity growth rate is consistent (19) and (20).

\footnotetext{
${ }^{11}$ In our quantitative analysis, we will allow for additional differences and we will explicitly show that doing so is important.
} 
In our quantitative analysis we will calibrate this model to micro-data from India and the U.S. While we assume that the U.S. economy has converged to a balanced growth path, where all aggregate variables grow at a constant rate, we allow for the Indian economy remain along its transition path, i.e. catching-up with the U.S. As far as the firm size distributions are concerned, we initialize the distribution in both countries at their BGP distribution. As we show in Section A.3 of the Appendix, this implies that the firm-size distribution will remain stationary during the transition, i.e. despite the fact that the aggregate economy has not reached a BGP yet. In Section OA-2.2 of the Online-Appendix, we present direct evidence that size distribution of firms in India is relatively stable over time.

\section{Data and Calibration}

\subsection{Data}

Our quantitative analysis uses both establishment-level and individual-level micro data. To measure properties of the process of firm dynamics, we rely on micro data for the population of manufacturing establishments in the U.S. and India. We then combine this information with individual-level census records from both countries to measure the importance of managerial employment. Here we briefly describe the main data sources. A detailed description of all of our data sources is contained in Section B.1 in the Appendix.

Establishment level data for the U.S. and India: We calibrate our model to data for the manufacturing sector of the U.S. and India. For the case of the U.S. we rely on publicly available data from the Business Dynamics Statistics (BDS). The BDS is provided by the U.S. Census Bureau and compiled from the Longitudinal Business Database (LBD), which draws on the U.S. Census Bureau's Business Registry to provide longitudinal data for each establishment with paid employees. These data have also been used in Haltiwanger et al. (2013) and Moscarini and Postel-Vinay (2012). We focus on the data from 2012. As for India, we follow Hsieh and Klenow (2014) and Hsieh and Olken (2014) and use the Annual Survey of Industries (ASI) and the National Sample Survey (NSS). The ASI focuses on the formal sector and covers all establishments employing ten or more workers using electric power, and employing twenty or more workers without electric power. To overcome this oversampling of large producers in the ASI, we complement the ASI with data from the NSS, which (every five years) surveys a random sample of the population of manufacturing establishments without the minimum size requirement of the ASI. We merge these two datasets using the sampling weights provided in the data and focus on the year 2010, which is the latest year for which both data sets are available. To be consistent with the existing literature (e.g., Hsieh and Klenow, 2014) and because the Indian data is collected at the level of the establishment, our benchmark analysis will focus on individual establishments. We will conduct robustness checks using firm-level data in Section 7.12

\footnotetext{
${ }^{12}$ While a establishment is a fixed physical location where economic activity occurs, firms are defined at the enterprise level such that all establishments under the operational control of the enterprise are considered part of the firm.
} 
Table 1 contains some basic descriptive statistics about the distribution of establishment size in the U.S. and India. The importance of large firms varies enormously between countries. In the U.S., two-thirds of manufacturing employment is concentrated in establishments with at least 100 employees; and only one-third of the establishments have fewer than four employees. In India, more than nine out of ten establishments have fewer than four employees and they account for more than half of aggregate employment. Below, we will use our theory to rationalize these empirical facts.

Table 1: Establishment Size and Managerial Employment in the U.S. AND India

\begin{tabular}{l|c|cc|cc||c}
\hline \hline & \multicolumn{4}{|c||}{ Establishment Size } & Empl. share \\
& & \multicolumn{2}{|c}{$1-4$ employees } & \multicolumn{2}{c}{$\geq 100$ employees } & of outside \\
& Mean empl. & Share & Empl. share & Share & Empl. share & managers \\
\hline U.S. & 42.7 & $32.8 \%$ & $1.8 \%$ & $8.8 \%$ & $65.6 \%$ & $12.4 \%$ \\
India & 2.7 & $93.0 \%$ & $54.8 \%$ & $0.1 \%$ & $18.6 \%$ & $1.7 \%$ \\
\hline \hline
\end{tabular}

Notes: The table contains summary statistic from the firm size distribution in the U.S. and India. The U.S. data come from the BDS in 2012, the data for India from the NSS and ASI in 2010. In the last column, we report the share of outside managers, i.e. all workers who are classified as managers according to the occupation classification ISCO and who are hired as wage workers.

Data on Managerial Employment: To infer countries' delegation efficiency, we require data on the equilibrium level of managerial employment. Such data is available from the national census data provided by the IPUMS project. For each country we get a sample from the census, which has detailed information about individual characteristics. We observe each respondent's education, occupation, employment status, sex and industry of employment. We focus on male workers in the manufacturing industry working in private-sector jobs. We always use the most recent data available, which is 2004 in the case of India and 2010 in the case of the U.S.

To classify workers as managers in the sense of our model, we use information about workers' occupational and employment status. As our theory stresses the importance of delegating authority to outside managers, we classify employees as managers if they assigned the occupational code "Legislator, Senior official and manager" and they are hired as wage workers instead of being, for example, family members of the firms' owner or the employer themselves. As shown in the last column of Table 1, in the U.S. roughly $12.4 \%$ of employees satisfy this criterion. In India, less than $2 \%$ are employed as outside managers. Note that insisting on outside managers is important. For the case of the U.S., roughly $14 \%$ of the labor force is classified as managers according to their occupational code. The majority, namely $90 \%$, are wage workers, hence outside managers in the sense of our theory. This is very different in the case of India, where conditional on being in a managerial occupation, only $12 \%$ of individuals are wage workers and the majority of individuals working in managerial occupations are either entrepreneurs themselves or unpaid family members. The latter is consistent with the findings in Bloom et al. (2013), who also argue that Indian firms acquire managerial services mostly from their owners or close family members. This pattern is very much the exception in the U.S. 


\subsection{Identification and Calibration}

We now turn to our calibration strategy. To credibly identify the partial effect of the delegation environment $(\alpha)$, we independently calibrate our model to the Indian data and the U.S. data. Hence, we allow the key parameters of our model to differ between these economies. By doing so, we capture various alternative mechanisms determining the process of firm-dynamics in a parsimonious way.

By allowing high types' growth potential $\theta$ to vary across countries, we allow - in a reduced form way - for differences in capital market efficiency, whereby frictions in the Indian financial system might prevent firms from investing and hence cause them to remain small (see, for instance, Cole et al., 2016), size-dependent policies, whereby Indian firms might be subject to steeper increases of (implicit) tax rates in firm size (see, for example, Hsieh and Klenow, 2014, Guner et al., 2008, Ulyssea, 2016, and Bento and Restuccia, 2017) or product market frictions, which might be more severe in India (see, for example, Foster et al., 2016, Gourio and Rudanko, 2014, and Perla, 2016). In our model, we capture such explanations by allowing Indian firms to potentially face high costs of expansion $\left(\theta_{I N D}<\theta_{U S}\right)$. Similarly, inefficiencies in the allocation of start-up capital or frictions in labor markets might induce more subsistence firms to enter in India. If this is an important aspect of the data, our model should estimate low-type firms in India to be plentiful upon entry $\left(\delta_{I N D}<\delta_{U S}\right)$. Finally, the Indian economy might be characterized by higher entry costs due to bureaucratic red tape. Our model allows for this margin through variation in the efficiency of entry $\left(\theta_{I N D}^{E}<\theta_{U S}^{E}\right)$.

\section{Identification}

Our model has 13 parameters:

$$
\Omega \equiv\{\underbrace{\alpha, \sigma, T, \mu_{M}, \vartheta}_{\text {Management }}, \underbrace{\theta, \theta_{E}, \zeta, \delta, \beta}_{\text {Firm dynamics }}, \underbrace{\gamma^{U S}, \lambda, \rho}_{\text {Macro }}\}
$$

where we define the parameter set as $\Omega$. Five parameters relate directly to the demand and supply of managerial services: The delegation efficiency $(\alpha)$, the managerial output elasticity $(\sigma)$, the owners' own human capital $(T)$, and the distribution of managerial skills ( $\mu_{M}$ and $\left.\vartheta\right)$. The process of firmdynamics is captured by the innovation and entry efficiencies $\left(\theta\right.$ and $\left.\theta_{E}\right)$, the convexity of the cost function $\zeta$, the share of high-type entrants $(\delta)$ and the difference in type-specific creative destruction rates $(\beta)$. Finally, the remaining three "macro" parameters capture the process of the innovation step size $\left(\gamma^{U S}\right.$ and $\left.\lambda\right)$ and the patience of the household $(\rho)$.

We fix two of the parameters exogenously $(\rho$ and $\zeta$ ) and calibrate the remaining 11 parameters by minimizing the distance between several empirical moments and their model counterparts. ${ }^{13}$ In particular, let $M^{E}$ denote the vector of empirical moments and $M(\Omega)$ denote the vector of modelsimulated moments for a given $\Omega$. We then chose $\Omega$ to minimize the absolute relative deviation

\footnotetext{
${ }^{13}$ As we do not have data on spending on innovation, we do not attempt to estimate the curvature of the expansion cost function, $\zeta$. Instead we follow the microeconomic literature, whose estimates imply a quadratic cost function, i.e., $\zeta=0.5$. See Akcigit and Kerr (2017) and Acemoglu et al. (2017), who discuss this evidence in more detail. In Section 7 we provide a battery of robustness checks. We set the discount rate $\rho$ equal to $2 \%$, which roughly corresponds to an annual discount factor of $97 \%$.
} 
between the model and data, i.e. we solve

$$
\min _{\Omega} \sum_{m=1}^{11} \frac{\left|M_{m}^{E}-M_{m}(\Omega)\right|}{\left|M_{m}^{E}\right|} .
$$

Even though our parameters are calibrated jointly, and most of the target moments cannot be expressed analytically, our aim is to be transparent about the parameter identification. Therefore, we proceed in two steps. First, below we provide a heuristic description about the relationship between the parameters and specific moments. Second, in Appendix B.2, we not only provide a more formal identification discussion, we also verify these relationships numerically using a sensitivity matrix, where we report the elasticity of each moment used in the internal calibration with respect to the parameters of the model (see Table 10). ${ }^{14}$

Identifying $\theta, \delta, \beta$ and $\theta_{E}$ : The expansion efficiency $\theta$ is mostly identified from the profile of firms' life-cycle growth. This is seen in Panel A of Figure 4, where we depict the extent to which firms grow as they age for different values of $\theta$, holding all other parameters fixed. The higher $\theta$, the faster firms will grow conditional on survival. To identify the share of high-type producers $\delta$, we focus on the age-profile of exit rates conditional on firm size. Without type heterogeneity, the likelihood of exit would be independent of age conditional on size. In the data, however, such conditional exit rates are strongly decreasing in firm age [see e.g., Haltiwanger et al. (2013)]. Through the lens of our model, this pattern is rationalized through endogenous selection, whereby the share of high-type firms within a given cohort increases as the cohort ages. This is shown in Panel B of Figure 4 , where we show the exit rate of small firms by age for different values of $\delta$. Without any heterogeneity, i.e. $\delta=1$, the conditional exit hazard is flat.The parameter $\beta$, which determines how quickly low-type firms lose market share relative to high-type competitors, is identified from the aggregate employment share of old firms. ${ }^{15}$ Finally, the entry efficiency $\theta_{E}$ is identified from the aggregate entry rate.

Identifying $\alpha, \mu_{M}, \vartheta, \sigma$ and T: As the delegation efficiency $\alpha$ affects firms' demand for outside managers, it is mainly identified from the aggregate managerial employment shares reported in Table 1. In particular, the lower share of outside managers in India implies - all else equal - that $\alpha_{I N D}<\alpha_{U s} \cdot{ }^{16}$ As we discuss in Section B.2 in the Appendix, by choice of units for managerial skills, all allocations in the model only depend on $\mu_{M} \times \alpha$. To separately identify the delegation efficiency $\alpha$ from the supply of managerial skills $\mu_{M}$, we require variation in the demand for managerial skills holding managerial human capital fixed. To do so, we use data from the New Immigrant Survey (NIS), which contains information about the pre- and post-migration outcomes of recent

\footnotetext{
${ }^{14}$ In particular, we report percentage change in the moment for a $1 \%$ change in the parameter from its benchmark calibrated value, while keeping the rest of the parameters at their benchmark values. We report the average elasticities based on $+1 \%$ and $-1 \%$ changes.

${ }^{15}$ Intuitively, as high-type firms are older on average, the aggregate size of old cohorts is informative about this parameter.

${ }^{16}$ This also illustrates why it is important to introduce other mechanisms that affect the firm size distribution in India: For a given level of delegation benefit $\alpha$, any shift in the distribution of firm size towards larger firms (due to an increase in $\theta$, for instance) will increase managerial demand.
} 
Figure 4: IDENTIFICATION OF $\delta$ AND $\theta$

Panel A: The Life-Cycle

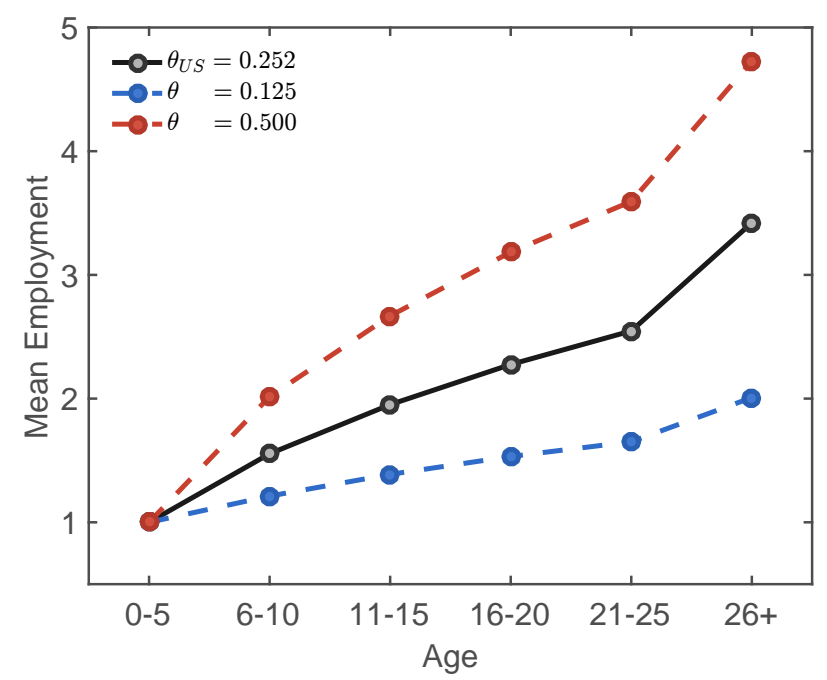

Panel B: Exit Rate of Small Firms by Age

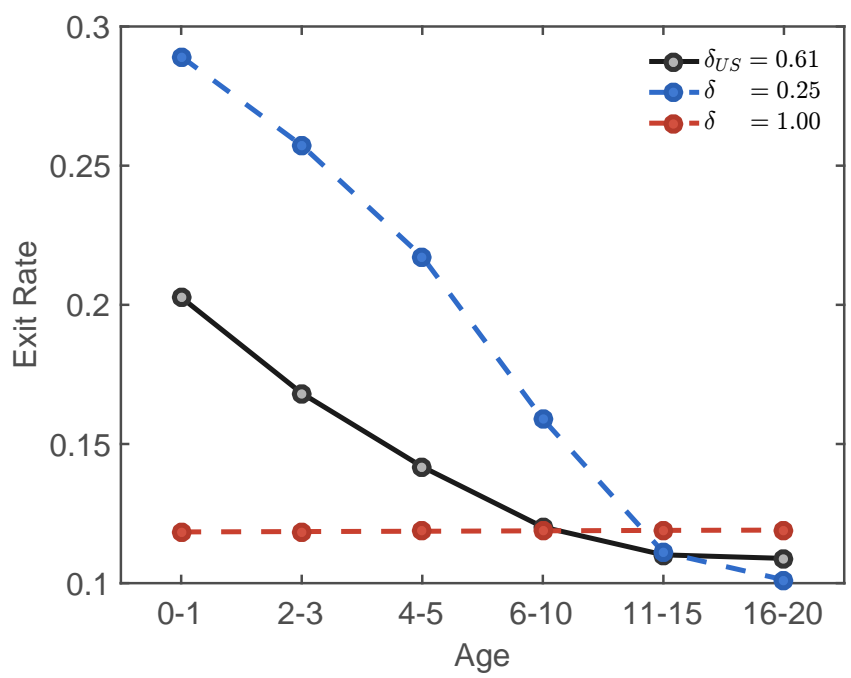

Notes: The left panel shows the employment life-cycle, i.e., average employment by age, for different values of $\theta$. The right panel shows the exit rate of one-product firms by age for different values of $\delta$. The black line depicts the U.S. calibration (i.e., $\theta_{U S}=0.25$ in the left panel and $\delta_{U S}=0.61$ in the right panel). The other lines are obtained by varying $\theta$ (left panel) or $\delta$ (right panel), while keeping the rest of the parameters constant.

immigrants to the U.S. and has recently been used by Hendricks and Schoellman (2016). As we show in detail in Section B.3 in the Appendix, this data is informative about the managerial human capital supply in India. Intuitively, Indian immigrants to the U.S. are almost as likely to work in managerial occupations as U.S. residents. However, they are much more likely to have worked in managerial jobs prior to emigrating. This implies that the average managerial human capital supply of the non-migrant Indian population is lower than in the U.S. The shape parameter of the managerial skill distribution $\vartheta$ can be directly calibrated to match the dispersion in managerial earnings as the model implies that the variance of log managerial earnings is given by $\vartheta^{-2}$. As $\sigma$ is the elasticity of profits with respect to managerial services, we identify it from the share of managerial compensation relative to corporate profits. The owner's time endowment $T$ is directly related to the need of managerial delegation and hence determines both the extensive margin of managerial hiring, i.e., the share of firms who hire outside managers, and the entrepreneurial profit share.

Identifying $\gamma^{U S}$ and $\lambda$ : The innovation step-size, $\gamma_{t}$, translates firms' innovation outcomes into aggregate growth. Note that $\gamma_{t}$ does not enter any other moment in the model. For the U.S., we assume that the economy is on a BGP and choose $\gamma^{U S}$ to match a growth rate of $2 \%$. For the case of India, $\lambda$ parametrizes the extent of catch-up growth [see (20)]. Empirically, relative productivity in the U.S. vis-à-vis India's decreased substantially from about 4 in 1985 to 3.2 in 2005 (see Figure 5). We therefore calibrate $\lambda$ to match these time-series dynamics of India's relative productivity. We use the TFP series from the Penn World Tables to measure productivity. 
Figure 5: IDENTIFICATION of $\lambda$ : TFP Differences BETWEen the U.S. AND INDiA

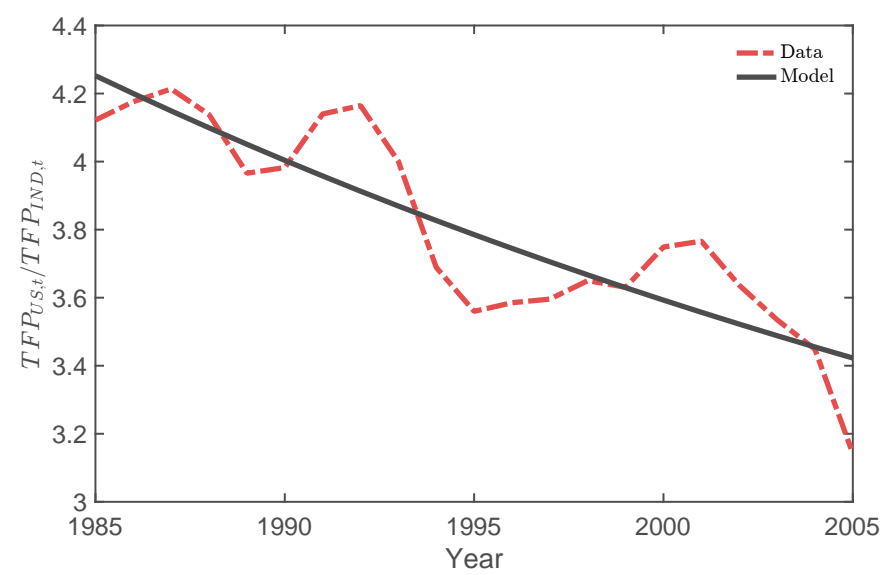

Notes: The figure shows the observed relative TFP between the U.S. and India (dashed) and the one implied by the model (solid).

\section{Results}

In this section we discuss our calibration results. Section 4.1 contains the calibrated structural parameters. In sections 4.2 and 4.3 we report a variety of targeted and non-targeted moments. Finally, in section 4.4 we report the implications for the economy-wide degree of creative destruction in the U.S. and India.

\subsection{Calibrated Parameters}

Table 2 contains the calibrated parameters. For convenience we also report the main target for the respective parameters even though the parameters are calibrated jointly.

The first two rows show that entrants in the U.S. economy are much more likely to be hightype firms, $\delta_{U S}>\delta_{I N D}$, and such firms are calibrated to be five times as efficient in expanding into new markets as their Indian counterparts $\left(\theta_{U S} \approx 5 \times \theta_{I N D}\right)$. Additionally, we estimate that $\beta>1$, which implies that low-type firms are subject to relatively higher probabilities of creative destruction, and that this asymmetry is more pronounced in the U.S. Empirically, these differences reflect mostly the observed differences in life-cycle growth and exit patterns. Economically, we find these estimates plausible in that they capture the above-mentioned additional reasons for why firms in India might not expand (e.g., due to the presence of credit constraints or size-dependent policies) or why unproductive firms are abundant upon entry (e.g., because of low opportunity costs of entrepreneurship in India).

The next two rows contain the estimates of the delegation environment. Our calibration implies that the delegation efficiency in the U.S. is about twice as large as in India $\left(\alpha_{U S} \approx 2 \times \alpha_{I N D}\right)$. Note that this low estimate of $\alpha_{I N D}$ is conditional on other determinants of firm size induced, for example, by differences in $\theta, \delta$, or $\theta_{E}$. This implies that other mechanisms are not able to explain both the differences in firm dynamics and managerial hiring, simultaneously. Because the cost of expansion and the share of subsistence firms are high in India, there are few large firms in the Indian economy, resulting potentially low level of managerial demand. However, to clear the labor market, managerial wages fall, limiting the impact of other mechanisms on managerial hiring. Therefore a 
TABLE 2: PARAMETERS FOR THE U.S. AND INDIA

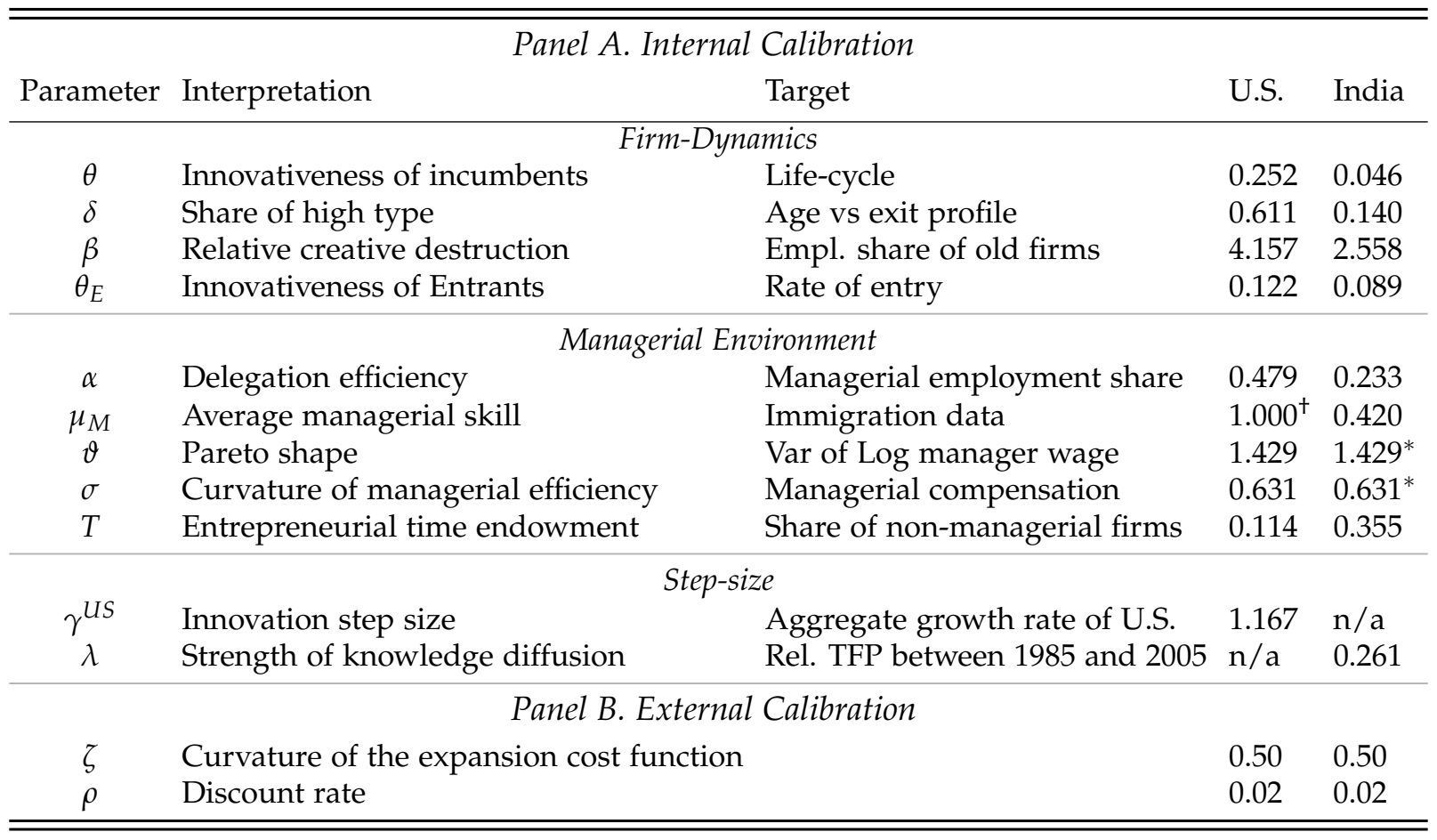

Notes: Table reports the parameter values that yield the model moments reported in Table 3. We denote normalized parameters by "t" and parameters which we do not calibrate to by "*".

lower delegation efficiency $\alpha$ is required to explain the lack in managerial hiring. ${ }^{17}$

Finally, also note that the U.S. labor force has a comparative advantage in managerial occupations $\left(\mu_{M, U S}>\mu_{M, I N D}\right)$. This is identified from the fact that the share of managers among Indian immigrants in the U.S. is $12.9 \%$ (hence very similar to the overall manager share in the U.S.), but they are much more likely to work as managers prior to migrating compared to the Indian population. Therefore, the unselected population in India has a comparative disadvantage in managerial occupations. $^{18}$

\subsection{Targeted Moments}

In Table 3 we report the targeted moments - for the model and the data. We start with the U.S. calibration. As seen in the first two columns of Table 3, the model is able to rationalize most empirical moments. In particular, it matches the observed life cycle, i.e., average employment for 21 to 25 year-old firms (relative to 1 to 5 year-old firms), the differences in exit rates, whereby small

\footnotetext{
${ }^{17}$ Another way to see this is the following: Suppose we kept the main parameters of the delegation margin, $\alpha$ and $\mu_{M}$, at the U.S. level, but re-calibrated the remaining parameters of the model to match all the Indian moments in Table 3 except the managerial employment share and relative employment patterns of Indian immigrants. While the model is again able to match the firm-level data moments equally well, the resulting equilibrium share of outside managers is $13.1 \%$, which is way above the Indian level and even higher than the U.S. level. Hence the model requires a low delegation efficiency $\alpha_{I N D}<\alpha_{U S}$ to explain the lack of managerial hiring in India.

${ }^{18}$ Recall that the equilibrium allocations only depend on $\mu_{M} \times \alpha$. This product is directly identified from the remaining set of moments discussed in Table 2. The additional information from the migration data is only required to distinguish the supply from the demand for managerial services.
} 
TABLE 3: MOMENTS FOR THE U.S. AND INDIA

\begin{tabular}{|c|c|c|c|c|}
\hline & \multicolumn{2}{|c|}{ U.S. } & \multicolumn{2}{|c|}{ India } \\
\hline & Data & Model & Data & Model \\
\hline \multicolumn{5}{|c|}{ Firm-Dynamic Moments } \\
\hline Employment share of 21-25-year-old firms (\%) & 8.10 & 6.50 & 7.70 & 6.32 \\
\hline Relative exit rate of small 21-25-year-old firms & 1.55 & 1.55 & 1.10 & 1.10 \\
\hline Mean employment of 21-25-year-old firms & 2.55 & 2.55 & 1.11 & 1.11 \\
\hline Entry rate $(\%)$ & 7.35 & 7.35 & 5.60 & 5.60 \\
\hline \multicolumn{5}{|c|}{ Managerial Moments } \\
\hline Share of managers in workforce (\%) & 12.4 & 12.4 & 1.70 & 1.70 \\
\hline Share of manager compensation $(\%)$ & 51.0 & 54.7 & $\mathrm{n} / \mathrm{a}$ & $\mathrm{n} / \mathrm{a}$ \\
\hline Employment share of no-manager firms (\%) & 5.00 & 0.00 & 77.5 & 78.6 \\
\hline Relative managerial share of Indian migrants & $\mathrm{n} / \mathrm{a}$ & $\mathrm{n} / \mathrm{a}$ & 2.11 & 2.11 \\
\hline Share of entrepreneurial profit (\%) & 21.0 & 21.1 & 48.3 & 48.3 \\
\hline Variance of log manager earnings & 0.49 & 0.49 & $\mathrm{n} / \mathrm{a}$ & $\mathrm{n} / \mathrm{a}$ \\
\hline \multicolumn{5}{|c|}{ Aggregate growth moments } \\
\hline BGP growth rate for the U.S. (\%) & 2.00 & 2.00 & $\mathrm{n} / \mathrm{a}$ & $\mathrm{n} / \mathrm{a}$ \\
\hline Time series of relative TFP in India (1985 - 2005) & $\mathrm{n} / \mathrm{a}$ & $\mathrm{n} / \mathrm{a}$ & \multicolumn{2}{|c|}{ See Figure 5} \\
\hline
\end{tabular}

Notes: Table reports both the data moments and the corresponding moments in the model for the U.S. and India. See Section B.1 in the Appendix for details. "n/a" implies that the moment is not targeted in the calibration for the corresponding country

young firms are around 1.5 times as likely to exit as small old firms, ${ }^{19}$ and the aggregate share of managerial workers reported in Table 1. The model underestimates the aggregate employment share of old firms, as well as the share of firms without any outside managers. ${ }^{20}$

This is similar for the calibration to the Indian economy. In contrast to the U.S. case, we do not explicitly target the share of managerial compensation, as the Indian data for informal firms in the NSS does not provide information on managerial compensation. Hence, we keep $\sigma$ constant at its respective U.S. value. ${ }^{21}$ We also keep the dispersion of managerial ability $\vartheta$ constant across countries. We do so mainly to keep $\mu_{I N D}$ and $\mu_{U S}$ as only difference in managerial skill supplies across countries. Note that this restriction is not very important as the cross-sectional dispersion in managerial wages is very similar across the two countries (0.49 in the U.S. vs. 0.45 in India). All remaining parameters are re-calibrated. The model is again able to match the data well. It replicates the essentially flat life-cycle of Indian establishments, the low share of aggregate managerial

\footnotetext{
${ }^{19}$ In particular, while young establishments (i.e., establishments of age 1-5) with 1-4 employees have an exit rate of $21 \%$ per year, 21-25 year old establishments of an equal size have an exit rate of only $14 \%$.

${ }^{20}$ One reason why the model predicts slightly too few old firms is that in our model growth is only driven by the extensive margin of adding products. Hence, the process of growth and the resulting exit hazard are tightly linked. If we allowed for growth on the intensive margin (e.g., through quality innovations within existing product lines as in Akcigit and Kerr, 2017, or Garcia-Macia et al., 2015), we could break this link. As for the share of firms without any managerial personnel, our calibration implies that the delegation cutoff in the U.S., $n^{*}$, is smaller than unity.

${ }^{21}$ The model implies this moment to be $5.5 \%$ for India. To get a sense of whether this is the right order of magnitude, note that it is arguably the firms in the ASI that mostly hire managerial personnel. For these firms, managerial compensation amounts to $18 \%$ of the aggregate profits. As the firms in the ASI account for roughly $25 \%$ of employment, the implied moment in India would be about $18 \% \times 25 \%=4.5 \%$ if the aggregate profits and employment were in the same proportion in the ASI and the NSS.
} 
employment, and the fact that, in contrast to the U.S., young establishments exit almost at the same rate as old establishments. ${ }^{22}$ As is the case for the U.S. calibration, the model underestimates the share of old firms in the economy. ${ }^{23}$ Also note that firms in India have a much higher share of entrepreneurial profits. This is due to the fact that most firms in India are small so that most of their sales are attributed as entrepreneurial compensation for the provision of the fixed factor $T$.

\subsection{Non-targeted Moments}

We now show that our model also performs well in matching a variety moments, which we did not explicitly target in our calibration. In Section 4.3.1 we focus on the process of firm selection, i.e. the extent to which small firms are able to survive. In Section 4.3.2 we explicitly compare our model to the observed distribution of product lines at the firm-level. Most importantly, in Section 4.3.3, we show that our model can quantitatively replicate the findings of the management experiment by Bloom et al. (2013). Finally, in Section 4.3.4, we will provide some qualitative correlations on delegation decision of Indian firms and compare them to the model's predictions.

\subsubsection{Survival Hazards}

In Figure 6 we compare our model to two aspects of the degree of selection. In Panel A we depict the survival rate, i.e. the size of a given age cohort relative to the entering cohort. The rate of firm survival is reasonably similar in the U.S. and India - both in the data and in the model. ${ }^{24}$ In Panel $\mathrm{B}$ we show the share of small firms by age (relative to their share among young firms). While the share of small firms in the U.S. declines to $40 \%$ by the age of 25 , the vast majority of old firms in India still only produces a single variety. Our model, again replicates these patterns reasonably well.

\subsubsection{The Product Line Distribution}

In our model, a firm is a collection of product lines. Our calibration focuses only on employment data but does not use direct data at the product level. Both the U.S. and the Indian data, however, contain information on the number of 5-digit product codes in which individual firms are operating. ${ }^{25}$ In Figure 7 we plot the distribution of products in the data and the model. Our model matches this aspect of the data remarkably well, despite the fact that this moment is not targeted. In particular, the vast number of Indian firms indeed only produce a single product.

\footnotetext{
${ }^{22}$ This result is consistent with the one reported in Hsieh and Klenow (2014, Figure 2).

${ }^{23}$ At first glance it might be surprising that old firms, i.e., firms of ages 21-25, have roughly the same aggregate employment share in the U.S. and India. The reason is that the aggregate employment share of very old firms is much higher in the U.S. In the U.S. (India) the share of firms older than 25 years is 55\% (20\%). See Sections OA-2.1 and OA-2.2 in the Online Appendix for details.

${ }^{24}$ As for the category of $26+$ firms: Note that this is the accumulated stock of surviving firms, who are older than 26 years. Hence, even though the U.S. exit rates are only slightly lower than the one in India, the small differences in the flow of exit add up to a sizable difference in the stock of old firms. See also Figure 2 and 3 in Hsieh and Klenow (2014), who also show that exit rates are only slightly lower in the U.S. but that the aggregate employment share of old firms is vastly larger in the U.S.

${ }^{25}$ The data for the U.S. firms come from Acemoglu et al. (2017)
} 
Figure 6: Firm SELECTION IN THE U.S. AND INDiA
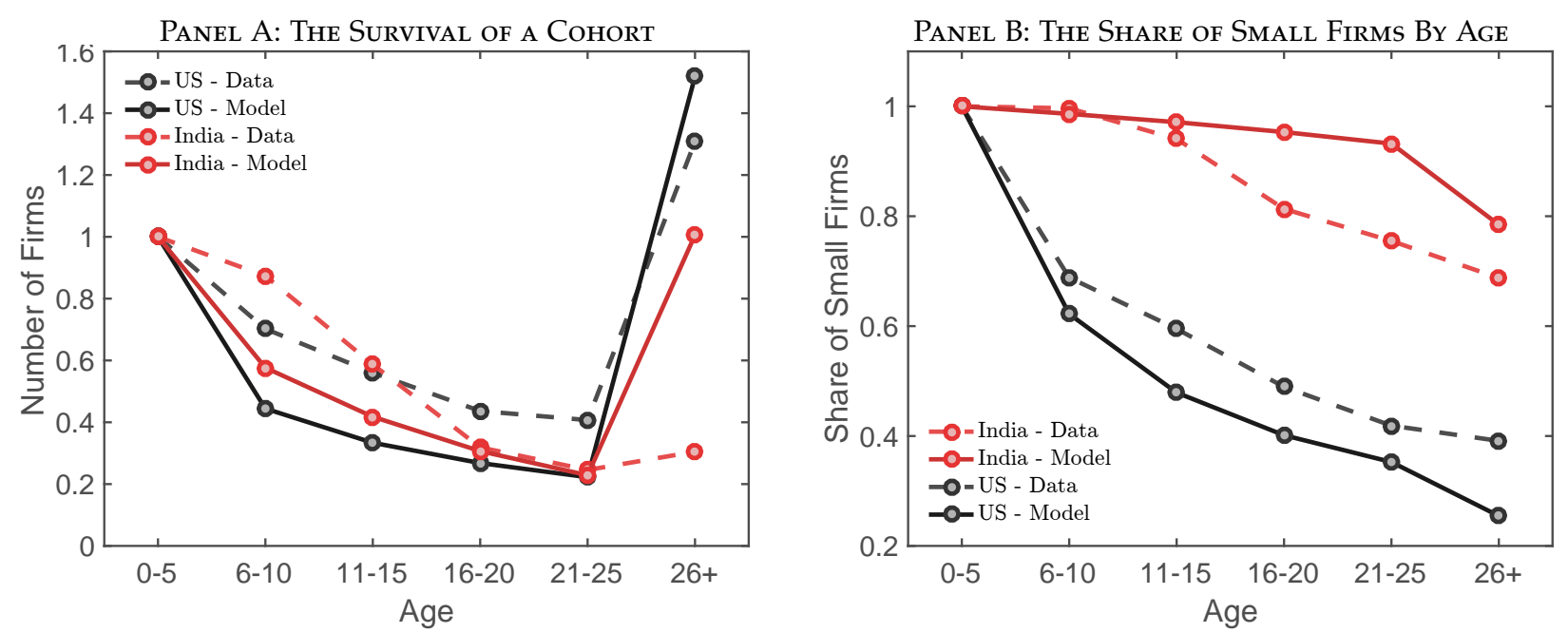

Notes: Panel A depicts the share of firms by age relative to the share of firms in the youngest age category. Panel B shows the share of small firms by age. We show the data in solid lines and the model in dashed lines.

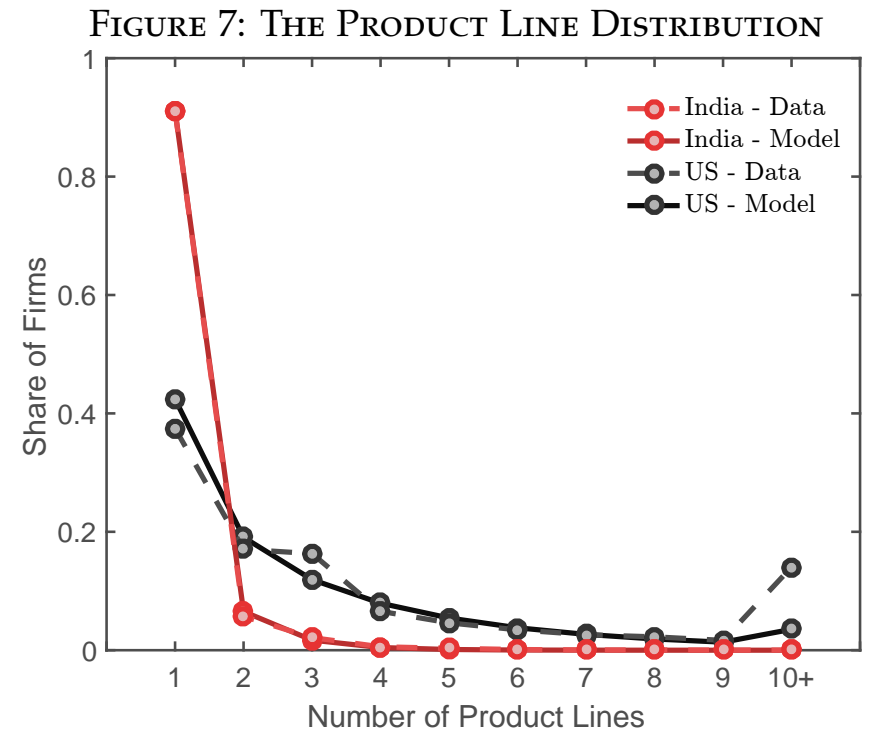

Notes: The figure shows the distribution of the number of products by firm in the data (dashed line) and the model (solid line).

\subsection{3 "Management Does Matter": Replicating the Experiment of Bloom et al. (2013)}

Perhaps the most important out-of-sample test for our model focuses on the delegation aspect of our model. Because we are interested in quantifying the aggregate effects of changes in delegation efficiency, we want to ensure that our model is quantitatively consistent with well-identified microeconomic evidence on the effects of delegation efficiency. In this section, we provide such an exercise, which is one-of-its kind and explicitly connects the micro evidence in the literature to a macro framework.

In Bloom et al. (2013), the authors provided free consulting on management practices to a set of randomly chosen textile establishments in India and compared their performance to a set of control establishments. In order to compare our model's implication for the effect of management practices 


\section{Figure 8: Simulated Partial Equilibrium Effect of Delegation Efficiency on Firm Output}

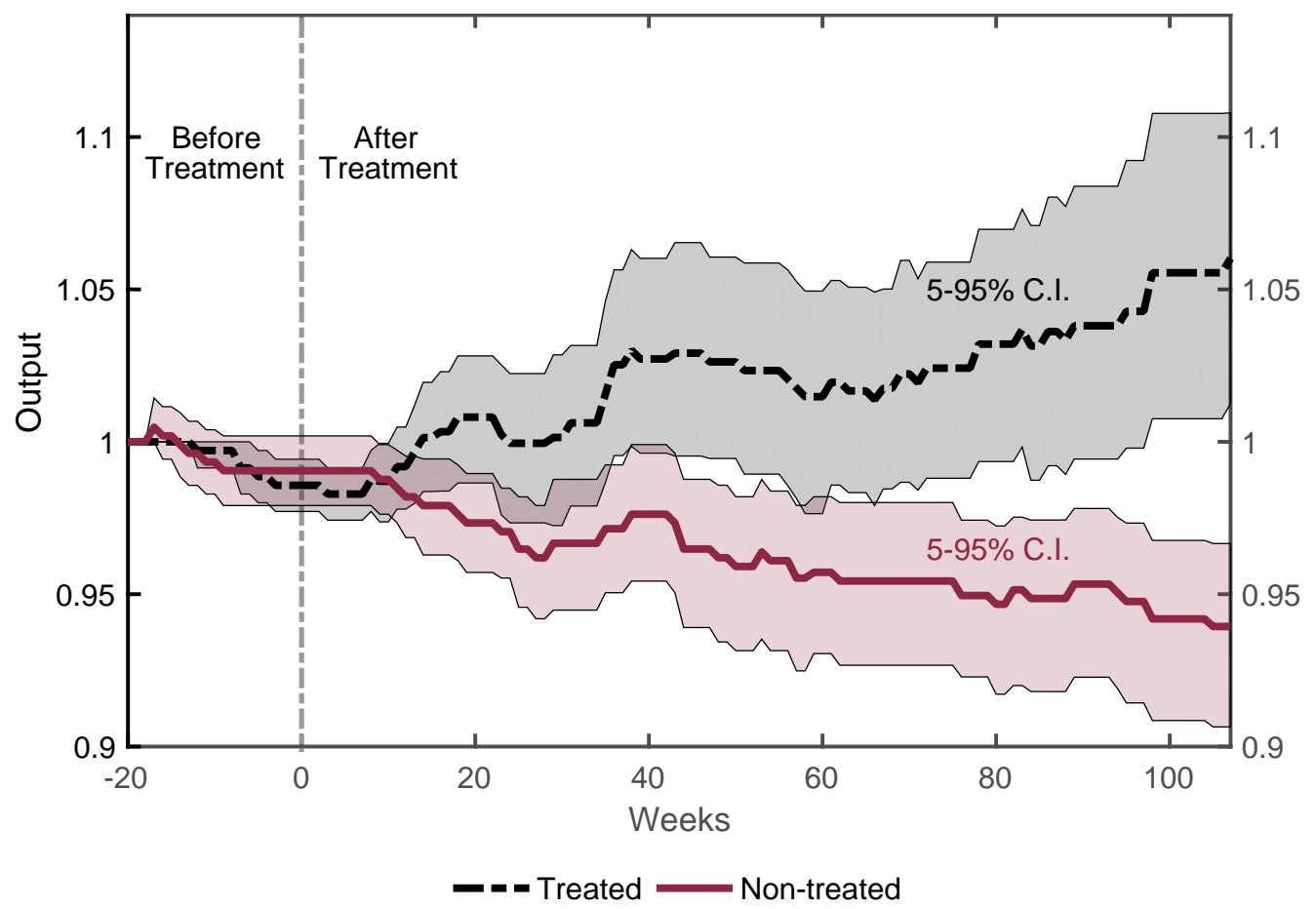

Notes: This figure depicts the dynamics of output of treated firms (i.e. firms with $\alpha=\alpha_{U S}$ ) and non-treated firms (i.e. firms with $\left.\alpha=\alpha_{I N D}\right)$. We normalize output to 1 for every firm at the beginning of the period. See text details. $5-95 \%$ confidence intervals are constructed based on bootstrapping the sample of firms 250 times.

on firms' outcomes with their results, we run a similar exercise in our model. In particular, we take 50 firms from our benchmark Indian economy, which have a similar employment level as the firms used in Bloom et al. (2013) (i.e. are in the top 1\% of the firm-size distribution), and increase their delegation efficiency $\alpha$ to the level calibrated for the U.S. ${ }^{26}$ Importantly, while increasing delegation efficiency, we keep all general equilibrium variables - such as managerial wages, $\omega_{M}$, and the rate of creative destruction, $\tau_{H}-$ at their Indian benchmark values. In other words, we implement a partial equilibrium analysis to be consistent with the Bloom et al. (2013) experiment.

To measure the size of this treatment effect in our model, we calculate the time-series of output for the next 100 weeks, after the delegation efficiency is increased for the set of treated firms. In Figure 8, we present the average output among these treated firms. To see the relative performance of Indian firms with $\alpha_{U S}$, we also present the same series for non-treated firms, i.e. firms with $\alpha_{I N D}$. The results imply that treated firms reach $15 \%$ higher output, on average, compared to nontreated firms at the end of 100 weeks. Moreover, the average effect of the treatment in the first 100 weeks after the implementation is an increase in output by about $5 \%$. This is slightly lower than, but qualitatively consistent with, the experimental findings in Bloom et al. (2013), who estimate an increase in production of 9.4\% (see Table II in Bloom et al., 2013).

\footnotetext{
${ }^{26}$ This approach is motivated by the fact that management practices introduced in the randomized experiment are widely used in the U.S. and many developed economies.
} 


\subsubsection{Qualitative Predictions on Delegation and the Indian Micro Data}

Finally, we can compare the qualitative predictions of our theory to various salient correlations in the Indian micro data. ${ }^{27}$ Our theory implies that firms' managerial hiring decision is given by [see (10)]:

$$
m_{j}=0 \quad \text { if } \quad n<n^{*}(\alpha) \equiv T\left(\frac{\omega_{M}}{\sigma \alpha}\right)^{\frac{1}{1-\sigma}} .
$$

Hence, firms are more likely to delegate if (i) firm size $n$ increases, (ii) the delegation environment $\alpha$ improves, and (iii) owner's inelastically provided managerial human capital $T$ is smaller.

To take this prediction to the data, we follow Bloom et al. (2013, p. 4), who argue that for Indian textile firms "managerial time was constrained by the number of male family members. Non-family members were not trusted by firm owners with any decision-making power, and as a result firms did not expand beyond the size that could be managed by close (almost always male) family members." Hence, we take the size of the entrepreneurs' family as a proxy for $T^{28}$ and use regional variation in trust within India as inducing variation in $\alpha$. The latter is calculated from the World Value Survey as the share of people providing the answer "Most people can be trusted" within the Indian state where the firm is located. This is the most common measure of trust used in the literature (see for instance, Bloom et al. (2012) and La Porta et al. (1997)).

More specifically, we regress firms' managerial hiring decision on firm size, household size and regional trust (in 22 Indian states). ${ }^{29}$ We always control for the market of a firm, i.e., whether or not the firm is urban or rural, firm age, state-level GDP per capita, and 2-digit sector fixed effects. Due to space constraints, below we provide only the estimated equation; the full analysis can be found in Appendix B.4. We find that:

$$
\begin{aligned}
{[\text { Manager=0/1] }=} & 0.039 \times \text { Firm_Size }-0.003 \times \text { Family_Size }+0.013 \times \text { Trust }, \\
& (0.003)^{* * *} \\
(0.001)^{* *} & (0.006)^{* * *}
\end{aligned}
$$

where "Manager" is an indicator variable whether the firm hires a manager and "Firm_Size" and "Family_Size" are the logarithms of the number of employees and household members, respectively. The results show that firm size and regional trust correlate positively, whereas family size correlates negatively with the probability of hiring an outside manager. These findings are, qualitatively, in line with the theoretical predictions of the model. ${ }^{30}$

Our model also has implications for the relationship between family size and firm size, which was emphasized in the quotation by Bloom et al. (2013) above. In our model, without delegation, firm owners run into a span-of-control problem as managerial resources within the family, $T$, are the constraining factor. This constraint, however, is less important, the higher the delegation efficiency $\alpha$. Hence, while family size should be a predictor of firm-size, the effect should be particularly strong in regions where trust, and hence the possibility of delegation, is less developed. We can identify

\footnotetext{
${ }^{27}$ See Section B.4 for the details of the empirical analysis and robustness.

${ }^{28}$ Our data does not have information on either age or sex of the entrepreneur's children.

${ }^{29}$ In Appendix B.4, we provide an explicit derivation of the regression equation based on the theory.

${ }^{30}$ These effects are also economically large. A one standard deviation increase in firm size is associated with an increase in the probability of managerial hiring by $110 \%$ relative its sample mean. Likewise, adding one more person to a singleperson household is associated with a decrease in the managerial hiring by $13 \%$ and moving from the lowest trust region to highest trust region in India is associated with an increase in managerial hiring by $37 \%$ relative to the sample mean.
} 
this prediction of our theory from the interaction between trust and family size in the data. This also allows us to include a full set of state-fixed effects in the regression to control for all characteristics (including the level of trust), which are constant within Indian states. ${ }^{31}$ We find that:

$$
\begin{aligned}
& \text { Firm_Size }=0.812 \times \text { Family_Size }-1.329 \times[\text { Family_Size } \times \text { Trust }] \text {. } \\
& (0.278)^{* * *} \quad(0.758)^{*}
\end{aligned}
$$

This regression highlights two key empirical findings. First, in line with Bloom et al. (2013), we find a strong positive correlation between family size and firm size. Secondly, the link between family size and firm size is much stronger in low-trust regions. Through the lens of our model, this occurs due to the imperfections in delegation in those regions. ${ }^{32}$

\subsection{Selection and Creative Destruction in India and the U.S.}

Our theory stresses that the extent of creative destruction is a key determinant of long-run productivity differences. Our calibration indeed implies that the degree of creative destruction in the U.S. is almost twice as large as in India. This is seen the first row in Table 4, where we report various properties of the stationary distribution in the U.S. and India.

Our model infers the extent of creative destruction only from firm-level moments, i.e. the extent of life-cycle growth, entry and exit rates, and the employment share of old firms. At first glance it seems surprising that we infer large differences in creative destruction despite the fact that both aggregate entry and exit rates and firms' survival probability by age are quite similar (see Figure 4.3.1). The key to reconcile these facts is differences in the distribution of firm size. Recall that the number of exiting firms is the product of the mass of firms operating in a single market, and the rate of creative destruction. Given the large share of small firms in India, the fact that exit rates are quite similar despite the fact that many firms in India are close to the exit threshold, implies that creative destruction in India has to be substantially smaller. Conversely, most creative destruction in the U.S. takes place in infra-marginal markets, where firms lose market share without exiting.

Table 4: Creative Destruction and Selection in India and the U.S.

\begin{tabular}{lcc}
\hline \hline & India & U.S. \\
\hline Rate of creative destruction, $\tau$ & 0.055 & 0.130 \\
\hline & Equilibrium Selection \\
Share of high-type firms upon entry $(\delta)$ & 0.140 & 0.611 \\
Long-run share of high-type firms & 0.356 & 0.944 \\
Long-run employment share of high-type firms & 0.445 & 0.981 \\
Long-run share of high-type firms among firms of age 21-25 & 0.340 & 0.999 \\
\hline \hline
\end{tabular}

Notes: The table contains various equilibrium objects from the stationary distribution of the calibrated model. The models are parametrized according to Table 2 .

\footnotetext{
${ }^{31}$ As before, we also control for location of the firm (rural vs. urban), firm age and 2-digit sector fixed effects.

${ }^{32}$ Quantitatively, a $1 \%$ increase in family size is associated with a $0.34 \%$ increase in firm size in a region with an average level of trust. The same elasticity increases to $0.66 \%$ when we move to the lowest-trust region.
} 
In the remaining rows of Table 4 , we report some properties of the degree of firm selection. In the stationary distribution in the U.S., almost 95\% of firms are high-type firms (compared to $61 \%$ at the time of entry) and they have a combined employment share of $98 \%$, as they are bigger on average. In India, even in the long-run, high-type firms account for only $36 \%$ of firms, and $45 \%$ of aggregate employment. This slower weeding-out process of low-type firms in India is also highlighted by the fact that even among old firms, i.e. firms of age 21-25, two thirds are subsistence entrepreneurs. This is in stark contrast to the U.S., where the population of old firms is only comprised of high types.

In Figure 9 we display the strength of this "shake-out" process in more detail. In Panel A we display the share of high-type firms within a cohort at different ages. Not only is the share of hightype firms in the U.S. significantly greater among the entering cohort, they also grow much faster, creating a much stronger selection force. This selection process is dampened in India: Even for 30-year-old plants, more than half of them are low-type firms. Importantly, this lack of selection in India is not only due to there only being very few high-type firms to begin with. To see that, in Panel B we simulate a counterfactual cohort of U.S. (Indian) firms, which starts with the initial type distribution of India (U.S.), i.e., where the initial share of high-type firms was $\alpha_{I N D}\left(\alpha_{U S}\right)$. It is clearly seen that the differences in growth incentives of existing high-type firms in the U.S. and India are a key aspect of the selection dynamics: By the age of 20, this counterfactual cohort in the U.S. would again be populated by only high-type firms, despite the high share of subsistence entrepreneurs at the time of entry. Conversely, even if a cohort in the Indian economy were to start with $\alpha_{U S}$ high-type firms, the process of selection would be very slow, and a substantial share of stagnant producers would be able to survive.

\section{Figure 9: ENdogenous Selection}
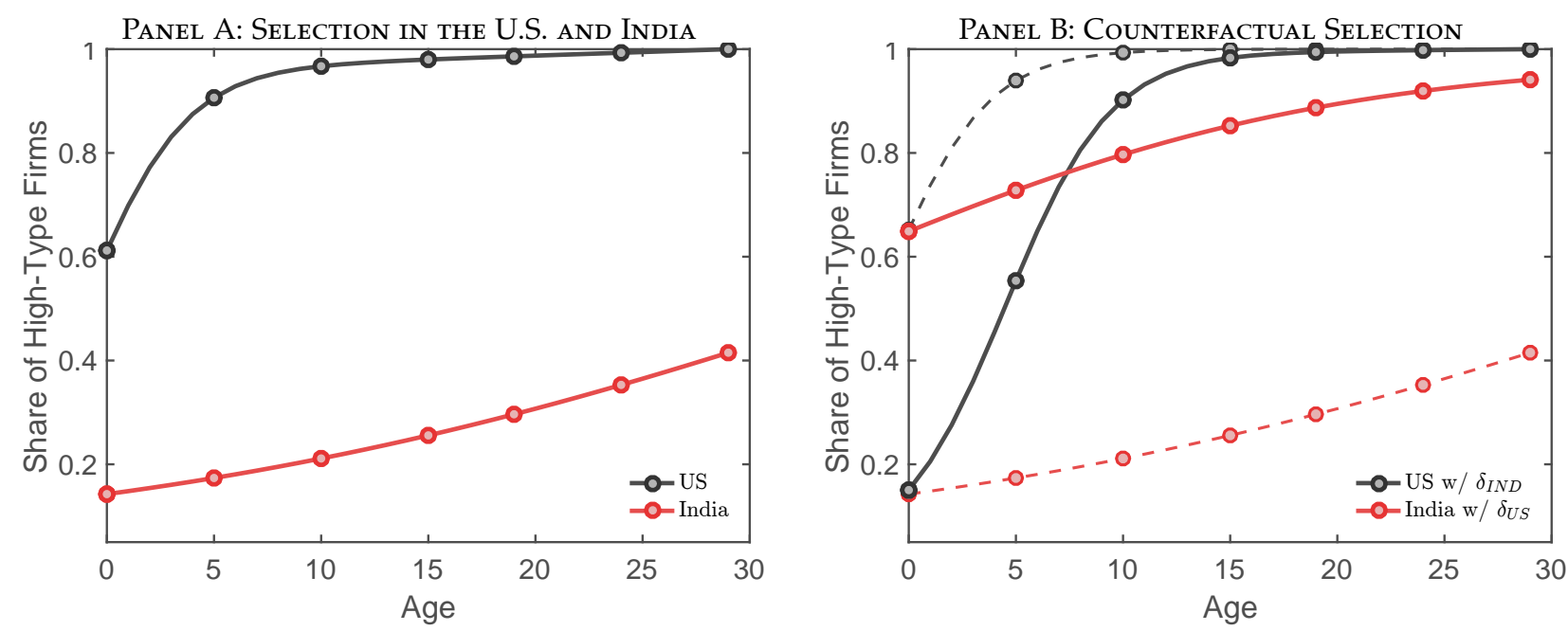

Notes: Panel A shows the share of high-type firms by age both for the India calibration (red line) and for the U.S. calibration (black line). Panel B shows the counterfactual share of high-type firms by age if the initial share of high-type firms in a cohort in the U.S. (India) was given by its Indian (U.S.) counterpart $\alpha_{I N D}\left(\alpha_{U S}\right)$. For comparison we also display the calibrated share of high-type firms contained in Panel A in dashed lines. All calibrated parameters are taken from Table 2. 


\section{Management and Firm Dynamics}

To what extent are differences in the delegation efficiency $\alpha$ responsible for the observed differences in firm-dynamics and aggregate economic performance between the U.S. and India? In the following sections we are going to answer these questions using our calibrated model. Specifically, we study a counterfactual Indian economy where we increase the efficiency of delegation from $\alpha_{I N D}$ to $\alpha_{U S}$. In Section 4.3.3 we showed that the partial equilibrium effects of this counterfactual are quantitatively consistent with the experimental findings in Bloom et al. (2013). We are now going to assess the full general equilibrium effects of such a policy. In this section we quantify the relationship between firm-level outcomes and the efficiency of delegation. In Section 6 we then turn to the aggregate effects and study the link between delegation efficiency and aggregate growth, long-run income, and productivity differences.

Table 5: Increasing the Delegation EfFiciency in India

\begin{tabular}{|c|c|c|c|c|c|c|}
\hline & \multicolumn{6}{|c|}{ Panel A: Equilibrium outcomes } \\
\hline & Average & $n=1$ & $n=2$ & $n=3$ & $n=4$ & $n=5$ \\
\hline Expansion rate $x(n ; \alpha)$ & $+16.02 \%$ & $+11.66 \%$ & $+15.64 \%$ & $+17.87 \%$ & $+19.21 \%$ & $+20.06 \%$ \\
\hline Entry intensity $z(\alpha)$ & \multicolumn{6}{|c|}{$+2.83 \%$} \\
\hline \multirow[t]{2}{*}{ Creative destruction $\tau$} & \multicolumn{6}{|c|}{$+4.12 \%$} \\
\hline & \multicolumn{6}{|c|}{ Panel B: Implications for firm dynamics } \\
\hline Average firm size & \multicolumn{6}{|c|}{$+1.47 \%$} \\
\hline Share of high type firms & \multicolumn{6}{|c|}{$+1.61 \%$} \\
\hline \multirow[t]{3}{*}{ Empl. share of small firms } & \multicolumn{6}{|c|}{$-1.31 \%$} \\
\hline & \multicolumn{6}{|c|}{ Effects by age } \\
\hline & $<=5$ & $6-10$ & $11-15$ & $16-20$ & $21-25$ & +26 \\
\hline Avg employment & $1.05 \%$ & $1.11 \%$ & $1.22 \%$ & $1.41 \%$ & $1.67 \%$ & $2.84 \%$ \\
\hline Share of small firms & $-0.07 \%$ & $-0.24 \%$ & $-0.46 \%$ & $-0.75 \%$ & $-1.12 \%$ & $-3.36 \%$ \\
\hline
\end{tabular}

Notes: The table reports the changes in various equilibrium outcomes after increasing the delegation efficiency in India from $\alpha_{I N D}$ to $\alpha_{U S}$. By "small firms" we refer to firms with a single product.

The firm-level implications of an increase in delegation efficiency for the Indian economy are summarized in Table 5. In Panel A, we focus on the changes in firm expansion, entry, and creative destruction. We see that firms' innovation incentives are much more responsive than the entry margin. While incumbent firms' expansion rates increase by $16 \%$ on average, the entry intensity increases by less than $3 \%$. These differences are due to the fact that delegation efficiency is complementary with firm-size and therefore not very important for subsistence firms, which never grow large. ${ }^{33}$ This complementarity also implies that the change in firm expansion is increasing in firm size. At the aggregate level, the change in creative destruction is much closer to the change in the entry intensity. This is due to the fact that in India, the market share of high-type firms is relatively small, so that the majority of creative destruction is accounted for by new entrants.

\footnotetext{
${ }^{33}$ Another way to see this complementarity is via the changes in the value functions. While the value of low types, $V^{L}$, only increases by about $2 \%$, the average increase in high-types' valuations, $V^{H}(n)$, is $19 \%$, with the biggest increases for large firms. Because $86 \%$ of Indian entrants are low-type firms (as $\delta_{I N D}=0.14$ ), the change in entry incentives is mostly governed by the change in $V^{L}$, which is modest.
} 
In Panel B we report the implications of these changes in firms' policies on the resulting process of firm-dynamics. If Indian firms had access to the delegation efficiency of the U.S., average firm size would increase by $1.5 \%$, the employment share of high-type would increase by $1.6 \%$, and the importance of small producers would decline by $1.3 \%$. We further report the effects of delegation efficiency on firm size and the share of small producers for different age bins. Focusing first on employment, we see that the effect of delegation efficiency on average firm size mirrors the patterns of firms' expansion incentives and is increasing in age. Hence, better delegation makes firms' lifecycle steeper as the effects of higher expansion rates accumulate over time. The reason why the effect on the life-cycle of the average firm seems small compared to the increase in high types' expansion rate , $x(n ; \alpha)$, is again due to the selection - even among old firms, the majority of firms in India are low-type firms, which do not show any life-cycle dynamics.

\section{The "Power of Complementarities"}

The results in Table 5 are suggestive of important complementarities between the efficiency of delegation and other aspects of the economy. In particular, improvements in the delegation are plausibly more potent if high-type firms are plentiful, and those firms can expand easily. To see that this intuition is indeed correct, Table 6 is the U.S. analogue of Table $5 .{ }^{34}$ In contrast to the results for the Indian economy, we find that a decrease in delegation efficiency in the U.S. would affect firm growth substantially. In particular, the rate of creative destruction decreases by $26 \%$, and average firm size declines by $15 \%$.

The reason for these larger effects is that the inherent complementarity between delegation and firm size implies an important interaction between delegation efficiency and other factors affecting firm growth. In contrast to the Indian economy, high-type firms are abundant and the cost of innovation is low in the U.S. Preventing these dynamic entrepreneurs from growing by imposing the inefficient delegation environment of India is costly in terms of life-cycle growth, and reduces the aggregate rate of churning substantially. In contrast, in India transformative entrepreneurs are not only relatively scarce, they also expand less efficiently. While there is a benefit to allowing these firms to sustain their expansion incentives through better delegation, the aggregate effects are much smaller. ${ }^{35}$

\section{Management, Aggregate Productivity and Transitional Dynamics}

Are the differences in delegation efficiency between the U.S. and India an important driver of the disparities in aggregate productivity and income per capita between these two economies? In this section, we answer this question through the lens of our calibrated model.

In our environment, a change in $\alpha$ has both dynamic and static consequences. Because seamless delegation increases the rate of creative destruction $\tau$, an increase in $\alpha$ will increase the growth rate

\footnotetext{
${ }^{34}$ For brevity we only report the aggregate outcomes. The results by firm size and firm age are available upon request.

${ }^{35}$ Relatedly, we also want to note that the counterfactual equilibrium managerial shares are quite different. If we endow the U.S. economy with India's delegation efficiency $\alpha_{I N D}$, the implied equilibrium managerial share declines from $12.4 \%$ to $4.9 \%$, which is in the same ballpark of India's actual share of $1.7 \%$. If, on the other hand, Indian firms could hire managers at the U.S. level of efficiency $\alpha_{U S}$, managerial employment would only increase to $4.6 \%$.
} 
Table 6: Decreasing the Delegation Efficiency in the U.S.

\begin{tabular}{ccc|ccc}
\hline \hline \multicolumn{2}{c|}{ Panel A: } & \multicolumn{3}{c}{ Equilibrium outcomes } & \multicolumn{2}{c}{ Panel Bmplications for firm dynamics } \\
Average & $\begin{array}{c}\text { Entry } \\
\text { Expansion rate }\end{array}$ & $\begin{array}{c}\text { Creative } \\
\text { intensity }\end{array}$ & $\begin{array}{c}\text { Average } \\
\text { Destruction }\end{array}$ & $\begin{array}{c}\text { Share of } \\
\text { Firm Size }\end{array}$ & $\begin{array}{c}\text { Empl. Share of type firms } \\
\text { small firms }\end{array}$ \\
\hline$-30.2 \%$ & $-9.7 \%$ & $-26.2 \%$ & $-14.9 \%$ & $-0.33 \%$ & $+24.1 \%$ \\
\hline \hline
\end{tabular}

Notes: The table reports the changes in various equilibrium outcomes after decreasing the delegation efficiency in the U.S. from $\alpha_{U S}$ to $\alpha_{I N D}$. By "small firms" we refer to firms with a single product.

of $Q_{I N D, t}$ during the transition and will lead to a permanent decline in the level of productivity differences between the U.S. and India. In particular, (21) implies that the long-run effect of the delegation environment is simply given by:

$$
d \ln \left(\frac{Q_{I N D}}{Q_{U S}}\right)=\frac{\ln \gamma_{U S}}{\lambda} \frac{\tau_{U S}}{\tau_{I N D}} \times d \ln \tau_{I N D} .
$$

Hence, the increase in creative destruction due to the improvements in delegation efficiency reduces the long-run level of technological differences between the U.S. and India. In addition, an increase in delegation efficiency increases the amount of available managerial efficiency units, $\mathcal{M}_{t}$, and hence raises income per capita, holding the level of the technology index $Q_{t}$ fixed [see (6)].

To quantify the strength of these forces, we consider an experiment, where in 2010 the delegation efficiency in India increases unexpectedly and permanently from $\alpha_{I N D}$ to $\alpha_{U S}$. We then trace out the dynamic evolution of the Indian economy. Prior to the shock, i.e in 2000, the technological backwardness allows the Indian economy to catch-up with the technological frontier and grow at $3 \%$, i.e. at a faster rate than the U.S. (which we calibrate to grow at rate $2 \%$ ). The increase in delegation efficiency in 2010 increases the rate of creative destruction in India and hence the rate of productivity growth - on impact, the growth rate increases by about 0.15 percentage points. Over time, this growth rate differential declines and in the long-run, the growth rate is again equal to the growth rate of the U.S. so that the relative income difference between the two countries is constant. The time path of the Indian growth rate is depicted in Figure 10.

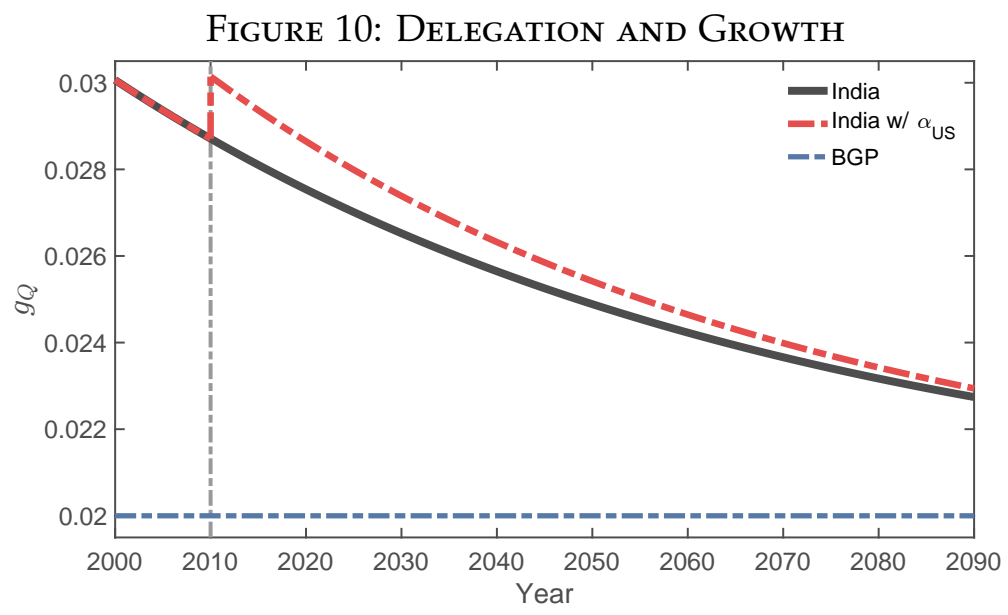

Notes: The figure depicts the growth rate of productivity $Q_{t}$ along the transition for baseline and counterfactual Indian economies. For the counterfactual, we increase the Indian delegation efficiency to the U.S. level in 2010. The change is unexpected and permanent. 
In Table 7, we summarize the aggregate implications of this shock. In Panel A, we report the implications for the growth rate of the technology index $Q_{t}$ shown in Figure 10. In Panel B we calculate the cumulative effect of this higher growth rate on the (relative) level of physical productivity $Q_{t}$. In 2000, Indian productivity is about $20 \%$ of the U.S. productivity. Higher growth in India means that the Indian economy is converging towards the U.S. economy. Our baseline estimates imply that the Indian economy reaches the US level of GDP per capita in about 45 years and that the long-run technological differences between the U.S. and India would be about $45 \%$, reflecting the fact that there is less creative destruction in India. Improvements in the efficiency of delegation increases creative destruction and hence reduces these productivity differences. Our estimates imply that this effect is modest. We find that India would reach the US level of income in 41 instead of 45 years. In the long-run, India's relative technology would be about 2.5 percentage points higher. Given the difference of roughly 50 percentage points in our baseline calibration, we conclude that the delegation environment can account for roughly $5 \%$ of the long-run differences in physical productivity between India and the U.S.

Table 7: The Aggregate Effects of Delegation Efficiency in India

\begin{tabular}{|c|c|c|c|c|c|c|}
\hline Year: & 2000 & 2010 & 2020 & 2030 & & $\infty$ \\
\hline \multicolumn{7}{|c|}{ Panel A: Productivity Growth $g_{Q}$} \\
\hline Baseline & $3.00 \%$ & $2.87 \%$ & $2.75 \%$ & $2.65 \%$ & $\ldots$ & $2.00 \%$ \\
\hline$\alpha=\alpha_{U S}$ & $3.00 \%$ & $3.01 \%$ & $2.87 \%$ & $2.74 \%$ & $\ldots$ & $2.00 \%$ \\
\hline \multicolumn{7}{|c|}{ Panel B: Relative productivity $Q_{I N D} / Q_{U S}$} \\
\hline Baseline & $22.6 \%$ & $24.8 \%$ & $26.9 \%$ & $28.8 \%$ & $\ldots$ & $45.3 \%$ \\
\hline$\alpha=\alpha_{U S}$ & $22.6 \%$ & $24.8 \%$ & $27.2 \%$ & $29.5 \%$ & $\ldots$ & $47.9 \%$ \\
\hline \multicolumn{7}{|c|}{ Panel C: Relative income pc $y_{I N D} / y_{U S}$} \\
\hline Baseline & $27.8 \%$ & $30.6 \%$ & $33.1 \%$ & $35.5 \%$ & $\ldots$ & $55.9 \%$ \\
\hline$\alpha=\alpha_{U S}$ & $27.8 \%$ & $32.8 \%$ & $35.9 \%$ & $38.8 \%$ & $\ldots$ & $62.7 \%$ \\
\hline
\end{tabular}

Notes: The table reports the aggregate implications of an increase in the delegation efficiency in India from $\alpha_{I N D}$ to $\alpha_{U S}$ in the year 2010 . In Panel A we report the rate of growth of the productivity index $Q_{t}$, in Panel B we report the differences in $Q_{t}$ between the U.S. and India and in Panel $\mathrm{C}$ we report the differences in income per capita between the U.S. and India.

The effect of a more efficient delegation environment on income per capita differences, shown in Panel C, are larger. In the long-run, an increase in delegation efficiency is predicted to improve the relative income per capita of India from 56\% to around 63\%. These higher effects stem from the static effects of delegation efficiency captured by $\mathcal{M}_{t}$ as a more efficient managerial technology increases firm-productivity, and therefore income per capita. ${ }^{36}$ By increasing relative income in India by 6.8 percentage points, differences in delegation efficiency can plausibly account for $15 \%$ of the long-run income differences between the U.S. and India.

\footnotetext{
${ }^{36}$ Additionally, the increase in $\alpha$ also reduces the number of production workers as individuals sort into managerial occupations. Quantitatively, the number of production workers declines by about $2.9 \%$.
} 


\section{Robustness}

In this section, we study the robustness of our results, in particular the quantitative importance of changes in the delegation efficiency $\alpha$ on the process of firm dynamics and macro outcomes characterized in Sections 5 and 6. We consider the robustness of our results with respect to (i) the entry elasticity, (ii) the convexity of incumbents' innovation cost function, (iii) the empirical moment to measure the share of managerial compensation, (iv) our measure of entrepreneurial profits, (v) the strength of knowledge diffusion, and (vi) using firm instead of establishment-level moments to estimate the model. For each specification, we recalibrate both the U.S. and the Indian economy and redo our analysis. Overall, we find that our main conclusions are fairly robust across these different specifications. All the results are reported in Table 8. In the table, we report the implied levels of creative destruction in both countries (columns 1 and 2); and the change in creative destruction, productivity and income differences, average firm size and the share of small firms for 21 to 25 year-old firms in India due to an increase in delegation efficiency.

Entry: In our benchmark specification, we assume that the entrants use the same form of innovation technology as incumbent firms, with curvature parameter $\zeta_{e}=0.5$. In order to assess the importance of entrants for our results, we recalibrate our model, for both the U.S. and India, while setting $\zeta_{e}$ to alternative values. The higher the value of $\zeta_{e}$, the more responsive are entrants to changes in the value of entry. Panel B of Table 8 suggests that as the entrants become less responsive, the effect of improving the delegation environment for India is dampened. Yet, the quantitative change, compared to the baseline calibration, is modest.

Convexity of incumbents' innovation cost function: As with our robustness exercise concerning entrants, we also study how the curvature parameter of the innovation production function for incumbents, $\zeta$, affects our results. We consider two alternative values for $\zeta$, which are in the ballpark of the lowest and highest micro estimates for this parameter. ${ }^{37}$ Panel $\mathrm{C}$ of Table 8 shows that our results are robust to these alternatives.

Managerial Compensation: The elasticity of profits with respect to managerial services, $\sigma$, is identified mainly from the share of managerial compensation relative to corporate profits. We calculate this moment from NIPA between 2000 and 2007 and target the average value for our main analysis. ${ }^{38}$ However, the precise value depends on the year used in the calculation. In Panel D of Table 8 we show that targeting lower $(40 \%)$ or higher $(60 \%)$ shares of managerial compensation yields quantitatively similar results.

Entrepreneurial Profits In the data, Indian entrepreneurs have a significantly higher profit share compared to U.S. entrepreneurs (48\% versus $21 \%$ ). In our quantitative analysis, this difference manifests itself in a higher level of $T$ in India. To see whether this feature of the data drives our main results, we recalibrate the model for India by targeting the U.S. value for the entrepreneurial profit share. As seen from Panel E of Table 8, the resulting impact of the delegation efficiency $\alpha$ from our counterfactual exercises are slightly higher, but very close to the baseline results.

\footnotetext{
${ }^{37}$ For more on this, see Akcigit and Kerr (2017) and Acemoglu et al. (2017)

${ }^{38}$ See Section B.1 in the Appendix for detailed information.
} 
TABle 8: Robustness Results

\begin{tabular}{|c|c|c|c|c|c|c|c|}
\hline & \multirow[b]{2}{*}{$\tau_{I N D}$} & \multirow[b]{2}{*}{$\tau_{U S}$} & \multicolumn{4}{|c|}{ Change in... } & \multirow[b]{2}{*}{$\begin{array}{c}\text { Share of } \\
\text { small firms }\end{array}$} \\
\hline & & & $\tau_{I N D}$ & $Q_{I N D} / Q_{U S}$ & $y_{I N D} / y_{U S}$ & $\begin{array}{c}\text { Avg. } \\
\text { firm size }\end{array}$ & \\
\hline \multicolumn{8}{|c|}{ Panel A. Baseline } \\
\hline & 0.055 & 0.130 & $4.12 \%$ & $5.63 \%$ & $12.30 \%$ & $1.67 \%$ & $-1.12 \%$ \\
\hline \multicolumn{8}{|c|}{ Panel B. Entry elasticity } \\
\hline Low & 0.055 & 0.130 & $2.49 \%$ & $3.42 \%$ & $9.71 \%$ & $1.60 \%$ & $-1.10 \%$ \\
\hline High & 0.055 & 0.130 & $6.89 \%$ & $9.33 \%$ & $16.66 \%$ & $1.78 \%$ & $-1.15 \%$ \\
\hline \multicolumn{8}{|c|}{ Panel C. Curvature of innovation function } \\
\hline Low & 0.056 & 0.127 & $4.28 \%$ & $5.90 \%$ & $13.09 \%$ & $1.28 \%$ & $-0.80 \%$ \\
\hline High & 0.056 & 0.134 & $4.01 \%$ & $5.41 \%$ & $11.52 \%$ & $2.03 \%$ & $-1.48 \%$ \\
\hline \multicolumn{8}{|c|}{ Panel D. Managerial compensation } \\
\hline Low & 0.056 & 0.127 & $4.03 \%$ & $5.02 \%$ & $10.90 \%$ & $1.40 \%$ & $-0.87 \%$ \\
\hline High & 0.056 & 0.131 & $4.34 \%$ & $6.05 \%$ & $13.20 \%$ & $1.69 \%$ & $-1.15 \%$ \\
\hline \multicolumn{8}{|c|}{ Panel E. Entrepreneurial profits } \\
\hline & 0.057 & 0.130 & $6.30 \%$ & $6.23 \%$ & $12.74 \%$ & $2.05 \%$ & $-1.71 \%$ \\
\hline \multicolumn{8}{|c|}{ Panel F. Estimation with firm level data } \\
\hline & 0.056 & 0.119 & $4.12 \%$ & $5.84 \%$ & $12.50 \%$ & $1.57 \%$ & $-1.09 \%$ \\
\hline \multicolumn{8}{|c|}{ Panel G. Strength of knowledge diffusion } \\
\hline Low & 0.055 & 0.130 & $4.12 \%$ & $7.89 \%$ & $14.70 \%$ & $1.67 \%$ & $-1.12 \%$ \\
\hline High & 0.055 & 0.130 & $4.12 \%$ & $3.87 \%$ & $10.43 \%$ & $1.67 \%$ & $-1.12 \%$ \\
\hline
\end{tabular}

Notes: Panel A contains our baseline results based on the parameters reported in Table 2. In Panel B we consider two different values for the elasticity of the entry technology, $\zeta_{e}^{L}=0.2$ and $\zeta_{e}^{H}=0.8$. In Panel $C$ we consider two different values for the convexity of the innovation function, $\zeta^{L}=0.4$ and $\zeta^{H}=0.6$. In Panel D we consider different moments for the share of managerial compensation. Instead of our baseline moment, we target either $40 \%$ and $60 \%$. Panel E recalibrate the model for India by targeting the U.S. value for the entrepreneurial profit share. In Panel F we report the results when we calibrate the model for the U.S. economy to firm-level moments. In Panel G, we consider two values for $\lambda$, which controls the strength of the knowledge diffusion in step size for India, $\lambda^{L}=0.181$ and $\lambda^{H}=0.343$. These values are chosen such that the speed of convergence (in terms of half-life) is $25 \%$ longer $\left(\lambda^{L}\right)$ and $25 \%$ shorter $\left(\lambda^{H}\right)$ compared to baseline Indian economy.

Firm-Level Analysis: In the main analysis, we have focused solely on establishment-level data. We did so to ensure comparability between the U.S. and India since we cannot link individual establishments to specific firms in the Indian data. ${ }^{39}$ Panel F shows that this choice has no substantial implications for our conclusions - the counterfactual implications of a change in the delegation efficiency are quantitatively similar, when we calibrate the U.S. parameters to firm-level moments. ${ }^{40}$

\footnotetext{
${ }^{39}$ Although firm-level data is not available for India, with the majority of employment being accounted for by very small producers, multi-establishment firms are unlikely to be of aggregate importance for India.

${ }^{40}$ The model is able to match the firm-level moments quite well. The main difference between establishments and firms at the horizon of age 21-25 is the life-cycle, the aggregate employment share, and the relative exit rate. The life-cycle is slightly steeper, the employment share is lower (because very old firms are much bigger than very old establishments), and the relative exit rate of young firms is higher than that of older establishments, because old firms exit less frequently
} 
While the estimated level of creative destruction in the U.S. based on firm-level is slightly lower, the counterfactual results are essentially unchanged, as the estimate of $\alpha$ based on U.S. firm-level data is very close to the one based on establishment-level data.

Strength of Knowledge Diffusion: Our benchmark calibration for the strength of the diffusion parameter $\lambda$ based on the time series dynamics of TFP differences between India and the U.S. implies a half-life to converges around 50 years. To study how this particular choice of calibration approach affects our results, we consider two alternative values for $\lambda$ which imply the speed of convergence (in terms of half-life) $25 \%$ longer $\left(\lambda^{L}\right)$ and $25 \%$ shorter $\left(\lambda^{H}\right)$, compared to baseline Indian economy. Panel F of Table 8 shows that faster (slower) transition speed decreases (increases) the impact of improved delegation efficiency on productivity and income differences, yet the quantitative results are in the ballpark of benchmark results. ${ }^{41}$

\section{Conclusion}

Many firms in poor countries start small, stay small, but nevertheless survive. This is very different in rich countries, where firms either exit or expand. In this paper we build a micro-founded model of firm growth to study why this is the case. The main focus of our analysis is whether cross-country differences in the efficiency of managerial delegation, as emphasized by a recent empirical literature (see e.g., Bloom and Van Reenen, 2007, 2010), can quantitatively account for such differences in firm dynamics. To this end, we construct a general equilibrium growth model, that allows us to connect managerial delegation, the distribution of firm size, and the degree of creative destruction, i.e., the speed with which firms lose market share and, eventually, exit.

Our theory has two main components. First of all, our model contains an explicit rationale for delegation: If the entrepreneur's own time is a fixed factor, firms need to delegate decision power to be able to grow large. Secondly, we allow firms to be heterogeneous in their growth potential whereby stagnant, subsistence firms survive if transformative entrepreneurs do not expand enough to replace them. Frictions in the delegation environment reduce such incentives to grow and thereby limit the degree of selection by allowing stagnant producers to survive.

We calibrate the model to the U.S. and Indian data and show that there is a tight relationship between the general equilibrium theory and the empirical micro moments on firm growth, firm exit, and managerial employment. In particular, we show that the estimated model generates results that are very much in line with the well-known field experiment by Bloom et al. (2013).

We draw three main lessons from our quantitative analysis. First, our model implies that the majority of Indian entrepreneurs are subsistence entrepreneurs, which are not destined to grow. At the same time, they also do not exit as transformative firms' growth incentives are also low, which implies a low level of creative destruction in equilibrium. Our model emphasizes that the existence of small firms may not be a sign of the frictions these firms face, but rather a symptom that other, more dynamic firms do not grow sufficiently. Policies targeted at small firms could therefore end

than older establishments. Moreover, the aggregate entry rate is slightly lower at the firm level. In Section OA-2.1 in the Online Appendix, we provide more details on establishment-firm comparison for the U.S.

${ }^{41}$ Note that different values of $\lambda$ only affects the transition speed. The firm size distribution is not affected. 
up supporting stagnant, subsistence producers and have negative productivity consequences.

Second we find that differences in the delegation environment have important macroeconomic implications. In particular, in the current setting, India is expected to reach the current U.S.-level of income per capita in about 45 years. An improvement in the Indian delegation efficiency to the U.S.-level could reduce this time by $10 \%$. In addition, our estimates imply that the lower delegation efficiency in India can plausibly account for $5 \%$ of the steady-state productivity and for $15 \%$ of the steady-state income differences between the U.S. and India.

Finally, we find that there are important complementarities between the efficiency of managerial delegation and other factors affecting firm growth. If U.S. producers were to face the Indian delegation environment, their growth incentives would be much lower. Quantitatively, this would lead to a $15 \%$ decrease in average firm size and and a decline in creative destruction by $25 \%$. Conversely, the direct effect of increases in delegation efficiency on Indian firms is more limited. This suggests that for improvements in the efficiency of delegation to have sizable long-run effects in India, other aspects that affect firm expansion, such as financial frictions or distortionary regulations, also need to be addressed. Effective growth policies have to consider the fact that even if one of its tires is fixed, a car cannot run when the rest of the tires remain broken.

An important future step in this research agenda is to study the sources of differences in delegation efficiency $\alpha$. How could different degrees of financial development, legal systems, or monitoring technologies determine that delegation efficiency? What kind of policies could provide more effective growth incentives to medium-sized firms, induce more competition, and produce national champions? These are just some of the many important questions that await further research.

\section{References}

Acemoglu, D., U. Akcigit, H. Alp, N. Bloom, and W. Kerr: 2017, 'Innovation, Reallocation and Growth'. NBER Working Paper 18993.

Aghion, P., U. Akcigit, and P. Howitt: 2014, 'What Do We Learn From Schumpeterian Growth Theory?'. In: P. Aghion and S. N. Durlauf (eds.): Handbook of Economic Growth, Volume 2. pp. 515-563.

Aghion, P. and P. Howitt: 1992, 'A Model of Growth through Creative Destruction'. Econometrica 60(2), 323-351.

Akcigit, U.: 2017, 'Economic Growth: The Past, the Present, and the Future'. Journal of Political Economy 125(6), 1736-1747.

Akcigit, U., H. Alp, and M. Peters: 2016, 'Lack of Selection and Limits to Delegation: Firm Dynamics in Developing Countries'. NBER Working Paper 21905.

Akcigit, U. and W. Kerr: 2017, 'Growth through Heterogeneous Innovations'. Journal of Political Economy. forthcoming.

Banerjee, A., E. Breza, E. Duflo, and C. Kinnan: 2015, 'Do Credit Constraints Limit Entrepreneurship? Heterogeneity in the Returns to Microfinance'. Working Paper.

Bento, P. and D. Restuccia: 2017, 'Misallocation, Establishment Size, and Productivity'. American Economic Journal: Macroeconomics. forthcoming. 
Bertrand, M. and A. Schoar: 2006, 'The Role of Family in Family Firms'. Journal of Economic Perspectives 20(2), 73-96.

Bloom, N., B. Eifert, T. Heller, E. Jensen, and A. Mahajan: 2009, 'Contract Enforcement and Firm Organization: Evidence from the Indian Textile Industry'. Center on Democracy, Development, and The Rule of Law Working Paper 104.

Bloom, N., B. Eifert, D. McKenzie, A. Mahajan, and J. Roberts: 2013, 'Does Management Matter: Evidence from India'. Quarterly Journal of Economics 128(1), 1-51.

Bloom, N., R. Sadun, and J. Van Reenen: 2012, 'The Organization of Firms Across Countries'. Quarterly Journal of Economics 127(4), 1663-1705.

Bloom, N. and J. Van Reenen: 2007, 'Measuring and Explaining Management Practices Across Firms and Countries'. Quarterly Journal of Economics 122(4), 1351-1408.

Bloom, N. and J. Van Reenen: 2010, ‘Why Do Management Practices Differ across Firms and Countries?'. Journal of Economic Perspectives 24(1), 203-224.

Buera, F., J. Kaboski, and Y. Shin: 2011, 'Finance and Development: A Tale of Two Sectors'. American Economic Review 101(5), 1964-2002.

Caselli, F. and N. Gennaioli: 2013, 'Dynastic Management'. Economic Inquiry 51(1), 971-996.

Cole, H. L., J. Greenwood, and J. M. Sanchez: 2016, 'Why Doesn't Technology Flow from Rich to Poor Countries?'. Econometrica 84(4), 1477-1521.

Collard-Wexler, A., J. Asker, and J. De Loecker: 2011, 'Productivity Volatility and the Misallocation of Resources in Developing Economies'. NBER Working Paper 17175.

De Mel, S., D. McKenzie, and C. Woodruff: 2008, 'Returns to Capital in Microenterprises: Evidence from a Field Experiment'. Quarterly Journal of Economics pp. 1329-1372.

Decker, R., J. Haltiwanger, R. Jarmin, and J. Miranda: 2014, 'The Role of Entrepreneurship in US Job Creation and Economic Dynamism'. Journal of Economic Perspectives pp. 3-24.

Foster, L., J. Haltiwanger, and C. Syverson: 2016, 'The Slow Growth of New Plants: Learning about Demand?'. Economica 83(329), 91-129.

Fukuyama, F.: 1996, Trust: The Social Virtues and the Creation of Prosperity, Vol. 457. Free Press New York.

Gabaix, X., J.-M. Lasry, P.-L. Lions, and B. Moll: 2016, 'The Dynamics of Inequality'. Econometrica. forthcoming.

Garcia-Macia, D., C.-T. Hsieh, and P. Klenow: 2015, 'How Destructive is Innovation?'. Stanford University mimeo.

Garicano, L. and E. Rossi-Hansberg: 2015, 'Knowledge-based Hierarchies: Using Organizations to Understand the Economy'. Annual Review of Economics 7, 1-30.

Gennaioli, N., R. L. Porta, F. Lopez-De-Silanes, and A. Shleifer: 2013, 'Human Capital and Regional Development'. Quarterly Journal of Economics 128(1), 105-164.

Gopinath, G., S. Kalemli-Ozcan, L. Karabarbounis, and C. Villegas-Sanchez: 2017, 'Capital Allocation and Productivity in South Europe'. Quarterly Journal of Economics. Forthcoming. 
Gourio, F. and L. Rudanko: 2014, 'Customer Capital'. Review of Economic Studies 81(3), 1102-1136.

Grobvosek, J.: 2015, 'Managerial Delegation, Law Enforcement, and Aggregate Productivity'. Working Paper.

Guner, N., A. Parkhomenko, and G. Ventura: 2015, 'Managers and Productivity Differences'. Working Paper.

Guner, N., G. Ventura, and Y. Xu: 2008, 'Macroeconomic Implications of Size-dependent Policies'. Review of Economic Dynamics 11(4), 721-744.

Haltiwanger, J., R. Jarmin, and J. Miranda: 2013, ‘Who Creates Jobs? Small Versus Large Versus Young'. Review of Economics and Statistics 128(2), 347-361.

Hendricks, L. and T. Schoellman: 2016, 'Human Capital and Development Accounting: New Evidence from Wage Gains at Migration'. Working Paper.

Hopenhayn, H.: 2012, ‘On the Measure of Distortions'. Working Paper.

Hsieh, C.-T., E. Hurst, P. Klenow, and C. Jones: 2013, 'The Allocation of Talent and U.S. Economic Growth'.

Hsieh, C.-T. and P. Klenow: 2009, 'Misallocation and Manufacturing TFP in China and India'. Quarterly Journal of Economics 124(2), 771-807.

Hsieh, C.-T. and P. J. Klenow: 2014, 'The Life Cycle of Plants in India and Mexico'. Quarterly Journal of Economics 129(3), 1035-1084.

Hsieh, C.-T. and B. A. Olken: 2014, "The Missing "Missing Middle"'. Journal of Economic Perspectives 28(3), 89-108.

Hurst, E. and B. Pugsley: 2012, 'What Do Small Businesses Do'. Brookings Papers on Economic Activity.

Jones, C.: 2013, 'Misallocation, Economic Growth and Input-Output Economics'. In: D. Acemoglu, M. Arrelano, and E. Dekel (eds.): Advances in Econometrics: 10th World Congress, Vol. 2. Cambridge University Press.

Klette, T. J. and S. Kortum: 2004, 'Innovating Firms and Aggregate Innovation'. Journal of Political Economy 112(5), 986-1018.

La Porta, R., F. Lopez-de Silanes, A. Shleifer, and R. W. Vishny: 1997, 'Trust in Large Organizations'. American Economic Review 87(2), 333-38.

La Porta, R. and A. Shleifer: 2008, 'The Unofficial Economy and Economic Development'. Brookings Papers on Economic Activity pp. 123-135.

La Porta, R. and A. Shleifer: 2014, 'Informality and Development'. Journal of Economic Perspectives pp. 109-126.

Laeven, L. and C. Woodruff: 2007, 'The Quality of the Legal System, Firm Ownership, and Firm Size'. Review of Economics and Statistics 89(4), 601-614.

Lentz, R. and D. T. Mortensen: 2005, 'Productivity Growth and Worker Reallocation'. International Economic Review 46(3), 731-751.

Lentz, R. and D. T. Mortensen: 2008, 'An Empirical Model of Growth through Product Innovation'. Econometrica 76(6), 1317-1373. 
Lentz, R. and D. T. Mortensen: 2016, 'Optimal Growth Through Product Innovation'. Review of Economic Dynamics 19, 4-19.

Lucas, R. E.: 1978, 'On the Size Distribution of Business Firms'. Bell Journal of Economics 9(2), 508-523.

Luttmer, E. G.: 2011, 'On the Mechanics of Firm Growth'. Review of Economic Studies 78(3), 1042-1068.

Midrigan, V. and D. Y. Xu: 2014, 'Finance and Misallocation: Evidence From Plant-Level Data'. American Economic Review 104(2), 422-458.

Moll, B.: 2014, 'Productivity Losses from Financial Frictions: Can Self-Financing Undo Capital Misallocation?'. American Economic Review 104(10), 3186-3221.

Moscarini, G. and F. Postel-Vinay: 2012, 'The Contribution of Large and Small Employers to Job Creation in Times of High and Low Unemployment'. American Economic Review 102(6), 25092539.

Nakamura, E. and J. Steinsson: 2018, 'Identification in Macroeconomics'. Journal of Economic Perspectives. forthcoming.

Penrose, E. T.: 1959, Theory of the Growth of Firms. New York: J. Wiley \& Sons.

Perla, J.: 2016, 'Product Awareness, Industry Life-Cycles, and Aggregate Profits'. Working Paper.

Peters, M.: 2016, 'Heterogeneous Mark-Ups, Growth and Endogenous Misallocation'. Working Paper.

Powell, M.: 2012, 'Productivity and Credibility in Industry Equilibrium'. Technical report, Working Paper.

Restuccia, D. and R. Rogerson: 2008, 'Policy Distortions and Aggregate Productivity with Heterogenous Establishments'. Review of Economic Dynamics 11(4), 707-720.

Roys, N. and A. Seshadri: 2014, 'Economic Development and Organization of Production'. Working Paper.

Schoar, A.: 2010, 'The Divide between Subsistence and Transformational Entrepreneurship'. In: Innovation Policy and the Economy, Volume 10. University of Chicago Press, pp. 57-81.

Stokey, N., R. Lucas, and E. Prescott: 1989, Recursive Methods in Economic Dynamics. Harvard University Press, Cambridge, MA.

Ulyssea, G.: 2016, 'Firms, Informality and Development: Theory and Evidence from Brazil'. Working Paper. 


\section{Appendices}

\section{A Theoretical Appendix}

\section{A.1 Firm Size Distribution}

Let $v_{n, t}^{H}$ denote the share of high-type firms with $n$ products, and $F_{t}^{j}$ be the number of firms of type $j$. Then, firm size distribution of the economy can be represented by the following differential equations:

$$
\begin{aligned}
\frac{\partial F_{t}^{H} v_{1, t}^{H}}{\partial t} & =z_{t} \times \delta-F^{H, t} v_{1, t}^{H} \tau_{H, t} \\
\frac{\partial F_{t}^{H} v_{n, t}^{H}}{\partial t} & =\left[v_{n-1, t}^{H}(n-1) x_{n-1, t}+v_{n+1, t}^{H} \tau_{H, t}(n+1)-v_{n, t}^{H} n\left(\tau_{H, t}+x_{n, t}\right)\right] \times F_{t}^{H} . \\
\frac{\partial F_{t}^{L}}{\partial t} & =z_{t} \times(1-\delta)-F^{L, t} \tau_{L, t} .
\end{aligned}
$$

and the requirement that $v_{n, t}^{H}$ be a proper distribution, $\sum_{n=1}^{\infty} v_{n, t}^{H}=1$.

Equation (23) states that the number of one-product high type firms is given by difference between entering high-type firms and exiting high-type firms. Recall that $\tau_{j, t}$ denotes the rate at which a firm of type $j$ loses a given product at each point in time. Similarly, equation (24) is an accounting equation for the net-change in the number of high type firms with $n$ products. Finally, (25) is the analogue of (23) for low-type firms, which always have a single product.

Proposition 1 Consider a stationary equilibrium and let the flow of entry $z$ and high-type firms' expansion rates $\left\{x_{n}\right\}_{n=1}^{\infty}$ at stationary equilibrium be given. The distribution of high-type firms is

$$
v_{n}^{H}=\frac{n^{-1} \frac{\tau_{H}}{x_{n}} \prod_{j=1}^{n}\left(\frac{x_{j}}{\tau_{H}}\right)}{\sum_{s=1}^{\infty} s^{-1} \frac{\tau_{H}}{x_{s}} \prod_{j=1}^{s}\left(\frac{x_{j}}{\tau_{H}}\right)},
$$

the measure of high-and low-type firms is

$$
F^{H}=\frac{\delta z}{\tau_{H}} \times\left[\sum_{n=1}^{\infty} \frac{\tau_{H}}{n x_{n}} \prod_{j=1}^{n}\left(\frac{x_{j}}{\tau_{H}}\right)\right] \quad \text { and } \quad F^{L}=\frac{(1-\delta) z}{\tau_{L}},
$$

the aggregate rate of creative destruction is

$$
\tau=z \times\left[\delta \sum_{s=1}^{\infty} \prod_{j=1}^{s}\left(\frac{x_{j}}{\tau_{H}}\right)+1\right]
$$

and the type-specific creative destruction rates are

$$
\tau_{H}=\tau-z(1-\delta)\left(\frac{\beta-1}{\beta}\right) \quad \text { and } \quad \tau_{L}=\beta \tau-z(1-\delta)(\beta-1) .
$$

Proof. By setting the time derivatives to zero in (23), (24) and (25), stationary firm size distribution 
is described by the following equations

$$
\begin{aligned}
F^{H} v_{1}^{H} \tau_{H} & =z \times \delta \\
v_{n}^{H} n\left(\tau_{H}+x_{n}\right) & =v_{n-1}^{H}(n-1) x_{n-1}+v_{n+1}^{H} \tau_{H}(n+1) \\
F^{L} \tau_{L} & =z \times(1-\delta)
\end{aligned}
$$

Let $v_{1}^{H}$ and $\tau$ be given. First note that consistency requires that the total amount of innovation has to be equal to the total rate of creative destruction:

$$
\tau=\tau_{H}\left(1-F^{L}\right)+\tau_{L} F^{L}
$$

Then, by using (32), (33) and $\tau_{L}=\beta \tau_{H}$, we get

$$
\tau_{H}=\tau-z(1-\delta)\left(\frac{\beta-1}{\beta}\right) \quad \text { and } \quad \tau_{L}=\beta \tau-z(1-\delta)(\beta-1) .
$$

Next, by using (30) - (32), we calculate $F^{L}, F^{H}$, and $\left\{v_{n}\right\}_{n=2}^{\infty}$.

Lemma 1 The distribution of high types takes the following form

$$
v_{n}^{H} n=\frac{\prod_{j=1}^{n} x_{j}}{\tau_{H}^{n}} \frac{\tau_{H}}{x_{n}} v_{1}^{H} .
$$

Proof. Substituting (35) in (30) - (32) shows that if $v_{n}^{H}$ satisfies (35), it satisfies all the flow equations in (30) - (32).

This implies that $1=\sum_{n=1}^{\infty} v_{n}^{H}=v_{1}^{H} \sum_{n=1}^{\infty} \frac{1}{n} \frac{\tau_{H}}{x_{n}} \prod_{j=1}^{n}\left(\frac{x_{j}}{\tau_{H}}\right)$, so that (35) reads

$$
v_{n}^{H}=\frac{1}{n} \frac{\prod_{j=1}^{n} x_{j}}{\tau_{H}^{n}} \frac{\tau_{H}}{x_{n}} \frac{1}{\sum_{s=1}^{\infty} \frac{1}{s} \frac{\tau_{H}}{x_{s}} \prod_{j=1}^{s}\left(\frac{x_{j}}{\tau_{H}}\right)} .
$$

Then, from (30) and (32), we have

$$
F^{H}=\frac{\delta z}{\tau_{H}} \times\left[\sum_{n=1}^{\infty} \frac{1}{n} \frac{\tau_{H}}{x_{n}} \prod_{j=1}^{n}\left(\frac{x_{j}}{\tau_{H}}\right)\right] \quad \text { and } \quad F^{L}=\frac{(1-\delta) z}{\tau_{L}} .
$$

Hence, we only need to determine $\tau$, which we get from (18) as

$$
\tau=\sum_{n=1}^{\infty} n x_{n} v_{n}^{H} F^{H}+z=\left[\sum_{n=1}^{\infty} \delta\left(\prod_{j=1}^{n}\left(\frac{x_{j}}{\tau_{H}}\right)\right)+1\right] z .
$$

Together with (34), one can show that (37) has a unique solution for $\tau$.

\section{A.2 Derivation of Equation (19)}

We can express $\ln Q_{t}$ after an instant $\Delta t$ as

$$
\begin{aligned}
\ln Q_{t+\Delta t} & =\int_{0}^{1}\left[\tau_{t} \Delta t \ln \left(\gamma_{t} q_{j t}\right)+\left(1-\tau_{t} \Delta t\right) \ln q_{j t}\right] d j \\
& =\tau_{t} \Delta t \ln \left(\gamma_{t}\right)+\ln Q_{t}
\end{aligned}
$$


where second and higher order terms in $\Delta t$ are omitted. By subtracting $\ln Q_{t}$ from both sides, dividing by $\Delta t$, and taking the limit as $\Delta t \rightarrow 0$, we get

$$
g_{t}=\frac{\dot{Q}_{t}}{Q_{t}}=\lim _{\Delta t \rightarrow 0} \frac{\ln Q_{t+\Delta t}-\ln Q_{t}}{\Delta t}=\ln \left(\gamma_{t}\right) \tau_{t}
$$

\section{A.3 Transitional Dynamics with Stationary Firm Size Distribution}

Proposition 2 Suppose that the firm-size distribution at time $t$ coincides with the stationary distribution characterized in Proposition 1. Then, for any path of the step size $\gamma_{t}$, there is an equilibrium path, where (i) the firm size distribution remains stationary, (ii) all aggregate variables grow at the same rate $\ln \left(\gamma_{t}\right) \tau_{B G P}$, where $\tau_{B G P}$ is the constant rate of creative destruction rate at the stationary equilibrium.

Proof. Note that in the stationary equilibrium of the model described in Online Appendix OA-1.3, the step size $\gamma_{t}$ does not affect any expressions. Hence, we need to show that there exists an interest rate path $r_{t}$ such that $C_{t}, Q_{t}$ and $Y_{t}$ grow at the same rate during the transition. If this was the case, firms' innovation and entry choices would not change and the distribution would remain stationary. It is easy to see that interest rate path

$$
r_{t}=\ln \left(\gamma_{t}\right) \tau_{B G P}+\rho
$$

serves the purpose. Recall that consumption decisions of the household yield the usual Euler equation which implies that

$$
r_{t}=g_{C, t}+\rho
$$

so that under the proposed interest rate path, $g_{C, t}=\ln \left(\gamma_{t}\right) \tau_{B G P}$. Moreover $g_{Q, t}=\ln \left(\gamma_{t}\right) \tau_{B G P}$ as shown in Appendix A.2. Lastly we have $Y_{t}=Q_{t} \mathcal{M}_{t} L_{P, t}$. Since $\mathcal{M}_{t}$ and $L_{P, t}$ are constant at the proposed equilibrium, this implies that $g_{Y, t}=g_{Q, t}$. Therefore all growing variables grows at the same rate.

\section{B Empirical Appendix}

\section{B.1 Data}

In this section we provide more information about our data sources.

Establishment- and Firm-level Information for the U.S. We use data from the Business Dynamics Statistics (BDS). BDS is a product of the U.S. Census Bureau. The BDS data are compiled from the Longitudinal Business Database (LBD). The LBD is a longitudinal database of business establishments and firms covering the years between 1976 and 2012. We focus on the manufacturing sector in 2012. The data are publicly available at http://www.census.gov/ces/dataproducts/bds/.

For our analysis, we utilize the following four moments from the U.S. data: (i) the cross-sectional relationship between age and size, which we refer to as the life-cycle, (ii) the aggregate employment share by age, (iii) the exit rate as a function of age conditional on size, and (iv) the rate of entry. For our main analysis we focus on establishments. The BDS reports both aggregate employment and the number of establishments by age. This allows us to calculate the first two moments. The BDS also directly reports both entry and exit rates for each size-age bin. The entry rate at the establishment level is calculated as the number of new establishments at time $t$ relative to the average number of establishments in $t$ and $t-1$. Similarly, the exit rate at the establishment level is calculated as the number of exiting establishments in $t$ relative to the average number of establishments in $t$ and $t-1$. The corresponding information is also reported at the firm level. In particular, the BDS reports the number of exiting firms for different size-age bin. Note that all establishments owned by the firm 
must exit for the firm to be considered an exiting firm. As for firm entry, we treat firms of age 0 as an entering firm. Because a firm's age is derived from the age of its establishments, this implies that we treat firms as entering firms only if all their establishments are new. In Section OA-2.1 in the Online Appendix we provide detailed descriptive statistics about the dynamic process at both the firm- and establishment-level.

Establishment-Level Information for India As explained in the main body of the text, we construct a representative sample of the Indian manufacturing sector by combining data from the Annual Survey of Industries (ASI) and the National Sample Survey (NSS), which - every five years has a special module to measure unorganized manufacturing establishments. We use cross-sectional data from 2010. In contrast to the U.S., both the ASI and NSS are based on establishments and we cannot link establishments to firms. With the majority of employment being accounted for by very small producers, multi-establishment firms are unlikely to be important for the aggregate in India. Firms in the NSS account for $99.2 \%$ of all establishments and for $76 \%$ of manufacturing employment. In Section OA-2.2 in the Online Appendix we provide more detailed descriptive statistics and additional results concerning the process of firm dynamics of ASI and NSS establishments.

Data on Managerial Compensation and Profits for the U.S. We identify $\sigma$ from the share of managerial compensation in aggregate profits before managerial payments [see equation (38)]. To estimate this moment, we use two data sources. From NIPA we can retrieve a measure of aggregate profits in the manufacturing industry. Specifically, we start with aggregate corporate profits, which are directly measured in NIPA. The BEA's featured measure of corporate profits -profits from current production - provides a comprehensive and consistent economic measure of the income earned by all U.S. corporations. As such, it is unaffected by changes in tax laws, and it is adjusted for non- and misreported income. We then add to this measure non-farm proprietors' income in the manufacturing sector, which provides a comprehensive and consistent economic measure of the income earned by all U.S. unincorporated non-farm businesses.

To measure managerial wages, we augment the information in NIPA from information in the census. While NIPA reports compensation for workers, managerial payments are not directly recorded in NIPA. To calculate the managerial wage bill, we therefore use the U.S. census data. In the census we have micro data on labor compensation and occupations at the micro level. Hence, we calculate the share of managerial payments in the total wage bill and apply that share to the aggregate compensation data in NIPA. According to the census, managerial compensation amounts to roughly $20 \%$ of total wages. Recall that the managerial employment share in the U.S. is about $12 \%$ so that managerial wages are relatively high. We then calculate the share of managerial compensation $(C S M)$ in aggregate profits net of managerial wages as

$$
C S M=\frac{\text { Managerial Compensation }}{\text { Corporate Profits + Nonfarm Proprietor's Income + Managerial Compensation' }}
$$

where "Managerial Compensation" is simply $20 \%$ of the total labor compensation in NIPA. We also calculate a second measure of CSM, where we do not include "Nonfarm Proprietor's Income." We calculate CSM before the Great Recession, because we were concerned about corporate profits being very low during the financial crisis. CSM is quite volatile. It ranges from $65 \%$ in 2001 to $33 \%$ in 2006. For our calibration we focus on the average across the years $2000-2007$, which is $51 \%$. If we do not include "Nonfarm Proprietor's Income", the numbers are very similar and only slightly larger, ranging from $69 \%$ in 2001 to $35 \%$ in 2006 . Hence, it is not essential for us to take "Nonfarm Proprietor's Income" into account. 
Data on Managerial Employment and Earning: To measure managerial employment and earnings in the U.S. and India, we employ national Census data from the IPUMS project. We focus on the most recent year, which is 2010 for the U.S. and 2004 for India. For each country we get a sample from the census, which has detailed information about personnel characteristics. In particular we observe each respondent's education, occupation, employment status, sex, and industry of employment. We focus on male workers in the manufacturing industry working in private-sector jobs.

The list of occupations according to ISCO is contained in Table 9. To qualify as a manager in the sense of our theory, two characteristics have to be satisfied. First, the respective individual has to work as a "Legislator, senior official, and manager." In order to focus on managers, which are agents of a firm owner, i.e., outside managers, we also require workers to be wage workers and not working on their own account or to be unpaid family members. This information is also contained in the IPUMS census data in the variable "worker type." As we showed in Table 1 above, it is important to take these differences into account as poor countries have a higher share of people working on their own account (or as a family member) conditional on being classified as a manager according to ISCO.

TABle 9: List OF OCCUPATIONS ACCORDING TO ISCO

\begin{tabular}{|l|l|}
\hline Legislators, senior officials, and managers & Plant and machine operators and assemblers \\
\hline Professionals & Elementary occupations \\
\hline Technicians and associate professionals & Armed forces \\
\hline Clerks & Other occupations, unspecified or n.e.c. \\
\hline Service workers and shop and market sales & Response suppressed \\
\hline Skilled agricultural and fishery workers & Unknown \\
\hline Crafts and related trades workers & NIU (not in universe) \\
\hline
\end{tabular}

Notes: Table 9 contains the occupational categories available in the IPUMS data. A necessary condition for someone to be classified as an outside manager is to be assigned the occupational title "Legislators, senior officials, and managers." See the main body of the text for the additional requirements.

\section{B.2 Identification of the Model}

We will now discuss the identification of our model in more detail. In total, there are 11 parameters to identify ${ }^{42}$ :

$$
\Omega \equiv\left\{\alpha, \sigma, T, \mu_{M}, \vartheta, \theta, \theta_{E}, \delta, \beta, \gamma^{U S}, \lambda\right\}
$$

In Section A.1, we discussed how the distribution of firm size is determined given the optimal innovation and entry rates $\left\{x_{n}\right\}_{n=1}^{\infty}$ and $z$. More specifically, $\left\{x_{n}\right\}_{n=1}^{\infty}$ and $z$ determine the aggregate innovation rate $\tau$ and these three objects together uniquely pin down the joint distribution of age and size, i.e., the entire process of firm-dynamics. The four parameters that affect this process directly are $\left(\theta, \theta_{E}, \beta, \delta\right)$. We therefore use the following four firm-level moments to calibrate these parameters: (i) the life cycle, i.e., the relative size of firms of age 21-25 to firms of age 1-5, (ii) the share of aggregate employment accounted for by firms of age 21-25, (iii) the relative exit rate of 1-5 year old firms relative firms of age 21-25 conditional on size, and (iv) the entry rate. Intuitively, the slope of the life-cycle is informative about $\theta$, which determines the level of incumbent's innovation effort. As $\beta$ effectively controls the size of old cohorts (by determining the speed with which hightype firms exit), it is related to the aggregate importance of old cohorts in the economy, i.e., the relative employment share of old firms. The exit hazard conditional on size is informative about the degree of selection. If there was no type heterogeneity, the exit rate would only be a function of

\footnotetext{
${ }^{42}$ Recall that we calibrate $\zeta$ and $\rho$ outside of the model.
} 
size. To the extent that older firms are positively selected, they are less likely to exit conditional on size. The ex-ante heterogeneity $\delta$ determines how strong this effect can be. Finally, the entry rate is informative about $\theta_{E}$.

We then use several moments related to managerial employment patterns - namely the compensation of managers relative to corporate profits, the entrepreneurial share in total compensation, the dispersion of managerial wages, and managerial employment shares - to identify $\sigma, T, \vartheta, \alpha$ and $\mu_{M}$. Consider first $\sigma$, the elasticity of profits with respect to managerial services. ${ }^{43}$ In the model, the total compensation for managerial personnel relative to aggregate profits (before managerial payments) is given by

$$
\frac{w_{M} H^{M}}{\Pi+w_{M} H^{M}}=\frac{\sum_{n=1}^{\infty} w_{M} \times n \times m(n) \times \varphi_{n}}{\sum_{n=1}^{\infty} e(n)^{\sigma} Y \times n \times \varphi_{n}},
$$

where $\varphi_{n}=F^{H} v_{n}^{H}$ and $\varphi_{1}=F^{H} v_{1}^{H}+F^{L}$ is the endogenous firm size distribution. By using $m(n)=$ $T \alpha^{-1} \times \max \left\{0,\left(n^{*}\right)^{-1}-(n)^{-1}\right\}, \omega_{M} \equiv \frac{w_{M}}{Y}=\sigma \alpha\left(\frac{n^{*}}{T}\right)^{1-\sigma}$ and $e(n)=T \max \left\{n^{-1},\left(n^{*}\right)^{-1}\right\}$, we get that

$$
\frac{w_{M} H^{M}}{\Pi+w_{M} H^{M}}=\sigma \frac{\sum_{n=1}^{\infty}\left(n^{*}\right)^{1-\sigma}\left(\max \left\{0, \frac{1}{n^{*}}-\frac{1}{n}\right\}\right) \times n \times \varphi_{n}}{\sum_{n=1}^{\infty}\left(\max \left\{\frac{1}{n}, \frac{1}{n^{*}}\right\}\right)^{\sigma} \times n \times \varphi_{n}} .
$$

Hence, conditional on $n^{*}$ and the firm size distribution, (38) only depends on $\sigma$.

To determine $T$, we target the share of income accruing to entrepreneurs after paying for their factors of production. As entrepreneurs are the residual claimants on firm profits, this moment is simply given by

$$
\begin{aligned}
\frac{\Pi}{Y} & =\sum_{n=1}^{\infty}\left[e(n)^{\sigma}-\omega_{M} m(n)\right] \times n \times \varphi_{n} \\
& =T^{\sigma} \sum_{n=1}^{\infty}\left[\left(\max \left\{n^{-1},\left(n^{*}\right)^{-1}\right\}\right)^{\sigma}-\sigma n^{*} \max \left\{0, \frac{1}{n^{*}}-\frac{1}{n}\right\}\right] \times n \times \varphi_{n},
\end{aligned}
$$

which is directly informative about $T$ for given $n^{*}, \varphi_{n}$, and $\sigma$.

The shape parameter of skill distribution $\vartheta$ can be identified directly from the dispersion of managerial earnings. To see this, note that the earnings of a manager with relative skill $h$ is $w_{M} h$. The distribution of managerial earning is therefore given by

$$
P\left[w_{M} h>x \mid h \geq \frac{w_{P}}{w_{M}}\right]=\left(\frac{w_{P} / w_{M}}{x / w_{M}}\right)^{\vartheta}=\left(\frac{w_{P}}{x}\right)^{\vartheta},
$$

which is pareto with shape $\vartheta$ and location $w_{P}$. Defining the relative managerial earnings $y \equiv$ $\ln \left(\frac{w_{M} h}{w_{P}}\right)$, we get $P\left(y \leq y_{0}\right)=1-e^{-\vartheta y_{0}}$, so that

$$
\operatorname{var}(y)=\operatorname{var}\left(\ln \left(\frac{w_{M} h}{w_{P}}\right)\right)=\operatorname{var}\left(\ln \left(w_{M} h\right)\right)=\vartheta^{-2}
$$

Hence, we can calibrate $\vartheta$ directly to the variance of log managerial earnings.

Finally, we identify $\alpha$ and $\mu_{M}$ by using the share of managers in the whole economy and among Indian immigrants to the U.S. economy. Let $\chi$ denote the equilibrium managerial employment share

\footnotetext{
${ }^{43}$ Although the specific ordering of parameters in the identification discussion is not essential, it facilitates the argument.
} 
which is given by

$$
\chi=P\left[h_{M} w_{M} \geq w_{P}\right]=\left(\frac{\frac{\vartheta-1}{\vartheta} \mu_{M}}{w_{P} / w_{M}}\right)^{\vartheta}=\left(\frac{\vartheta-1}{\vartheta} \mu_{M} \frac{\sigma \alpha}{\omega_{P}}\left(\frac{n^{*}}{T}\right)^{1-\sigma}\right)^{\vartheta} .
$$

Using the expression for total managerial demand, the equilibrium condition for the managerial labor market can be written as

$$
\mu_{M} \alpha=(\chi)^{-\frac{\theta-1}{\theta}} \times \sum_{n \geq n^{*}}^{\infty} T\left(\frac{1}{n^{*}}-\frac{1}{n}\right) \times n \times \varphi_{n} .
$$

Hence, given $n^{*}, T, \vartheta$, and $\varphi_{n}$, we can directly determine $\mu_{M} \times \alpha$ from the data on the share of managers in the whole population (i.e., $\chi$ ). To separate the effect of managerial human capital $\left(\mu_{M}\right)$ from delegation efficiency $(\alpha)$, we use data on managerial employment pattern of Indian immigrants. Because our approach uses additional data and because all allocations in the model only depend on $\mu_{M} \times \alpha$, we discuss the details of our strategy in Section B.3. Once we identify $\mu_{M}$, we get $\alpha$ from (39).

Lastly we use moments regarding aggregate dynamics of the economies to pin down $\gamma$ and $\lambda$. In particular, we calibrate the step-size for U.S., $\gamma^{U S}$, to fit the aggregate growth rate as $g=\ln \left(\gamma^{U S}\right) \tau$ and U.S. is assumed to be on the balanced growth path. In the case of India, step size is partly determined by the productivity gap between U.S. and India and $\lambda$ parametrizes the importance of this channel on step size [see (20)]. By using (19) and (20), we can write productivity differences as

$$
\dot{Z}_{t}=Z_{t}\left\{\ln \left(\gamma^{U S} \tau_{U S, t}-\tau_{I N D, t}\left[\ln \left(\gamma^{U S}\right)+\lambda \ln \left(Z_{t}\right)\right]\right\}\right.
$$

where $Z_{t} \equiv \frac{Q_{U S, t}}{Q_{I N D, t}}$. Therefore, given $\gamma^{U S}$ and aggregate creative destruction for U.S. and India, dynamics of productivity differences is informative about $\lambda$. We therefore calibrate $\lambda$ to match the

\begin{tabular}{|c|c|c|c|c|c|c|c|c|c|c|}
\hline & & $\delta$ & $\beta$ & $\gamma$ & $\theta$ & $\alpha \times \mu$ & $\vartheta$ & $\theta_{E}$ & $T$ & $\sigma$ \\
\hline M1. & Empl. share of 21-25-year-old firms & 0.58 & -0.02 & 0.00 & -0.09 & 0.11 & -0.17 & 0.63 & 0.21 & -0.34 \\
\hline M2. & Rel. exit rate of small 21-25-year-old firms & -0.80 & 0.01 & 0.00 & -0.24 & -0.19 & 0.21 & -0.09 & -0.04 & 0.49 \\
\hline M3. & Aggregate growth rate & 0.08 & 0.00 & 6.48 & 0.86 & 0.60 & -0.67 & 0.27 & 0.17 & -1.58 \\
\hline M4. & Mean empl. of 21-25-year-old firms & -0.40 & -0.02 & 0.00 & 0.61 & 0.26 & -0.21 & -0.34 & -0.01 & -0.65 \\
\hline M5. & Share of managers in the workforce & 0.02 & 0.00 & 0.00 & -0.03 & 1.44 & 0.82 & 0.03 & 0.03 & -0.53 \\
\hline M6. & Variance of log manager wage & 0.00 & 0.00 & 0.00 & 0.00 & 0.00 & -2.00 & 0.00 & 0.00 & 0.00 \\
\hline M7. & Entry rate & -0.13 & 0.00 & 0.00 & 0.25 & 0.55 & -0.63 & 0.86 & 0.19 & -1.47 \\
\hline M8. & Share of entrepreneurial profit & 0.17 & -0.02 & 0.00 & -0.23 & 0.49 & -0.42 & 0.23 & 0.29 & -1.90 \\
\hline M9. & Share of manager compensation & -0.09 & 0.01 & 0.00 & 0.12 & 0.22 & -0.19 & -0.12 & -0.15 & 0.90 \\
\hline M10. & Employment share of no-manager firms & \multicolumn{9}{|c|}{ See Table Notes } \\
\hline M11. & Rel. manager share of Indian migrants & \multicolumn{9}{|c|}{ See Table Notes } \\
\hline
\end{tabular}
time-series evolution of India's productivity relative to the U.S.

Table 10: Moment Sensitivity

Notes: The table presents the elasticity for each moment used the internal calibration with respect to the parameters of the model. In particular, we report percentage change in the moment for a $1 \%$ change in the parameter from its benchmark value in the U.S. calibration, while keeping the rest of the parameters at their benchmark values. We report the average elasticities based on $+1 \%$ and $-1 \%$ changes. Our calibration for the U.S. implies that employment share of no-manager firms (M10) is zero, i.e., all the firms hire managers. Due to discrete nature of extensive margin of managerial hiring, M10 does not move as a response to a small change in the parameters. Relative manager share of Indian migrants (M11) is used identify the relative managerial skill supply of workers in India relative to the U.S., $\frac{\mu_{M, I N D}}{\mu_{M, U S}}$. 


\section{B.3 Identifying Managerial Skill Supplies $\mu_{M}$}

To decompose differences in the managerial environment in India and the U.S. into supply and demand factors, we start out with 4 parameters: $\left(\mu_{M, U S}, \alpha_{U S}, \mu_{M, I N D}, \alpha_{I N D}\right)$. Without loss of generality we can normalize $\mu_{M, U S}=1$. Since $\mu_{M, c} \times \alpha_{c}$ is identified from the equilibrium managerial employment shares [see (39)], we require one additional equation to determine the relative managerial human capital in India, $\mu_{M, I N D}$. To do so, we use data on employment patterns of immigrants from India to the U.S.

Let $\chi_{c}$ be the managerial share of the native population in country $c$. Let $\chi_{I N D}^{M}$ be the managerial employment share in the population of Indian migrants in India (i.e., pre-migration). Let $\chi_{U S}^{M}$ be the managerial employment share in the population of Indian migrants in the U.S. (i.e., post-migration). Suppose that the distribution of managerial ability of Indians who migrate to the U.S. is distributed Pareto with shape $\vartheta$ and mean $\hat{\mu}_{M, I N D}$. If $\hat{\mu}_{M, I N D}=\mu_{M, I N D}$, migration is orthogonal to managerial skills. If $\hat{\mu}_{M, I N D}>\mu_{M, I N D}$, migrants have, on average, a comparative advantage in managerial work. Given these assumptions it follows that

$$
\chi_{c}=\tilde{\vartheta}\left(\omega_{M}^{c}\right)^{\vartheta}\left(\mu_{M, c}\right)^{\vartheta} \text { and } \quad \chi_{c}^{M}=\tilde{\vartheta}\left(\omega_{M}^{c}\right)^{\vartheta}\left(\hat{\mu}_{M, c}\right)^{\vartheta}
$$

where $\tilde{\vartheta}=\left(\frac{\vartheta-1}{\vartheta}\right)^{\vartheta}$ and $\omega_{M}^{c}$ is the relative managerial wage $\frac{w_{M}}{w_{P}}$ in country $c$. Hence,

$$
\frac{\mu_{M, I N D}}{\mu_{M, U S}}=\underbrace{\left(\frac{\chi_{U S}^{M}}{\chi_{U S}}\right)^{1 / \vartheta}}_{\text {uncorrected ratio }} \times \underbrace{\left(\frac{\chi_{I N D}}{\chi_{I N D}^{M}}\right)^{1 / \vartheta}}_{\text {selection correction term }} .
$$

The first term in (40) compares migrants and U.S. natives in the U.S. economy, i.e., holding $\alpha$ constant. Differences in managerial employment are therefore interpreted as differences in human capital. The second term accounts for selection into migration: if immigrants are positively selected on their managerial skills, i.e., $\chi_{I N D}^{M}>\chi_{I N D}$, the observed differences in outcomes in the U.S. underestimate the differences in skills in the population. ${ }^{44}$ The last term in equation (40) corrects for that potential selection.

Note that we already calibrated $\vartheta$ and we already used $\chi_{I N D}$ and $\chi_{U S}$ in our calibration. $\chi_{U S}^{M}$ is directly observable in the U.S. Census, because we see the employment structure among recent Indian immigrants. Finally, $\chi_{I N D}^{M}$ can be estimated from the New Immigration Study, which explicitly asks immigrants about the occupations prior to migration [see Hendricks and Schoellman (2016)].

The data to quantify (40) is contained in Table 11. Column 1 and 3 report the managerial share in the U.S. and India, respectively. In column 2 we report the managerial share among Indian immigrants in the U.S. To ensure that this population is informative about the human capital of recent Indian migrants, we restrict the sample to migrants that arrived in the U.S. within the last 5 years. The managerial share in this population is given by $12.9 \%$. In the last column we exploit information from the New Immigration Study to measure the share of migrants that used to work as managers in India. We find that roughly $6 \%$ of them worked as outside manager.

The sample size for estimating the managerial share of migrants in India, $\chi_{I N D}^{M}$, is only 403 , i.e., quite small. To judge the robustness of our results, we report the implied differences in delegation quality $\frac{\alpha_{U S}}{\alpha_{I N D}}$ as a function of the point estimate of $\chi_{I N D}^{M}$. We treat the other empirical objects in (40), as fixed as these are precisely estimated. We construct the confidence intervals for $\frac{\alpha_{U S}}{\alpha_{I N D}}$ using a Bootstrap procedure, where we repeatedly draw samples with replacement from the New

\footnotetext{
${ }^{44}$ We want to note that this identification relies on there not being excessive frictions to enter managerial positions (relative to other jobs) for Indians in the U.S. If immigrants from India do not enter managerial occupations because they are discriminated against, we would conclude that they have relatively little human capital. See also Hsieh et al. (2013) for an elaboration of this point.
} 
Table 11: Identification of Managerial Skills: Managerial Employment Shares

\begin{tabular}{|c|c|c|c|c|}
\hline \multirow{3}{*}{$\begin{array}{l}\text { Sample } \\
\text { Population }\end{array}$} & \multicolumn{2}{|c|}{ U.S. } & \multicolumn{2}{|r|}{ India } \\
\hline & \multicolumn{4}{|c|}{ Male, 20-60 years, employed } \\
\hline & $\begin{array}{c}\text { U.S. population } \\
\chi_{U S}\end{array}$ & $\begin{array}{c}\text { Indian migrants } \\
\chi_{U S}^{M}\end{array}$ & $\begin{array}{c}\text { Indian population } \\
\chi_{I N D}\end{array}$ & $\begin{array}{c}\text { Indian migrants } \\
\chi_{I N D}^{M}\end{array}$ \\
\hline Managerial share & $12.4 \%$ & $12.9 \%$ & $1.7 \%$ & $6.1 \%$ \\
\hline Data source & U.S. Census & U.S. Census & Indian Census & New Immigration Study \\
\hline
\end{tabular}

Notes The table contains estimates for the managerial employment share in the native population of the U.S. (column 1), the population Indian immigrants in the U.S. (column 2), the native population in India (column 3), and the sample of Indian migrants to the U.S. in India (column 4). For the definition of outsider managers, see Table 1 and the discussion there. $\chi_{U S}$ and $\chi_{U S}^{M}$ are calculated from the U.S. census and $\chi_{I N D}$ from the Indian census. $\chi_{I N D}^{M}$ is calculated from the data of the New Immigration Study. We refer to Hendricks and Schoellman (2016) for a detailed description of the data. For the New Immigration Study we use the occupational codes "10 to 430: executive, administrative and managerial" and "500 to 950: management related" as referring to managers. We also insist on the individual having received a salary (instead of, for example, being self-employed).

Immigration Study data and calculate $\chi_{I N D}^{M}$. The results of this exercise are contained in Figure 11. We find that the relative delegation efficiency of the U.S. is between 1.7 and 3.1 of the one in India with $90 \%$ probability. We also want to stress that this uncertainty only affects the decomposition of the implied counterfactual into the human capital and the delegation efficiency component, as all allocation only depend on $\mu_{M, c} \alpha_{c}$.

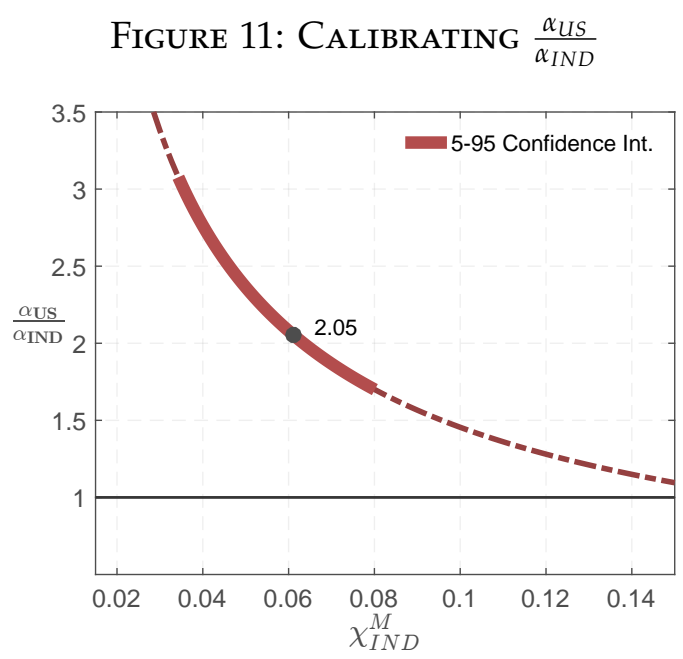

Notes: The figure depicts the resulting $\frac{\alpha_{U S}}{\alpha_{I N D}}$ as a function of $\chi_{I N D}^{M}$. Our point estimate for the immigrants' managerial share in India $(6.1 \%)$ yields a relative delegation quality of 2.05. The 5-to-95 confidence interval around that value ranges from about 1.7 to 3.1 .

\section{B.4 Reduced-Form Evidence based on Variation across Indian Establishments}

In Section 4.3.4, we reported some basic patterns on managerial hiring and firm size from the Indian micro data and discussed how they relate to our theory. This section describes this analysis in more detail.

Our empirical investigation mainly focuses on the implications of the two parameters of our model: (i) entrepreneur's time endowment $T$ and (ii) delegation efficiency $\alpha$. In the theory, time endowment of entrepreneurs $T$ has the interpretation that it can neither be sold on the market, 
nor is there any need to monitor. The NSS data for 1995 contain information on the size of the family of the establishment's owner. As long as family members require less monitoring time than outside managers, we can think of family size as inducing variation in the time endowment $T$. As for the delegation efficiency $\alpha$, we will rely on the variation in trust across 22 Indian states. The Indian micro data contain information about the state in which the respective establishment is located. Additionally, we extract information on the general level of trust between people at the state level from the World Value Surveys. The World Values Survey is a collection of surveys based on representative samples of individuals and provides an index of trust in different regions of India. The primary index we use is derived from the answers to the question "Generally speaking, would you say that most people can be trusted, or that you can not be too careful in dealing with people?". Following Bloom et al. (2012) and La Porta et al. (1997), the regional trust index is constructed as the percentage of people providing the answer "Most people can be trusted" within the state where the firm is located. This is the most common measure of trust used in the literature. While this variable is not directly aimed at eliciting the (perceived) quality of the prevailing legal environment, it fits well into our theoretical framework as long as trust reduces the required time the owner needs to spend to incentivize outside managers. See also Bloom et al. (2012), who also use this variable to proxy the efficiency with which decisions can be delegated.

In Table 12, we look at some of the implications of our theory based on the above-mentioned proxies. We first focus on the extensive margin of managerial hiring. In the model, a firm hires an outside manager only when its size $n$ is above a certain (endogenous) threshold which we denote as $n^{*}$

$$
n^{*} \equiv T \times\left(\frac{\omega_{M}}{\sigma \alpha}\right)^{\frac{1}{1-\sigma}} .
$$

For the purpose of the empirical analysis, in addition to firm size $n$, suppose that firms also differ in (i) owner's time endowment $T$ and (ii) delegation efficiency $\alpha$. Then, the extensive margin of managerial hiring decision for firm $f$ can be summarized as

$$
\begin{aligned}
\mathbb{1}\left[\text { Manager }_{f}>0\right] & =\mathbb{1}\left[n_{f} \geq n_{f}^{*}\right] \\
& =\mathbb{1}\left[n_{f} \geq T_{f} \times\left(\frac{\omega_{M}}{\sigma \alpha_{f}}\right)^{\frac{1}{1-\sigma}}\right] \\
& =\mathbb{1}\left[\log n_{f}-\log T_{f}+\frac{1}{1-\sigma} \times \log \alpha_{f}+\text { const. } \geq 0\right],
\end{aligned}
$$

where subscript $f$ indicates firm specific values and const. includes all terms that are not firm specific. This relation can be converted to an estimable one by introducing some stochasticity. In particular, by introducing a uniformly distributed random variable, which can be considered as measurement error, to the RHS of the above equation and taking the expectation of both sides, we get

$$
\mathbb{P}\left(\text { Manager }_{f}>0\right)=\beta_{0}+\beta_{1} \log n_{f}-\beta_{2} \log T_{f}+\beta_{3} \log \alpha_{f} .
$$

This equation implies that the likelihood of hiring a manager should be increasing in firm size and delegation efficiency and declining in the owner's time endowment. To test these predictions empirically, we estimate the coefficients of (41) by using the proxy variables mentioned above. ${ }^{45}$ Column 1 of Table 12 summarizes the results. It suggests that the predictions of the model regarding extensive margin of managerial hiring are in line with the data: empirically large firms and firms in states with favorable trust measures are more likely to hire outside managers, while firms with

\footnotetext{
${ }^{45}$ Note that (41) implies a linear probability model and its parameters can be estimated using OLS. We also include additional control variables in the regression. Details are given in the notes under Table 12.
} 
larger families abstain from hiring outside managerial personnel holding firm size constant.

\begin{tabular}{|c|c|c|c|c|c|}
\hline \multirow[b]{2}{*}{ Log Empl } & \multicolumn{3}{|c|}{$\begin{array}{r}\text { Dependent Variable } \\
\text { Log empl (Manager }>0)\end{array}$} & \multicolumn{2}{|c|}{ Log empl } \\
\hline & $\begin{array}{l}0.039^{* * * *} \\
(0.003)\end{array}$ & & & & \\
\hline Log HH Size & $\begin{array}{c}-0.003^{* *} \\
(0.001)\end{array}$ & $\begin{array}{c}0.927^{* * *} \\
(0.306)\end{array}$ & $\begin{array}{c}0.812^{* * * *} \\
(0.278)\end{array}$ & $\begin{array}{c}0.224^{* * *} \\
(0.033)\end{array}$ & $\begin{array}{c}0.235^{* * * *} \\
(0.032)\end{array}$ \\
\hline Trust & $\begin{array}{l}0.013^{* *} \\
(0.006)\end{array}$ & $\begin{array}{l}3.264^{* *} \\
(1.628)\end{array}$ & & $\begin{array}{c}0.094 \\
(0.174)\end{array}$ & \\
\hline Log HH Size* Trust & & $\begin{array}{c}-1.694^{* *} \\
(0.818)\end{array}$ & $\begin{array}{l}-1.329^{*} \\
(0.758)\end{array}$ & $\begin{array}{c}0.036 \\
(0.093)\end{array}$ & $\begin{array}{c}0.028 \\
(0.090)\end{array}$ \\
\hline State FE & $\mathrm{N}$ & $\mathrm{N}$ & $\mathrm{Y}$ & $\mathrm{N}$ & $\mathrm{Y}$ \\
\hline$N$ & 178,999 & 2,350 & 2,350 & 178,999 & 178,999 \\
\hline$R^{2}$ & 0.04 & 0.42 & 0.50 & 0.18 & 0.20 \\
\hline
\end{tabular}

Notes: Robust standard errors in parentheses. ${ }^{* *} \mathrm{p}<0.01,{ }^{* *} \mathrm{p}<0.05,{ }^{*} \mathrm{p}<0.10$. All regressions include 2-digit fixed effects, the age of the establishment, year dummies, and a dummy variable for the establishment to be in a rural area as control variables. For the regressions that do not include state-level fixed effects, log GDP per capita at the state level is included as a control variable. "Log Empl" denotes the (log of) total employment at the establishment. "Log HH size" denotes the (log of) the size of the household of the establishment's owner. This variable is only available for the NSS data. "Trust" is the measure of trust at the state level, which we calculate from the World Value Surveys. The dependent variables are: an indicator of managerial hiring (column 1), log employment conditional on managerial hiring (columns 2 - 3), log employment (columns 4-5).

These static determinants of managerial hiring have dynamic implications relating to firms' expansion incentives and hence firm size. In particular, conditional on hiring managers, growth incentives and hence firm size are increasing in delegation efficiency. Our theory implies that delegation efficiency $\alpha$ and the owner's time endowment $T$ are substitutes, i.e., we should expect a tighter link between family size and firm size in low-trust regions. Columns 2 and 3 show that this is the case. First, similar to Bloom et al. (2013), we also find a tight relationship between firm size and family size. We interpret this correlation as family members substituting for the scarcity of available outside managers. Furthermore, the coefficient on the interaction term is negative, which means that the positive relationship between firm size and family size is weaker in regions where trust is higher and hence delegation is more efficient. ${ }^{46}$ In column 3 , we replicate these results with state fixed effects to control for all time-invariant regional characteristics.

In columns 4 and 5, we redo the analysis of columns 2 and 3 for the whole sample of firms, i.e., we do not condition on delegation. Again we find a positive correlation between the size of the family and firm size. Note that the effect of trust for the entire sample of firms is much weaker. This is consistent with our theory, which implies that delegation efficiency only matters for the firms that actually delegate. For firms without outside managers (i.e., firms with $n<n^{*}$ ), growth incentives are only determined by the owner's time endowment $T$.

Finally, we replicated the entire analysis of Table 12, which controlled for 2-digit sector fixed effects, with 3-sector fixed effects. The results are contained in Table 13. It is seen that results are similar. The only exception are the results in columns 2 and 3, which are conditioned on managerial hiring and hence have a small sample size ${ }^{47}$. While all point estimates are of the same sign, they are not significantly different from zero.

\footnotetext{
${ }^{46}$ In a separate regression, not shown here, we also control for the assets of the firm as both family size and the level of regional trust could be correlated with the supply of capital to the firm. The results are very similar.

${ }^{47}$ Given the small sample size, finer controls for sector fixed effect leave less variation in the data for the relations we are interested in.
} 
Table 13: Managerial Hiring, Firms Size and Growth in India: Robustness

\begin{tabular}{l|c|cc|cc}
\hline \hline & \multicolumn{5}{|c}{ Dependent Variable } \\
& Manager $>0$ & Log empl (Manager $>0)$ & Log empl \\
\hline Log Empl & $0.040^{* * *}$ & & & \\
& $(0.003)$ & & & & \\
Log HH Size & $-0.004^{* * *}$ & 0.389 & $0.394^{*}$ & $0.207^{* * *}$ & $0.220^{* * *}$ \\
& $(0.001)$ & $(0.248)$ & $(0.231)$ & $(0.030)$ & $(0.030)$ \\
Trust & $0.012^{*}$ & 0.570 & & -0.008 & \\
& $(0.006)$ & $(1.300)$ & & $(0.160)$ & \\
Log HH Size* Trust & & -0.443 & -0.359 & 0.062 & 0.040 \\
& & $(0.658)$ & $(0.614)$ & $(0.086)$ & $(0.084)$ \\
\hline State FE & $\mathrm{N}$ & $\mathrm{N}$ & $\mathrm{Y}$ & $\mathrm{N}$ & $\mathrm{Y}$ \\
\hline$N$ & 178,999 & 2,350 & 2,350 & 178,999 & 178,999 \\
$R^{2}$ & 0.05 & 0.58 & 0.63 & 0.28 & 0.30 \\
\hline \hline
\end{tabular}

Notes: Robust standard errors in parentheses. ${ }^{* * *} \mathrm{p}<0.01,{ }^{* *} \mathrm{p}<0.05,{ }^{*} \mathrm{p}<0.10$. All regressions include 3-digit fixed effects, the age of the establishment, and a dummy variable for the establishment to be in a rural area as control variables. For the regressions that do not include state level fixed effects, log GDP per capita at the state-level is included as a control variable. "Log Empl" denotes the (log of) total employment at the establishment. "Log HH size" denotes the (log of) the size of the household of the establishment's owner. This variable is only available for the NSS data. "Trust" is the measure of trust at the state level, which we calculate from the World Value Surveys. The dependent variables are: an indicator of managerial hiring (column 1), log employment conditional on managerial hiring (columns 2 - 3), log employment (columns 4-5). 


\title{
Online Appendix for "Lack of Selection and Limits to Delegation: Firm Dynamics in Developing Countries"
}

\author{
by Ufuk Akcigit, Harun Alp, Michael Peters
}

April 14, 2018

- Not for Publication Unless Requested -

\section{OA-1 Online Appendix - Theory}

\section{OA-1.1 Static Equilibrium}

Consider the equilibrium in the product market. At each point in time, each product line $j$ is produced by a single firm with productivity $q_{j t}$. We normalize the price of aggregate output $Y$ to one. As firms set a price equal to $p_{j f}=q_{j f}^{-1} w_{t}$ we get that

$$
\ln (Y)=\int_{0}^{1} \ln \left(y_{j}\right) d j=\int_{0}^{1} \ln \left(p_{j} y_{j}\right) d j-\int_{0}^{1} \ln \left(p_{j}\right) d j=\ln (Y)-\ln \left(w_{P}\right)+\int_{0}^{1} \ln \left(q_{j}\right) d j
$$

which implies $w_{P}=Q \equiv \exp \left[\int_{0}^{1} \ln q_{j} d j\right]$. The production function [see equation (3)] also implies that

$$
\ln \left(L^{P}\right)=\int_{0}^{1} \ln \left(l_{j}\right) d j=\int_{0}^{1} \ln \left(y_{j}\right) d j-\int_{0}^{1} \ln \left(q_{j}\right) d j-\int_{0}^{1} \ln \left(\mu\left(e_{j}\right)\right) d j
$$

where $L^{P}$ is the aggregate demand for production labor. Then, we get $L^{P}=\frac{Y}{Q \mathcal{M}}=\frac{1}{\mathcal{M}} \frac{1}{\omega_{P}}$ where $\omega_{P}=\frac{w_{P}}{Y}$ and $\mathcal{M}$ is defined as

$$
\mathcal{M}=\left[1-\sum_{n=1}^{\infty}(e(n))^{\sigma} \times n \times\left(v_{n}^{H} F^{H}+v_{n}^{L} F^{L}\right)\right]^{-1}
$$

where function $e($.$) is defined in (8), v_{n}^{i}$ and $F^{i}$ are the size distribution and the measure of $i$-type firms, $i \in\{H, L\}$, respectively (see Proposition 1).

\section{OA-1.2 A Simple Microfoundation for $\alpha$}

In this section, we provide a simple example of how $\alpha$ could depend on various institutional parameters in an economy. Please note that none of the analysis in the main text depends on this particular example. This example is provided to fix ideas.

Suppose that both managers and entrepreneurs each have one unit of time at their disposal. While the latter can provide $T$ units of effort during that time interval, managers can provide 1 unit of effort. Suppose that the provision of managerial effort is subject to contractual frictions. For simplicity, assume that the manager can decide to either provide effort or shirk, in which case he adds no usable services to the firm. The firms can translate each unit of managerial effort into $\eta$ units of managerial services.

While the manager's effort choice is not contractible, the entrepreneur can monitor the manager to prevent him from shirking. If the entrepreneur spends $s$ units of her time monitoring the manager, she will catch a shirking manager with probability s. Whenever the manager shirks and gets caught, 
the entrepreneur can go to court and sue the manager for the managerial wage $w$. In particular, the court (rightly) decides in the entrepreneur's favor with probability $\kappa$. Hence one can think of $\kappa$ as parameterizing the efficiency of the legal system. Finally, the demand for shirking arises because shirking carries a private benefit $b w$, where $b<1 .^{48}$

It is straightforward to characterize the equilibrium of this simple game. If the entrepreneur spends $s$ units of her time monitoring the manager, the manager does not shirk if and only if

$$
w \geq b w+w(1-\kappa s)
$$

where $(1-\kappa s)$ is the probability that the manager gets paid despite having shirked. Clearly the owner will never employ a manager without inducing effort. Hence, the owner will spend $s=b / \kappa$ units of time monitoring the manager. The overall amount of managerial services in product line $j$ is therefore given by ${ }^{49}$

$$
e_{j}=\frac{T}{n}-m_{j} s+\eta m_{j}=\frac{T}{n}+\left(\eta-\frac{b}{\kappa}\right) \times m_{j}=\frac{T}{n}+\alpha(\kappa, \eta, b) \times m_{j} .
$$

Hence, $\alpha$ measures precisely the net increase in managerial services through delegation. In particular, the delegation efficiency is increasing in the firm's efficiency to employ managers $(\eta)$ and in the state of the contractual environment $(\kappa)$, because monitoring and the strength of the legal system are substitutes. Note also that the whole purpose of delegation is to increase a firm's managerial resources, so that firms will never hire a manager if $\alpha(\kappa, \eta) \leq 0$. Hence, whenever managers are sufficiently unproductive or the quality of legal systems is sufficiently low, firms will never want to hire outside managers because owners need to spend more of their own time to prevent the opportunistic behavior of managers than they gain in return.

\section{OA-1.3 Stationary Equilibrium of the Model}

In this section, we describe the stationary equilibrium of the model in detail. To do so, we proceed in two steps.

Step 1 Fix $s \equiv\left(n^{*}, \omega_{P}\right)$ where $n^{*}$ and $\omega_{P}$ are delegation cut-off and normalized wage rate for production workers, respectively. By using (28) and (29), we can write the rate of destruction for high types $\tau_{H}(s)$ as

$$
\tau_{H}(s)=z(s) \times\left\{\left[\delta \sum_{h=1}^{\infty} \prod_{j=1}^{h}\left(\frac{x_{j}(s)}{\tau_{H}(s)}\right)\right]+1-(1-\delta)\left(\frac{\beta-1}{\beta}\right)\right\},
$$

where $\left[x_{j}(s)\right]_{j=1}^{\infty}$ is the optimal innovation policy by high types implicitly defined in (14) and $z(s)$ is the optimal entry rate. We focus on a solution where $x_{j}<\tau_{H}$ for all $\tau_{H}$. This is a sufficient condition for a stationary solution. ${ }^{50}$ We will show below that such a solution exists for all $s$ provided that $\theta_{E}$ is large enough.

Let $v_{H}(n)$ be normalized value function (normalized with $Y_{t}$ ) of a high-type firm depicted in

\footnotetext{
${ }^{48}$ The necessity for the private benefit being proportional to the wage arises in order to make the contract stationary.

${ }^{49}$ Note that we do not require that $s<T$, i.e., we do not require the owner to perform the monitoring himself. We rather think of managerial efficiency units to be perfect substitutes within the firm, i.e., an owner can hire a manager to monitor other managers.

${ }^{50} \mathrm{~A}$ necessary condition is that there exists $\hat{n}$ with $x_{j}<\tau_{H}$ for all $j>\hat{n}$.
} 
(14). ${ }^{51}$ At BGP where both $C_{t}$ and $Y_{t}$ grows at the same rate and $\dot{v}_{H, t}=0$, it can be written as

$$
\rho v_{H}(n)=\max _{x_{n}}\left\{\tilde{\pi}\left(n ; n^{*}\right)-\omega_{p} \theta^{-\frac{1}{\zeta}} n x_{n}^{\frac{1}{\zeta}}+x_{n} n\left[v_{H}(n+1)-v_{H}(n)\right]+\tau_{H} n\left[v_{H}(n-1)-v_{H}(n)\right]\right\} .
$$

where we use the fact that $w_{p}=Q$ to substitute $\frac{Q}{Y}$ with $\omega_{P}$ and $r=\rho+g$ from household problem. ${ }^{52}$ By rearranging terms and explicitly imposing the restriction $x_{j}<\tau_{H}$, we can write $v_{H}$ as

$$
v_{H}(n)=n \times \max _{x_{n}<\tau_{H}}\left\{\frac{\frac{\tilde{\pi}\left(n ; n^{*}\right)}{n}-\omega_{p} \theta^{-\frac{1}{\zeta}} x_{n}^{\frac{1}{\zeta}}+x_{n} v_{H}(n+1)+\tau_{H} v_{H}(n-1)}{\rho+\left(x_{n}+\tau_{H}\right) n}\right\} .
$$

Now consider the function $b(n) \equiv \frac{v_{H}(n)}{n}$, which - by using the above equation - can be written as

$$
b(n)=\max _{x_{n}<\tau_{H}}\left\{h\left(n, x_{n}\right)+\frac{x_{n}(n+1)}{\rho+\left(x_{n}+\tau_{H}\right) n} b(n+1)+\frac{\tau_{H}(n-1)}{\rho+\left(x_{n}+\tau_{H}\right) n} b(n-1)\right\},
$$

where $h\left(n, x_{n}\right) \equiv \frac{\frac{\tilde{\pi}\left(n ; n^{*}\right)}{n}-\omega_{p} \theta^{-\frac{1}{\zeta}} x_{n}^{\frac{1}{\zeta}}}{\rho+\left(x_{n}+\tau_{H}\right) n}$.

We will show that the right-hand side of (OA-4) satisfies Blackwell's sufficient conditions for a contraction. To see this, define the operator $T$ by

$$
(T f)(n) \equiv \max _{x_{n}<\tau_{H}}\left\{h\left(n, x_{n}\right)+\frac{x_{n}(n+1)}{\rho+\left(x_{n}+\tau_{H}\right) n} f(n+1)+\frac{\tau_{H}(n-1)}{\rho+\left(x_{n}+\tau_{H}\right) n} f(n-1)\right\} .
$$

Hence, $b$ can be defined as a fixed point of $T$, i.e., a function such that $(T b)(n)=b(n)$. First, note that $h\left(n, x_{n}\right)$ is bounded [see (11)] so that $T$ maps the space of continuous bounded functions into itself (Berge's Maximum Theorem). Moreover, for any continuous bounded functions $f, g$ with $f(n) \leq g(n)$ for all $n \in Z^{++}$, we have

$$
\begin{aligned}
(T f)(n) & =\max _{x_{n}<\tau_{H}}\left\{h\left(n, x_{n}\right)+\frac{x_{n}(n+1)}{\rho+\left(x_{n}+\tau_{H}\right) n} f(n+1)+\frac{\tau_{H}(n-1)}{\rho+\left(x_{n}+\tau_{H}\right) n} f(n-1)\right\} \\
& \leq \max _{x_{n}<\tau_{H}}\left\{h\left(n, x_{n}\right)+\frac{x_{n}(n+1)}{\rho+\left(x_{n}+\tau_{H}\right) n} g(n+1)+\frac{\tau_{H}(n-1)}{\rho+\left(x_{n}+\tau_{H}\right) n} g(n-1)\right\} \\
& =(T g)(n),
\end{aligned}
$$

so that the monotonicity condition is satisfied. Lastly, for any continuous bounded function $f$ and $a \geq 0$,

$$
\begin{aligned}
(T[f+a])(n) & =\max _{x_{n}<\tau_{H}}\left\{h\left(n, x_{n}\right)+\frac{x_{n}(n+1)}{\rho+\left(x_{n}+\tau_{H}\right) n}[f(n+1)+a]+\frac{\tau_{H}(n-1)}{\rho+\left(x_{n}+\tau_{H}\right) n}[f(n-1)+a]\right\} \\
& \leq \max _{x_{n}<\tau_{H}}\left\{h\left(n, x_{n}\right)+\frac{x_{n}(n+1)}{\rho+\left(x_{n}+\tau_{H}\right) n} f(n+1)+\frac{\tau_{H}(n-1)}{\rho+\left(x_{n}+\tau_{H}\right) n} f(n-1)\right\}+\Omega a \\
& =(T F)(n)+\Omega a
\end{aligned}
$$

where

$$
\Omega \equiv \max _{x_{n}<\tau_{H}}\left\{\frac{\left(x_{n}+\tau_{H}\right) n}{\rho+\left(x_{n}+\tau_{H}\right) n}+\frac{x_{n}-\tau_{H}}{\rho+\left(x_{n}+\tau_{H}\right) n}\right\}<1 .
$$

\footnotetext{
${ }^{51}$ We drop the dependence of the value function on $s$ for notational clarity.

${ }^{52}$ See Section OA-1.1 for details.
} 
Hence, the operator $T$ satisfies the discounting condition, so that $T$ is a contraction mapping and therefore posses a unique fixed point [Stokey et al. (1989)], which is continuous in $s$ and $\tau_{H}$. Moreover, the expression inside the max operator in (OA-5) is continuous in $x_{n}$ and strictly concave so that Berge's Maximum Theorem implies that the set of maximizers $x_{n}^{*}$ is a continuous function of $s$ and $\tau_{H}$. The equilibrium entry rate $z$ is fully determined from $v_{H}$ and $v_{L}$ [see (17)] and hence also a continuous function of $s$ and $\tau_{H} .{ }^{53}$

Hence, equation (OA-3) is continuous in $\tau_{H}$. To see that there exists a fixed point for $\tau_{H}$, note that the RHS is bounded away from zero because $z(s)>0$ and that it is bounded from above. To see that, note that $\sum_{h=1}^{\infty} \prod_{j=1}^{h}\left(\frac{x_{j}(s)}{\tau_{H}(s)}\right)$ is bounded in a stationary equilibrium and that $z$ is bounded [see (17)]. Hence, there exits a fixed point for $\tau_{H}$. Moreover, because $z$ is increasing in $\theta_{E}$ for a given $s$ and $\tau_{H},(\mathrm{OA}-3)$ implies that for each $s$ there is $\theta_{E}$ large enough such that this fixed point satisfies $\tau_{H}>x_{n}$.

Step 2 We can now represent the whole model in terms of labor market clearing conditions. The Cobb-Douglas final good production function together with the market structure described in Section 2.1 implies that the total number of production workers hired for variety $j$ by a producer, who is active in $n$ markets, is given by ${ }^{54}$

$$
l_{j}=\left[\omega_{P} \mu(e)\right]^{-1}=\omega_{P}^{-1} \times\left(1-e(n)^{\sigma}\right) .
$$

Using firms' optimal delegation policy and aggregating over the firm size distribution yields the aggregate demand for production workers is given by

$$
H^{P}=\left[1-\sum_{n=1}^{\infty}\left(\max \left\{\frac{T}{n}, \frac{T}{n^{*}}\right\}\right)^{\sigma} \times n \times \varphi_{n}\right] \times \omega_{P}^{-1}
$$

Similarly, firms' managerial demand function implies that the aggregate demand for managers is given by

$$
H^{M}=\sum_{n \geq n^{*}}^{\infty} n \times m(n) \times \varphi_{n}=\left(\frac{\sigma}{\omega_{M}}\right)^{\frac{1}{1-\sigma}} \alpha^{\frac{\sigma}{1-\sigma}} \sum_{n \geq n^{*}}^{\infty} n \varphi_{n}-\frac{T}{\alpha} \sum_{n \geq n^{*}}^{\infty} \varphi_{n} .
$$

Given Step 1, we can calculate the firm size distribution $\varphi_{n}(s)=v_{n}^{H}(s) F^{H}(s)+v_{n}^{L}(s) F^{L}(s)$ from Proposition 1. From (7), (OA-6), and (OA-7), the labor market clearing conditions for managers and production workers can then be written by

$$
\begin{aligned}
0 & =\left(\frac{\vartheta-1}{\vartheta} \mu_{M}\right)^{\vartheta}\left(\frac{\left(n^{*}\right)^{1-\sigma} \sigma \alpha}{T^{1-\sigma} \omega_{P}}\right)^{\vartheta-1} \frac{\vartheta}{\vartheta-1}-\frac{T}{\alpha} \sum_{n>n *}\left(\frac{1}{n^{*}}-\frac{1}{n}\right) n \varphi_{n}(s) \\
0 & =1-\left(\frac{\vartheta-1}{\vartheta} \mu_{M}\right)^{\vartheta}\left(\frac{\left(n^{*}\right)^{1-\sigma} \sigma \alpha}{T^{1-\sigma} \omega_{P}}\right)^{\vartheta}-\frac{1}{\omega_{P}}\left[1-\sum_{n=1}^{\infty}\left(\max \left\{\frac{T}{n}, \frac{T}{n^{*}}\right\}\right)^{\sigma} n \varphi_{n}(s)\right]
\end{aligned}
$$

where two equations depend only on $s \equiv\left(n^{*}, \omega_{P}\right)$. Note that $\varphi_{n}(s)$ is continuous in $z, \tau_{H}$ and $x_{n}$. Therefore, from Step 1, left-hand-side of both equations are continuous in $\left(n^{*}, \omega_{P}\right)$. Solution to the system of equation given by (OA-8) and (OA-9) constitutes an equilibrium for our economy.

\footnotetext{
${ }^{53}$ Recall that $v_{L}(1)=\frac{\pi(1)}{\rho+\tau_{L}}$, where $\tau_{L}=\beta \times \tau_{H}$.

${ }^{54}$ To see this, note that $Y=p_{j} y_{j}=\frac{w_{P}}{q_{j}} q_{j} \mu\left(e_{j}\right) l_{j}$ and $\omega_{P}=w_{P} / Y$.
} 


\section{OA-2 Online Appendix - Empirical Analysis}

\section{OA-2.1 Firms vs. Establishments in the U.S. Manufacturing Sector}

In this section we compare the process of firm-dynamics across U.S. manufacturing firms and establishments. Table OA-1 provides some summary statistics about the size-distribution of firms and establishments in the U.S. The average manufacturing firm in the U.S. has 51 employees, while the average establishment only 43. It is also the case that large firms have multiple establishments (firms with more than 1000 employees have on average 13) so that large firms account for half of total employment. There is a lower concentration at the establishment level in that establishments with more than 1000 employees account for less than one-fifth of aggregate employment in manufacturing in the U.S.

Table OA-1: Descriptive Statistics: U.S. Micro Data

\begin{tabular}{|c|c|c|c|c|c|c|c|c|c|}
\hline \multirow[b]{2}{*}{ Size } & \multicolumn{5}{|c|}{ Firms } & \multicolumn{4}{|c|}{ Establishments } \\
\hline & No. & $\begin{array}{c}\text { Avg. } \\
\text { Employment }\end{array}$ & $\begin{array}{l}\text { Agg. } \\
\text { Share }\end{array}$ & $\begin{array}{c}\text { No. of } \\
\text { Establishments }\end{array}$ & $\begin{array}{l}\text { Exit } \\
\text { rate }\end{array}$ & No. & $\begin{array}{c}\text { Avg. } \\
\text { Employment }\end{array}$ & $\begin{array}{l}\text { Agg. } \\
\text { Share }\end{array}$ & $\begin{array}{l}\text { Exit } \\
\text { rate }\end{array}$ \\
\hline $1-4$ & 86936 & 2.30 & 1.65 & 1.00 & 13.22 & 93038 & 2.31 & 1.78 & 16.50 \\
\hline $5-9$ & 48178 & 6.68 & 2.66 & 1.00 & 3.46 & 54281 & 6.73 & 3.02 & 4.20 \\
\hline $10-19$ & 37942 & 13.80 & 4.33 & 1.01 & 2.66 & 45803 & 14.01 & 5.30 & 3.10 \\
\hline $20-49$ & 32555 & 30.92 & 8.31 & 1.05 & 2.27 & 44085 & 31.90 & 11.62 & 2.40 \\
\hline $50-99$ & 13516 & 67.94 & 7.58 & 1.21 & 2.03 & 21582 & 71.54 & 12.75 & 1.90 \\
\hline $100-249$ & 8914 & 139.90 & 10.30 & 1.61 & 1.59 & 16476 & 155.76 & 21.20 & 1.00 \\
\hline $250-499$ & 3167 & 280.96 & 7.35 & 2.47 & 0.92 & 5444 & 348.72 & 15.68 & 0.50 \\
\hline 500-999 & 1720 & 503.49 & 7.15 & 3.94 & 0.29 & 2120 & 677.19 & 11.86 & 0.30 \\
\hline $1000+$ & 2423 & 2531.92 & 50.67 & 12.68 & 0.25 & 984 & 2068.2 & 16.81 & 0.30 \\
\hline Aggregate & 235351 & 51.44 & 100 & & 6.53 & 283813 & 42.66 & 100 & 7.3 \\
\hline
\end{tabular}

Notes: This table contains summary statistics for U.S. manufacturing firms and establishments in 2012. The data are taken from the BDS.

We now turn to the implied dynamics. Because we focus on cross-sectional data, the information on firm (establishment) age is crucial for us. For establishments, the definition of age is straightforward. Birth year is defined as the year a establishment first reports positive employment in the LBD. Establishment age is computed by taking the difference between the current year of operation and the birth year. Given that the LBD series starts in 1976, the observed age is by construction left censored at 1975. In contrast, firm age is computed from the age of the establishments belonging to that particular firm. A firm is assigned an initial age by determining the age of the oldest establishment that belongs to the firm at the time of birth. Firm age accumulates with every additional year after that. In Figure OA-1 we show the cross-sectional age-size relationship for establishments (left panel) and firms (right panel) in the U.S.

Not surprisingly, the life-cycle is much steeper for firms, especially for +26-year-old ones, as firms grow both on the intensive margin at the establishment level and the extensive margin of adding establishments to their operation.

In Figure OA-2 we show the aggregate employment share of establishments and firms of different ages. As suggested by the life-cycle patterns in Figure OA-1, old firms account for the bulk of employment in the U.S. However, the relative importance of old establishments/firms is somewhat less pronounced because of exit, i.e., while the average firm/establishment grows substantially by age conditional on survival, many firms/establishments have already exited by the time they would have been 20 years old. Nevertheless, firms (establishments) older than 25 years account for 76\% $(53 \%)$ of employment in the manufacturing sector. 
Figure OA-1: Life CyCle of Establishments AND Firms in the U.S.

The Life Cycle in the US (Plants)

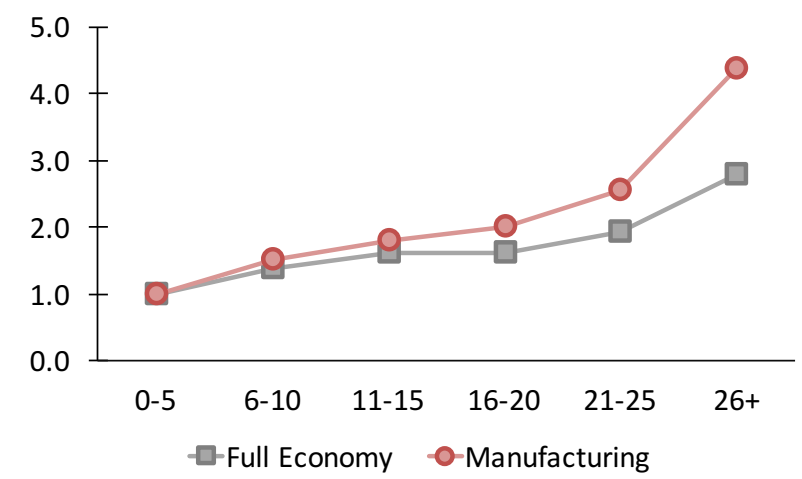

The Life Cycle in the US (Firms)

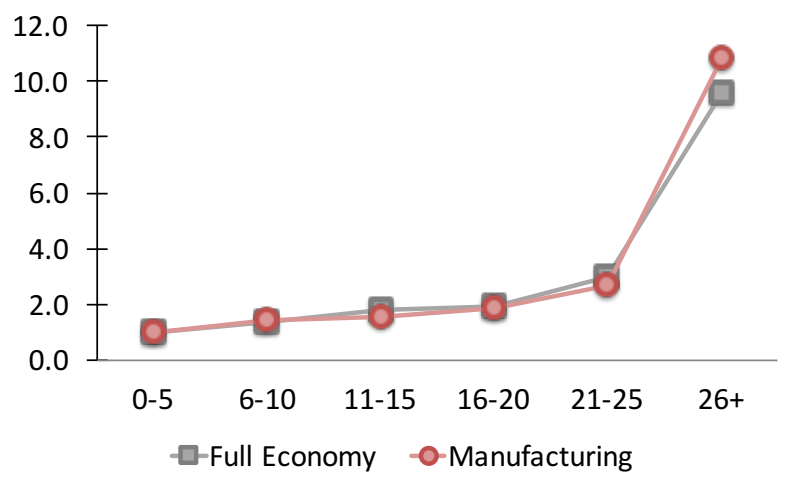

Notes: The figure contains the cross-sectional age-size relationship for establishments (left panel) and firms (right panel) in the U.S. The data are taken from the BDS and we focus on the data for 2012. We depict the results for both the manufacturing sector and the entire economy.

Figure OA-2: The EMPLOYMENT SHARE By AGE OF ESTABLISHMENTS AND FIRMS IN THE U.S.
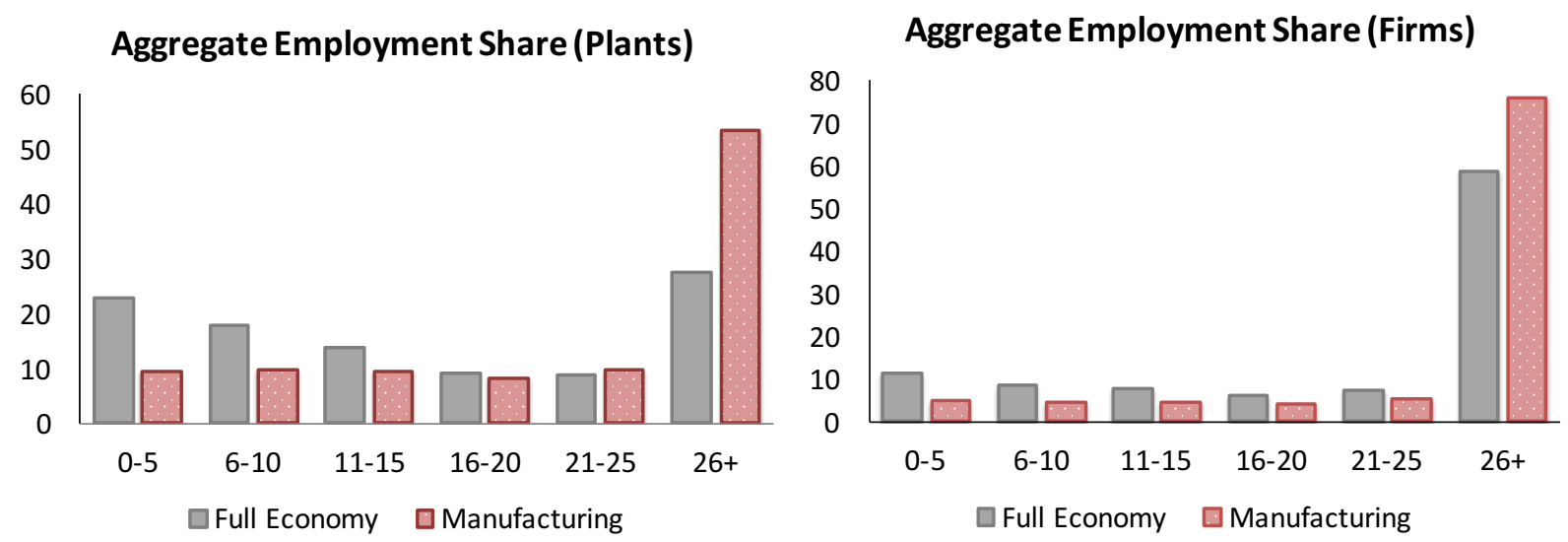

Notes: The figure contains the aggregate employment share of establishments (left panel) and firms (right panel) in the U.S. as a function of age. The data are taken from the BDS and we focus on the data for 2012. We depict the results for both the manufacturing sector and the entire economy.

This pattern of exit is depicted in Figure OA-3. There we show annual exit rates for firms and establishments as a function of age. The declining exit hazard is very much suggestive of a model of creative destruction, whereby firms and establishments grow as they age (conditional on survival) and exit rates are lower for bigger firms/establishments.

An important moment for us is the age-specific exit rate conditional on size. It is this moment that will identify the importance of selection. In a model without heterogeneity, size will be a sufficient statistic for future performance, so that age should not predict exit conditional on size. However, if the economy consists of high- and low-type entrepreneurs, old firms are more likely to be composed of high types conditional on size. Hence, the size-specific exit rate by age is monotone in the share of high types by age. In Figure OA-4 we report this schedule for both establishments 
Figure OA-3: The Exit Rates of Establishments and Firms in the U.S. by Age

Exit Rates in the US (Plants)

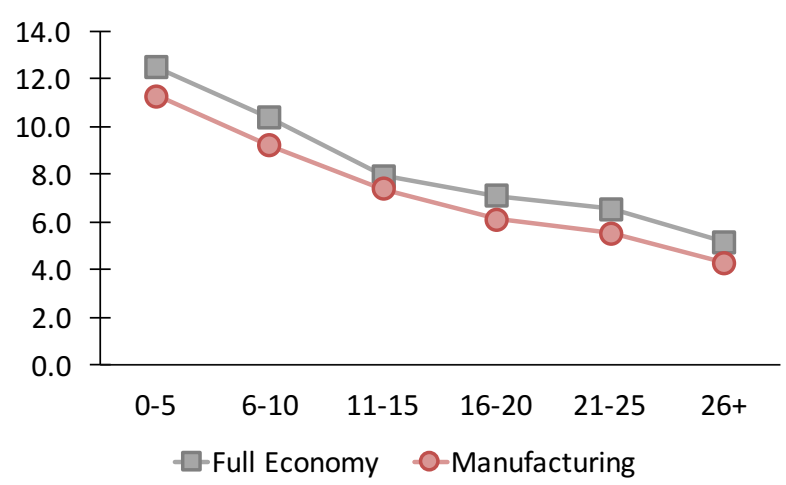

Exit Rates in the US (Firms)

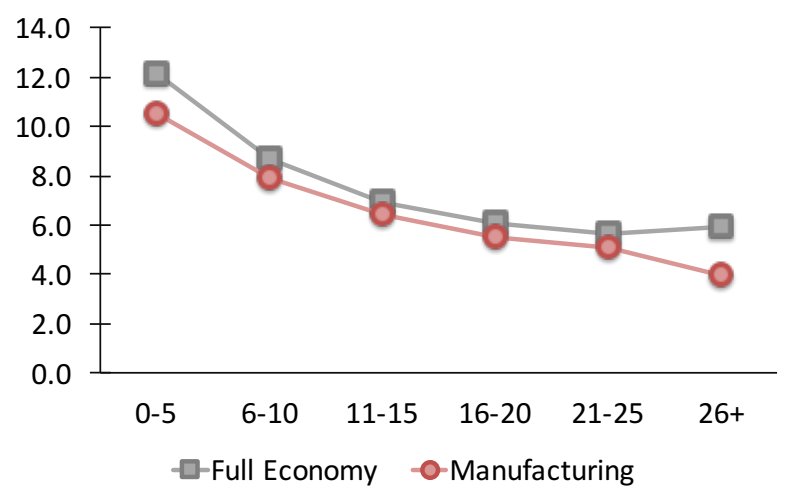

Notes: The figure contains the exit rates of establishments (left panel) and firms (right panel) in the U.S. as a function of age. The data are taken from the BDS and we focus on the data for 2012. We depict the results for both the manufacturing sector and the entire economy.

and firms. The data show a large degree of age-dependence (conditional on size). The schedules for small firms and establishments look almost identical. This is reassuring because small firms are almost surely single-establishment firms, so that a firm-exit will also be a establishment-exit and vice versa.

Figure OA-4: Size-dePENDENT EXIT RATES OF ESTAblishments AND FIRMS IN THE U.S. by age
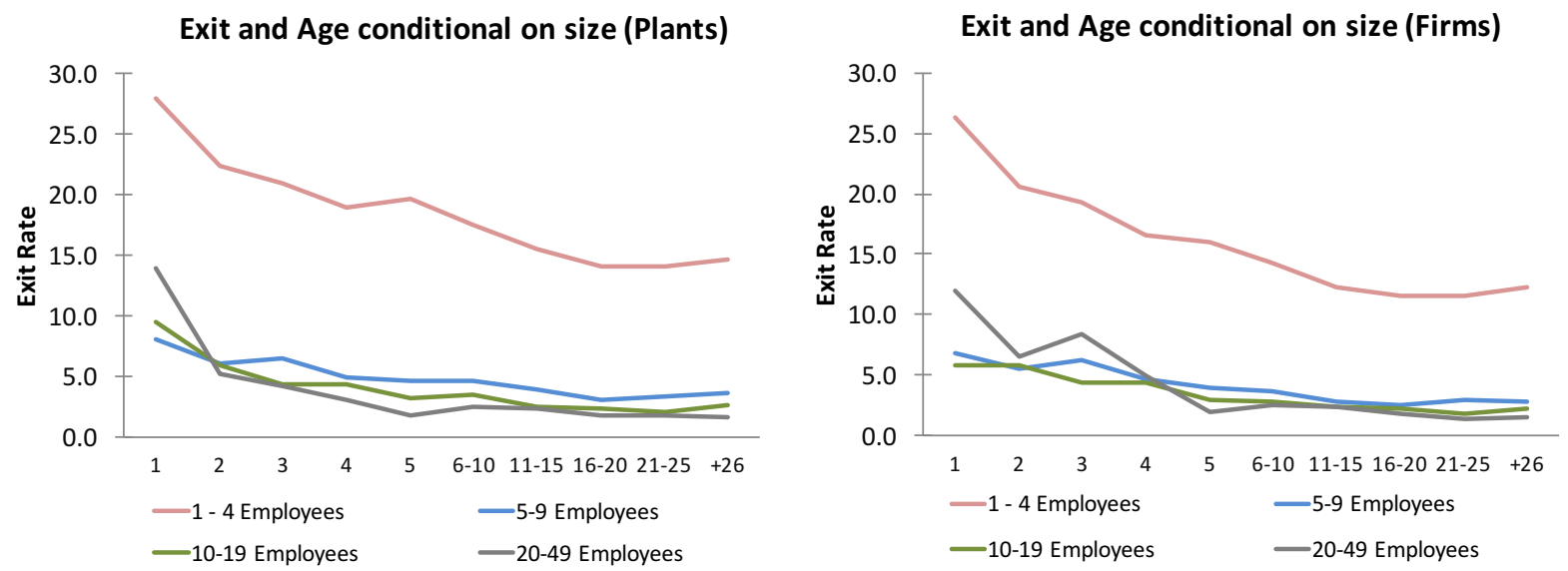

Notes: The figure contains the conditional exit rates by size of establishments (left panel) and firms (right panel) in the U.S. as a function of age. The data are taken from the BDS and we focus on the data for 2012. We depict the results for the manufacturing sector.

\section{OA-2.2 Establishments in the Indian Manufacturing Sector}

In this section we provide more descriptive evidence about the underlying process of firm dynamics in the manufacturing sector in India. Table OA-2 contains descriptive statistics for our sample of Indian manufacturing establishments. For comparison, we organize the data in the same way as in the left panel of Table OA-1, which contains the results for manufacturing establishments in the 
U.S. It is clearly seen that the establishment-size distribution in India is concentrated on very small firms. The average establishment has fewer than 3 employees and more than $50 \%$ of aggregate employment is concentrated in establishments with at most 4 employees. Such establishments account for $93 \%$ of all establishments in the Indian manufacturing sector. A comparison of establishment size distribution for the years 1995 and 2010 in Table OA-3 suggests that these patterns are stable over time.

Table OA-2: Descriptive Statistics: Indian Micro Data

\begin{tabular}{l|ccc}
\hline \hline Size & No. & Avg. Employment & Aggregate Employment Share \\
\hline $1-4$ & 15957296 & 1.56 & 54.76 \\
$5-9$ & 843091 & 6.26 & 11.61 \\
$10-19$ & 243868 & 12.98 & 6.96 \\
$20-49$ & 70834 & 29.22 & 4.55 \\
$50-99$ & 23242 & 69.89 & 3.57 \\
$100-249$ & 14898 & 149.31 & 4.89 \\
$250-499$ & 4701 & 346.69 & 3.58 \\
$500-999$ & 2283 & 683.86 & 3.43 \\
$1000+$ & 1232 & 2452.65 & 6.65 \\
\hline Aggregate & 17161445 & 2.65 & 100.00 \\
\hline \hline
\end{tabular}

Notes: This table contains summary statistics for establishments in the Indian manufacturing sector in 2010. The data are taken from the ASI and the NSS. To calculate the number of firms, we use the sampling weights provided in the data.

Table OA-3: Establishment Size Distribution in India

\begin{tabular}{cccccc}
\hline & \multicolumn{5}{c}{ Firm Size } \\
& $\mathbf{1 - 4}$ & $\mathbf{5 - 9}$ & $\mathbf{1 0 - 1 9}$ & $\mathbf{2 0 - 4 9}$ & $\mathbf{5 0 +}$ \\
\hline $\mathbf{1 9 9 5}$ & 0.9171 & 0.0631 & 0.0143 & 0.0035 & 0.0020 \\
$\mathbf{2 0 1 0}$ & 0.9297 & 0.0491 & 0.0143 & 0.0042 & 0.0027 \\
\hline \hline
\end{tabular}

Notes: This table presents the share of establishments for different size bins in India, for the years 1995 and 2010 . Size bins are constructed based on number of employees.

Figure OA-5 reports the aggregate employment share by age for Indian manufacturing establishments and is hence comparable to Figure OA-2 for the U.S.

It is clearly seen that the aggregate importance of old firms is very small in India. While firms, that are older than 25 years account for $55 \%$ of employment in the U.S., the corresponding number is less than $20 \%$ in India. This is a reflection of the shallow life-cycle in India and not of there being fewer old firms in the Indian economy. 
Figure OA-5: The EMPLOYMENT SHARE By AGE OF ESTABLISHMENTS IN INDIA

\section{Aggregate Employment Share (Plants)}

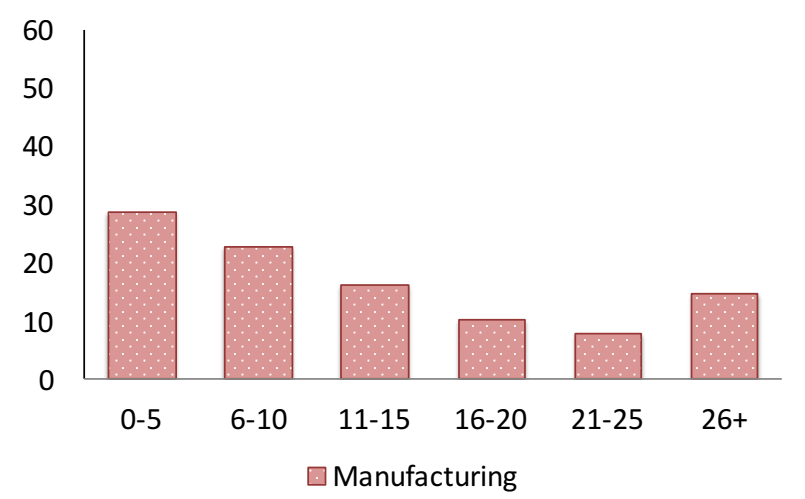

Notes: The figure contains the aggregate employment share of manufacturing establishments in India as a function of age. The data are taken from the ASI and the NSS and we focus on the data for 2010. We combine the two data sets using the sampling weights provided in the micro data. 